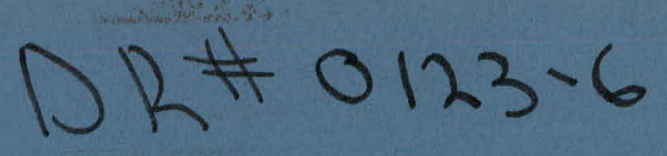

DOE/PC/30302-8

(DE84007766)

\title{
Energy
}

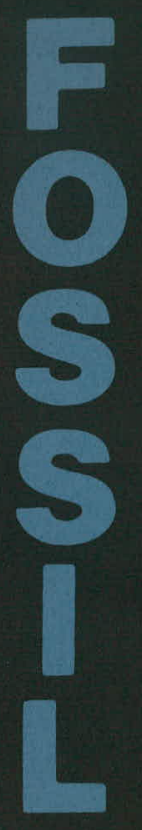

\section{SYNTHETIC FUEL AROMATICITY AND STAGED COMBUSTION}

Final Report for the Period September 23, 1980-September 23, 1982

By

James R. Longanbach

Lisa K. Chan

Arthur Levy

November 15, 1982

Work Performed Under Contract No. AC22-80PC30302

Battelle Columbus Laboratories

Columbus, Ohio

Technical Information Center

Office of Scientific and Technical Information

United States Department of Energy 


\section{DISCLAIMER}

This report was prepared as an account of work sponsored by an agency of the United States Government. Neither the United States Government nor any agency Thereof, nor any of their employees, makes any warranty, express or implied, or assumes any legal liability or responsibility for the accuracy, completeness, or usefulness of any information, apparatus, product, or process disclosed, or represents that its use would not infringe privately owned rights. Reference herein to any specific commercial product, process, or service by trade name, trademark, manufacturer, or otherwise does not necessarily constitute or imply its endorsement, recommendation, or favoring by the United States Government or any agency thereof. The views and opinions of authors expressed herein do not necessarily state or reflect those of the United States Government or any agency thereof. 


\section{DISCLAIMER}

Portions of this document may be illegible in electronic image products. Images are produced from the best available original document. 


\title{
DISCLAIMER
}

\begin{abstract}
This report was prepared as an account of work sponsored by an agency of the United States Government. Neither the United States Government nor any agency thereof, nor any of their employees, makes any warranty, express or implied, or assumes any legal liability or responsibility for the accuracy, completeness, or usefulness of any information, apparatus, product, or process disclosed, or represents that its use would not infringe privately owned rights. Reference herein to any specific commercial product, process, or service by trade name, trademark, manufacturer, or otherwise does not necessarily constitute or imply its endorsement, recommendation, or favoring by the United States Government or any agency thereof. The views and opinions of authors expressed herein do not necessarily state or reflect those of the United States Government or any agency thereof.
\end{abstract}

This report has been reproduced directly from the best available copy.

Available from the National Technical Information Service, U. S. Department of Commerce, Springfield, Virginia 22161.

Price: Printed Copy A06

Microfiche A01

Codes are used for pricing all publications. The code is determined by the number of pages in the publication. Information pertaining to the pricing codes can be found in the current issues of the following publications, which are generally available in most libraries: Energy Research Abstracts (ERA); Government Reports Announcements and Index (GRA and I); Scientific and Technical Abstract Reports (STAR); and publication NTIS-PR-360 available from NTIS at the above address. 


\title{
FINAL REPORT
}

\section{on \\ SYNTHETIC FUEL AROMATICITY AND STAGED COMBUSTION}

\author{
to \\ U.S. DEPARTMENT OF ENERGY \\ Pittsburgh Energy Technology Center
}

November 15, 1982

by

James R. Longanbach, Lisa K. Chan, and Arthur Levy

Period Covered: September 23, 1980-September 23, 1982

Contract No. DE-AC22-80PC-30302

Battelle No. G-7662

BATTELLE

Columbus Laboratories 505 King Avenue

Columbus, Ohio 43201 
THIS PAGE

WAS INTENTIONALLY

LEFT BLANK 


\section{TABLE OF CONTENTS}

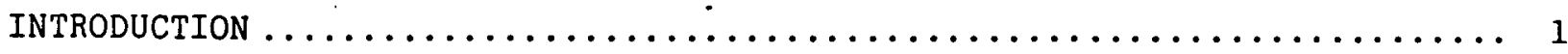

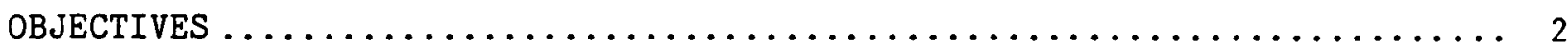

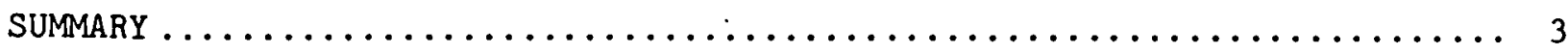

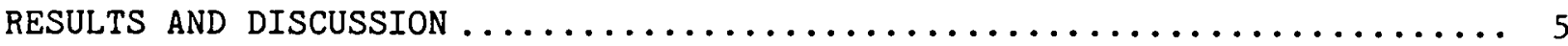

TASK 1. CHARACTERIZATION OF SRC II SAMPLES $\ldots \ldots \ldots \ldots \ldots \ldots \ldots \ldots \ldots$

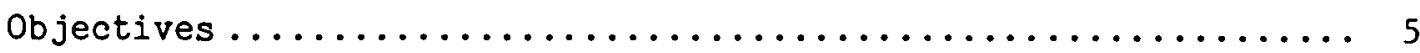

SRC II Samples $\ldots \ldots \ldots \ldots \ldots \ldots \ldots \ldots \ldots \ldots \ldots \ldots \ldots \ldots \ldots \ldots$

Analytical Methods ........................... 6

Elemental Analyses $\ldots \ldots \ldots \ldots \ldots \ldots \ldots \ldots \ldots \ldots \ldots \ldots$

Basic Nitrogen ......................... 6

Simulated Distillation by Gas Chromatography ........... 10

Aromatic Distribution by $\mathrm{H}^{\mathrm{I}}$ and $\mathrm{Cl3} \mathrm{NMR} \ldots \ldots \ldots \ldots \ldots$

Molecular Weight Measurements ................. 12

Distillation of SRC II Samples ..................... 15

Analysis of Distillation Cuts .......................

Improvement in the Measurement of Total Nitrogen ........... 21

Tests on the Method for Basic Nitrogen Determination ........ 27

Improvement in the Simulated Distillation Method ........... 30

Development of a Gas Chromatographic Method for the

Determination of Molecular Weight .................. 33

Comparison of Analytical Results with Literature Data......... 33

Summary -. Task 1. Characterization of SRC II Samples ........ 37 
TASKS 2 AND 3 - BENCH SCALE OXIDATIVE-PYROLYSIS STUDIES ......... 42

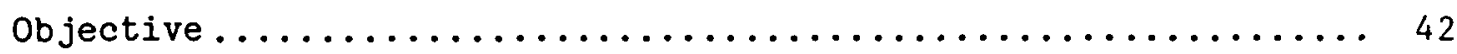

Development of a Bench Scale Oxidative-Pyrolysis Apparatus ..... 43

Drop Tube Furnace .......................... 43

Modification to Prevaporize the Fuel $\ldots \ldots \ldots \ldots \ldots \ldots \ldots$

Preliminary Experimental Results............... 46

Horizontal Furnace Modifications $\ldots \ldots \ldots \ldots \ldots \ldots \ldots \ldots$

Experimental Results......................... 52

Summary of Tasks 2 and 3 Reaction Conditions ............. 56

Summary of Liquid Product Properties ................ 56

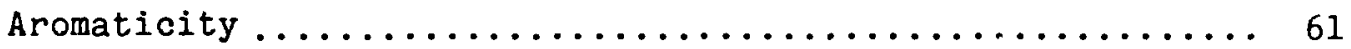

Molecular Weight $\ldots \ldots \ldots \ldots \ldots \ldots \ldots \ldots \ldots \ldots \ldots \ldots$

Elemental Composition $\ldots \ldots \ldots \ldots \ldots \ldots \ldots \ldots \ldots \ldots \ldots$

Nitrogen Concentration ............................ 72

Unsubstituted Aromatics ...................... 72

Tasks 2 and 3 Conclusions ............................ 79

Application of Results to Staged Combustion ............. 82

TASK $4-$ STAGED COMBUSTION STUDIES $\ldots \ldots \ldots \ldots \ldots \ldots \ldots \ldots \ldots \ldots \ldots$

objective ................................. 84

Staged Combustion Apparatus ...................... 84

Nozzle Assembly $\ldots \ldots \ldots \ldots \ldots \ldots \ldots \ldots \ldots \ldots \ldots \ldots \ldots \ldots$

Liquid Fuel Feed System.................... 86 


\section{TABLE OF CONTENTS}

$\underline{\text { Page }}$

Ventilated Enclosure...................... 89

Probe Design, Sampling and Analysis................. 89

Solid and Liquid Product Probe and Sampling System....... 89

Hydrogen Cyanide and Ammonia Probe and Sampling System.... 91

Instrument Gas Probe and Analysis System............ 95

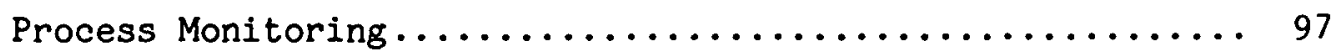

Staged Combustion Operating Conditions............ 97

Fuel Characterization....................... 97

Agreement Between Calculated and Measured Stoichiometry.... 99

Discussion of Staged Combustion Results............... 100

Total Fuel Nitrogen ........................ 100

Elemental Analyses of Solid Samples.............. 100

Gas Chromatographic Analyses of Liquid Samples.......... 103

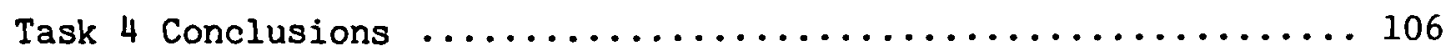

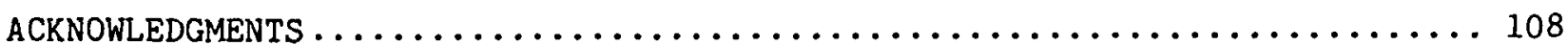

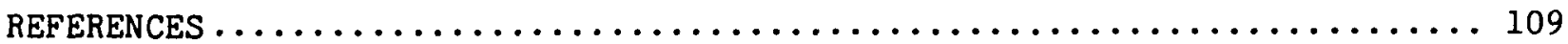




\section{LIST OF FIGURES}

\section{Page}

FIGURE 1. REPRESENTATIVE TYPES OF BASIC NITROGEN COMPOUNDS FOUND IN PETROLEUM..................... 7

FIGURE 2. REPRESENTATIVE TYPES OF NONBASIC NITROGEN COMPOUNDS

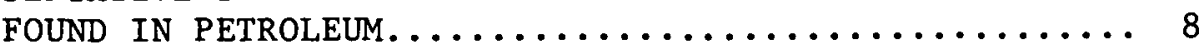

FIGURE 3. BOILING POINT VERSUS MOLECULAR WEIGHT IN VARIOUS TYPES OF AROHATICS AHD $n$ ALIPHATICS.............. 14

FIGURE 4. MOLECULAR WEIGHT - BOILING POINT DISTRIBUTION.......... 20

FIGURE 5. AVERAGE MOLECULAR STRUCTURES IN SRC II $\ldots \ldots \ldots \ldots \ldots \ldots \ldots$

FIGURE 6. ACTUAL PERCENT NITROGEN VERSUS PERCENT NITROGEN BY NITROGEN SPECIFIC DETECTOR/FID RESPONSE USING GAS CHROMATOGRAPHY..................... 29

FIGURE 7. COMPARISON OF MD-3 (250-300 C) BOILING POINT DISTRIBUTION BEFORE AND AFTER PYROLYSIS AT $800 \mathrm{c} \ldots \ldots \ldots \ldots \ldots \ldots . \ldots 32$

FIGURE 8. COMPARISON OF MD-3 (250-300 C) BOILING. POINT DISTRIBUTION BEFORE AND AFTER PYROLYSIS AT 800 c............... 34

FIGURE 9. COMPARISON OF LIQUID PRODUCT MOLECULAR WEIGHTS OBTAINED BY VAPOR PHASF. OSMOMETRY AND SIMULATED DISTILLATION BY GAS CHROMATOGRAPHY.................. 35

FIGURE 10. MOLECULAR WEIGHT VERSUS AVERAGE BOILING POINT........ 38

FIGURE 11. PERCENT CARBON VERSUS AVERAGE BOILING POINT $\ldots \ldots \ldots \ldots \ldots$

FIGURE 12. PERCENT HYDROGEN VERSUS AVERAGE BOILING POINT......... 39

FIGURE 13. PERCENT OXYGEN VERSUS AVERAGE BOILING POINT $\ldots \ldots \ldots \ldots \ldots 40$ FTGIIRE 14. H/C $\triangle$ TOMIC RATIO AND PERCENT SIIT.FUR VERSUS AVERAGE

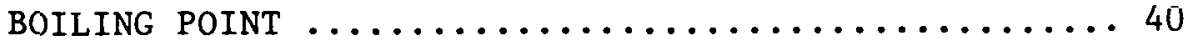

FIGURE 15. BASIC AND TOTAL NITROGEN VERSUS AVERAGE BOILING POINT $\ldots 41$ FIGURE 16. A SCHEMATIC DIAGRAM OF THE FIRST EXPERIMENTAL SET-UP.....44 FIGURE 17. A SCHEMATIC DIAGRAM OF THE MODIFIED EXPERIMENTAL SET-UP... 47 FIGURE 18. COMPARISON OF BOILING POINT DISTRIBUTION IN MD-3 (250-300 C) BEFORE AND AFTER PYROLYSIS AT 800 C FOR 0.3 AND 1.0 SECONDS IN HELIUM......... 50 


\section{LIST OF FIGURES (Continued)}

Page

FIGURE 19. SCHEMATIC OF THE MODIFIED EXPERIMENT APPARATUS....... 53

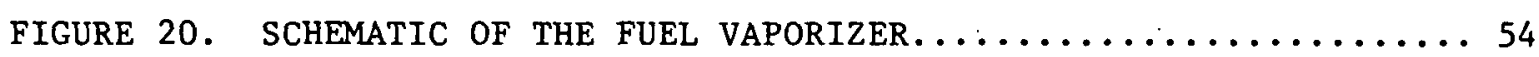

FIGURE 21. ATOMATICITY OF LIQUID PRODUCTS VERSUS PYROLYSIS TEMPERATURE............................ 64

FIGURE 22. ATOMATICITY VERSUS FRACTION OF STOICHIOMETRIC OXYGEN....6 65

FIGURE 23. NUMBER OF AROMATIC RING SUBSTITUENTS $\left(\mathrm{R}_{\mathbf{S}}\right)$ VERSUS

PYROLYSIS TEMPERATURE....................66

FIGURE 24. SUBSTITUENT LENGTH ( $n$ ) VERSUS PYROLYSIS TEMPERATURE..... 67

FIGURE 25. MOLECULAR WEIGHT AND ELEMENTAL COMPOSITION VERSUS

PYROLYSIS TEMPERATURE...................69

FIGURE 26. MOLECULAR WEIGHT VERSUS FRACTION OF STOICHIOMETRIC OXYGEN. 70

FIGURE 27. CARBON, HYDROGEN AND OXYGEN CONTENT VERSUS PYROLYSIS

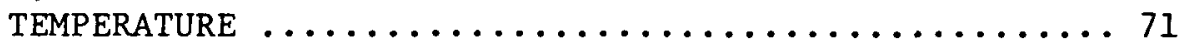

FIGURE 28. HYDROGEN DISTRIBUTION VERSUS PYROLYSIS TEMPERATURE.....7 73

FIGURE 29. CARBON COMPOSITION VERSUS FRACTION OF STOICHIOMETRIC

OXYGEN............................ 74

FIGURE 30. HYDROGEN COMPOSITION VERSUS FRACTION OF STOICHIOMETRIC OXYGEN........................... 75

FIGURE 31. HYDROGEN COMPOSITION VERSUS FRACTION OF STOICHIOMETRIC OXYGEN........................... 76

FIGURE 32. NITROGEN DISTRIBUTION VERSUS PYROLYSIS TEMPERATURE..... 77

FIGURE 33. NITROGEN DISTRIBUTION VERSUS FRACTION OF STOICHIOMETRIC OXYGEN........................... 78

FIGURE 34. PERCENT OF UNSUBSTITUTED AROMATICS VERSUS PYROLYSIS TEMPERATURE........................ 80

FIGURE 35. CONCENTRATION OF UNSUBSTITUTED AROMATICS IN THE LIQUID PRODUCT VERSUS FRACTION OF STOICHIOMETRIC OXYGEN.... 81

FTGIRE 36: CHEMISTRY OF UNBURNED COAL DERIVED LIQUID ........... 83

FIGURE 37 . SCHEMATIC OF THE TWO-STAGE COMBUSTOR............ 85 


\section{LIST OF FIGURES (Continued)}

$\underline{\text { Page }}$

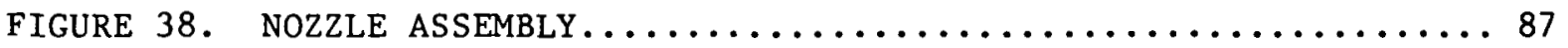

FIGURE 39. FUEL FEED SYSTEM......................... 88

FIGURE 40. WATER QUENCHED PROBE FOR PARTICULATE SAMPLING......... 90

FIGURE 41. PARTICULATE AND LIQUID PRODUCT PROBE AND SAMPLING SYSTEM... 92

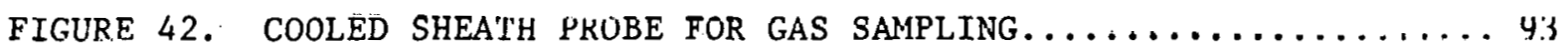

FIGURE 43. HYDROGEN CYANIDE AND AMMUNIA PROBE AND SAMPLING SYSTEM..... 94

FIGURE 44. INSTRUMENT GAS PROBE AND ANALYSIS SYSTEM........... 96

FIGURE 45. CONCENTRATION OF NITROGEN CONTAINING GASES VERSUS STOICHIOMETRY.

\section{LIST OF TABLES}

TABLE 1. BASIC AND NON-BASIC NITROGEN COMPOUNUS IN SRCII.......... 9

TABLE 2. COMPARISON OF DISTILLATION RESULTS USING WESTINGHOUSE SRC II. 11

TABt.F. 3. ANALYTICAL DATA FOR WESTINGHOUSE ANd GULF SRC II SAMPLES.... 17

TABLE 4. ANALYTICAL DATA FOR WESTINGHOUSE AND GULF SRC II SAMPLES.... 18

TABLE 5. ANALYTICAL DATA FOR WESTINGHOUSE AND GULF SRC II SAMPLES.... 19

TABLE 6. RFSULTS OF THE BATTELLE ANALYSES FOR NITROGEN USING

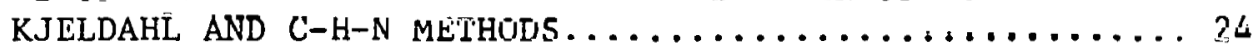

TABLE 7. RESULTS OF OUTSIDE LABORATORY ANALYSES FOR TOTAL NITROGEN.... 25

TABLE 8. RESIILTS OF ANALYSES FOR TOTAL NITROGEN BY TRUESDAIL

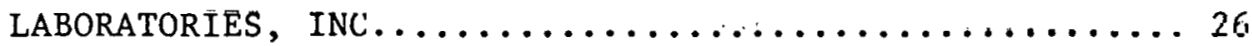

TABLE 9. NITROGEN DISTRIBUTION IN SRC II DISTILLATION FRACTION...... 28

TABLE 10. RESIJT.TS OF BATTELLE ANALYSES FOR BASIC NITROGEN USING TITRATION WITH PERCHLORIC ACID IN ACETIC ACID....... 31

TABLE 11. STRUCTURAL TYPES VERSUS BOILING POINT OF SRC II FRACTIONS... 36

TABLE 12. EXPERIMENTAL CONDITIONS FOR INITIAL. PYROLYSIS EXPERIMENTS... 48

TABLE 1.3. ANALYTICAL DATA FOR MD-3 PYROLYSIS EXPERIMENTS ........ 51 
TABLE 14. OXIDATIVE-PYROLYSIS REACTION CONDITIONS............ 57

TABLE 15. PYROLYSIS AND OXIDATIVE PYROLYSIS PRODUCT RECOVERIES

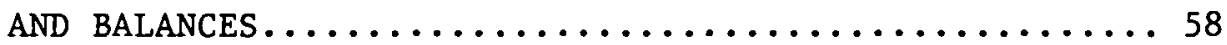

TABLE 16. NORMALIZED AVERAGE RECOVERIES OF SOLIDS, LIQUIDS AND GASES FROM PYROLYSIS AND OXIDATIVE-PYROLYSIS OF SRC II

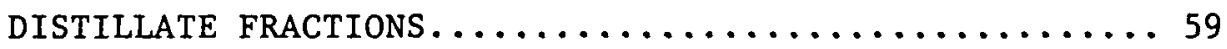

TABLE 17. MOLECULAR WEIGHTS AND ELEMENTAL ANALYSES OF PYROLYSIS AND PYROLYSIS-OXIDATION PRODUCTS.............6 60

TABLE 18. HYDROGEN DISTRIBUTION, STRUCTURAL PARAMETERS AND MOLECULAR FORMULAS FOR PYROLYSIS AND OXIDATIVE PYROLYSIS PRODUCTS OF SRC II DISTILLATION FRACTIONS .........62

TABLE 19. UNSUBSTITUTED AROMATICS IN PRODUCTS OF PYROLYSIS AND OXIDATIVE-PYROLYSIS OF SRC II DISTILLATION FRACTIONS... 63

TABLE 20. CONTINUOUSLY MONITORED GASES .................. 97

TABLE 21. ELEMENTAL ANALYSES OF SRC II AND \#2 FUEL OIL.......... 98

TABLE 22. AGREEMENT BETWEEN CALCULATED AND MEASURED STOICHIOMETRIES IN THE STAGED COMBUSTOR...................... 99

TABLE 23. SUMMARY OF OPERATING CONDITIONS AND GASEOUS PRODUCT CONCENTRATIONS FOR THE SRC II COMBUSTION EXPERIMENTS......101

TABLE 24. RESULTS OF ELEMENTAL ANALYSES ON SOLIDS RECOVERED FROM

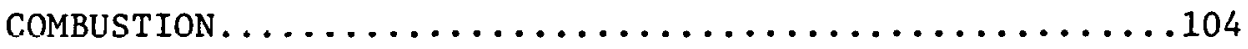

TABLE 25. AVERAGE BOITTNG POTNTS/MOLECULAR WEIGHTS OF LIQUID COMBUSTION SAMPLES ....................... 106 
FINAL REPORT

on

SYNTHETIC FUEL AROMATICITY AND

STAGED COMBUSTION

to

U.S. DEPARTMENT OF ENERGY

PITTSBURGH ENERGY TECHNOLOGY CENTER

Contract No. DE-AC22-80PC-30302

Battelle No. G-7662

Period Covered: September 23, 1980 -

September 23, 1982

November 15, 1982

by

James R. Longanbach, Lisa K. Chan, and Arthur Levy

\section{INTRODUCTION}

Synthetic liquid fuels, otherwise referred to as synfuels or coalderived liquids, are probably best characterized from a combustionenvironmental point of view as low in hydrogen, low in sulfur, high in nitrogen, and high in aromatics. As a consequence two of the more critical problems in synfuel combustion are $\mathrm{NO}_{x}$ formation and soot formation (and polycyclic organic matter). $(1,2)$. This program was directed to these two issues:

At first hand the solutions to burning synfuels high in aromatics and fuel-bound nitrogen are diametrically opposed, i.e., high temperature and excess air keep soot levels down and low temperatures and vitiated air keep nitrogen oxide levels down. Staged combustion however offers a logical solution to the above. This program separates and analyzes the synfuel combustion problem via its component parts and then puts them together again phenomenologically via the stage combustion process. 


\section{OBJECTIVES}

The overall objective of this program was to elucidate the pyrolysis and oxidation behavior of synfuel and to integrate this behavior in staged combustion to determine the effects of staged combustion on the formation of soot and $\mathrm{NO}_{\mathbf{x}}$.

More specifically, this program was divided into five tasks. The titles and objectives of these tasks were as follows.

Task 1. Characterization of the aromatics and the fuel-N components. The objective was to characterize the aromatic and fuel-N compounds present in a typical synfuel.

Task 2. Pyrolysis Studies. The objeotive was to determine the behavior of aromatic and fuel $\mathrm{N}$ components in narrow $(50 \mathrm{C})$ distillation cuts of synfuel as a function of time and temperature.

Task 3. Oxidative-Pyrolysis Studies. The objective was to study the oxidation of the pyrolysis products from Task 2 . However, the studies in Task 2 were simply extended to various levels of oxygen.

Task 4. Staged Combustion Studies. The objective was to define the burning characteristics of synfuel as a function of equivalence ratio, temperature and residence time in two-stage combustion. Only single-stage combustion studies were completed at various equivalence ratios. Residence time and temperature were not varied systematically.

Task 5. Modeling. The objective was to apply the results from Tasks 2,3 and 4 into existing models for soot and $\mathrm{NO}_{\mathbf{x}}$ formation in flames. No formal activity was carried out on this task but the data obtained were compared with results reported in the literature. 


\section{SUMMARY}

Samples of middle and heavy SRC II distillates were obtained and distilled into $50 \mathrm{C}$ boiling point range fractions. These were characterized by measurements of their molecular weight, elemental analysis and basic nitrogen content and calculation of average molecular structures by applying hydrogen distribution data obtained by $\mathrm{H}^{1}$-NMR to the Brown-Ladner correlations. The structures typically consisted of 1-3 aromatic rings fused to alicyclic rings with short, 1-3 carbon aliphatic side chains. The lower boiling fractions contained significant amounts ( 1 atom/molecule) of oxygen while the heavier fractions contained so few heteroatoms that they were essentially hydrocarbons. Basic nitrogen predominated in each of the SRC II distillate fractions.

Laboratory scale oxidative-pyrolysis experiments were carried out using the $50 \mathrm{C}$ SRC II distillation cuts prepared in Task 1. Pyrolysis temperatures of 500-1100 $\mathrm{C}$ and oxygen concentrations from 0 to 100 percent of stoichiometry were used. The fuels were prevaporized and carried through a horizontal quartz reactor tube in flowing helium. The liquid products were collected in condensers cooled with liquid nitrogen and analyzed using procedures developed in Task 1.

The liquid product analyses showed that aromatization is a major reaction in the absence of oxygen. The oxygen containing materials (phenolics) seem to be more resistant to thermal pyrolysis than unsubstituted aromatics. Short aliphatic side chains are lost to produce unsubstituted aromatic liquids up to $900 \mathrm{C}$. These go on to solid products consisting almost entirely of carbon at $1100 \mathrm{C}$. In the presence of oxygen, oxygen is added to the aromatic ring at $900 \mathrm{C}$, decreasing the concentration of soot precursors.

Nitrogen converts from basic to nonbasic forms at about $500 \mathrm{C}$. The nonbasic nitrogen is more stable and survives up to $700 \mathrm{C}$ after which it is slowly removed. Nitrogen content and basic/nonbasic nitrogen ratios were nearly unaffected by the presence of oxygen.

One area which requires significantly more research is the low temperature conversion between types of nitrogen compounds.

A recently constructed $50,000 \mathrm{Btu} / \mathrm{hr}$ staged combustor, equipped with a Sonicore nozzle to burn SRC and probes to take solid and liquid samples, HCN 
and $\mathrm{NH}_{3}$, combustion gases, NO and unburned hydrocarbons, was used to study the chemistry of the nitrogen and aromatics in SRC II under actual staged combustion conditions. SRC II combustion was studied under fuel-rich, first-stage conditions at air/fuel ratios from 0.6 to 1.0 times stoichiometric. TFN (total fuel nitrogen) showed a minimum at $\phi=0.8$ corroborating observations of others.

Analysis of the solid samples recovered from the combustion products showed that both oxygen and hydrogen concentrations increase with increasing air/fuel ratio, suggesting that oxygen is added to the fuel as oH resulting in the formation of phenols. The solids contained only about 1.7 hydrogens per 10 carbon atoms at $\phi=0.8$. Nitrogen contents were low and no trend in nitrogen retention with increasing stoichiometry was observable.

The liquid samples contained very high molecular weight materials (MW > 200) with the majority containing more than 4 aromatic rings. Apparently only the most highly condensed aromatics survive to be captured by the sampling probe. Again, no trend in fuel nitrogen could be measured.

The chemistry of the fuel during combustion calls for further investigation in order to examine the mechanism by which HCN is evolved as a common intermediate for the formation of the nitrogen containing gaseous combustion products. In this way it may be possible to increase the formation of $\mathrm{N}_{2}$ in competition with $\mathrm{HCN}$ formation and ultimately reduce $\mathrm{NO}_{\mathbf{x}}$ emissions from the combustion of synthetic fuels. 
RESULTS AND DISCUSSION

Task 1 - Characterization of SRC II Samples

\section{Objectives}

The objective of this task was to obtain suitable SRC II samples, distill them into narrow boiling point range cuts and characterize them with particular emphasis on the nitrogen content and aromatic structure.

SRC II Samples

Our initial activity was directed toward obtaining representative samples of SRC II for use in this program. We were also interested in defining suitable safety procedures for storing and handling SRC II in our laboratory.

Gulf and Westinghouse in Pittsburgh were visited to discuss safety procedures and SRC II samples. Gulf's safety procedures and the method and facilities used to transfer SRC II within their laboratory were explained. The names of people to contact at SRC International to obtain SRC II samples for use in the experimental program were also obtained. Battelle had a one-year old, 2-barrel sample of a blend of SRC II middle and heavy distillate from Westinghouse. Westinghouse provided analyses for this material and discussed their safety procedures for handling SRC II.

At a Workshop on Synthetic Fuel Combustion hosted by the Pi.t.tshurgh Energy Technology Center it was decided that standard SRC II samples would be provided through PETC. Since these would be available too late to fit into the Battelle program schedule, the Pittsburgh and Midway Coal Mining Company provided 5-gallon samples of SRC II naphtha, middle distillate, and heavy distillate. The Westinghouse sample and the three Pittsburg and Midway samples were characterized, but only the Pittsburg and Midway middle and heavy distillate SRC II samples were used in Tasks 2 and 3. 
The standard SRC II sample provided by the Pittsburgh Energy Technology Center (PETC) was used in the Task 4 staged combustion studies.

\section{Analytical Methods}

Analytical methods developed for use in this program are discussed in detail below. No distillation cuts were made on the SRC II blend (Westinghouse) sample; it was used as received.

Elemental Analyses for C, H, N, S and 0 . A Ferkin Elmer Elemental Analyzer was used inilially for $\mathrm{C}, \mathrm{H}$, and $\mathrm{N}$ analyses. Thete are no probloms with this method when low-ash liquid samples are used. However, it was fuund that this method did not give satisfactory results for total nitrogen and the samples were sent to an outslde laboratory which used the Kjeldahl method. This is discussed in more detail later. Sulfur was measured by $\mathrm{x}$-ray fluorescence and oxygen was calculated by difference. The sample size required was less than $10 \mathrm{ml}$, about $5 \mathrm{ml}$ of which was used for the sulfur analysis and about $5 \mathrm{ml}$ for the nitrogen analysis. Only a few milligrams were needed for the $\mathrm{C}$ and $\mathrm{H}$ analyses.

Basic Nitrogen. If typical nitrogen compounds are arranged in order of ionization constants in aqueous sulution, thooo above a sertiain value are titratable with perchiorlc acld while thouc with lower innination sonst.ant.s are not. The separation point is reported to be about $\mathrm{K}_{\mathrm{b}}=1 \times 10-11$. (3) Most. oxygen and sulfur compounds do not interfere. Examples of basic (titratable) nitrogen compounds include pyridines, quinolines, piperidines, and anilines (Figure 1). 2-Amino-benzothiazole is right on the separation point. Examples of nonbasic nitrogen compounds include pyrrole, indoles, carbazoles, urea, acetamide and cyanide (Figure 2).

Similar compounds are reported in SRC II. (4) A list of basic and nonbasic nitrogen compounds found in SRC II is given in Table 1.

The titration of basic nitrogen with perchloric acid in acetic acid was tested successfully. The method(3) consists of diluting an accurately weighed sample of SRC II (1.0 gram) with $100 \mathrm{ml}$ of glacial acetic acid and 
<smiles>[R]c1cccnc1</smiles>

PYRIDINES<smiles>[R]c1cnc2ccccc2c1</smiles><smiles>[R]c1ccc2nc3ccccc3cc2c1</smiles>

ACRIDINES<smiles>[R]c1ccc2nc3ccccc3nc2c1</smiles>

PHENAZINES<smiles>Cc1cc(C)c2c(n1)C(C)(C)C1(C)CCCC21</smiles>

PYRIDANS<smiles>C1=CC2N=Cc3ccccc3C2C=C1</smiles>

PHENANTHRIDINES<smiles>[R]c1ccccc1N</smiles>

ANILINES

FIGURE 1. REPRESENTATIVE TYPES OF BASIC NITROGEN COMPOUNDS FOUND IN PETROLEUM

(From Axworthy, A.E., et al., "Chemistry of Fue? Nitrogen Oxides in Combustion", Rocketdyne Division, Rockwell International Report to EPA, February 1976, p. 23) 
<smiles>[R]C1CC2C=CN(C1)C2</smiles>

PYRROLES<smiles>[R]c1ccc2[nH]c3ccccc3c2c1</smiles>

CARBAZOLES<smiles></smiles>

AMIDES<smiles>[R]CCC1C=CC=CC2C=CNC21</smiles>

INDOLES<smiles>[R]c1ccc2[nH]c3ccc4ccccc4c3c2c1</smiles>

BENZCARBAZOLES<smiles>[R]c1ccc2ccc(=O)[nH]c2c1</smiles>

QUINOLONES<smiles>[R]c1ccc(C#N)cc1</smiles>

BENZONITRILES

FIGURE 2. REPRESENTATIVE TYPES OF NONBASIC NITROGEN COMPOUNDS FOUND IN PETROLEUM

(From Axworthy, A.E., et al., "Chemistry of Fuel Nitrogen Conversion to Nitrogen Oxides in Combustion", Rocketdyne Division, Rockweli International report to EPA, February 1976 (p. 24) 
TABLE 1. BASIC AND NON-BASIC NITROGEN COMPOUNDS IN SRCII

\begin{tabular}{|c|c|c|}
\hline Basic & .. & Non-basic \\
\hline Alkylpyridines & & Phenolic pyridines \\
\hline Quinolines & & Alkyl indoles \\
\hline Anilines & & Phenolic amines \\
\hline \multirow{3}{*}{ Aliphatic amines } & $\therefore$ & - Indoles \\
\hline & . & Carbazoles \\
\hline & & Quinolenes \\
\hline , & $\cdot$ & Amides \\
\hline \multirow{3}{*}{ ". } & & Benzocarbazoles \\
\hline & & Phenazines \\
\hline & & Nitriles \\
\hline
\end{tabular}


$5 \mathrm{ml}$ of toluene (to improve solubility) and titrating the mixture while stirring with $0.1 \mathrm{~N} \mathrm{HClO}_{4}$ in glacial acetic acid. Water must be excluded from the system. After titration with a $\mathrm{pH}$ meter using a combination electrode, MV readings are plotted versus $m l$ of acid added to find the breakpoint on the curve. A sample of pure pyridine was used to standardize the perchloric acid titrant. Analysis of the SRC II blend sample gave a value for basic nitrogen of $0.54 \mathrm{~g} / 100 \mathrm{~g}$ sample. The total nitrogen content is $0.91 \mathrm{~g} / 100 \mathrm{~g}$. Thus, the ratio of basic/total nitrogen is 0.59 . Ratios of $0.30 \pm 0.05$ are typical for crude oils. (5)

Simulated Distillation by Gas Chromatography. Simulated distillation by gas chromatography, similar to the method described in ASTM 2887, was used for this analysis. This technique requires much less sample, time and cost compared to even small scale conventional distillation techniques.

A comparison of a preliminary result of the Battelle GC simulation method with the results reported for the SRC II blend sample is shown in Table 2. The Battelle results are closer to the ASTM D86 results at all points up to the end point. The end point cannot be determined accurately using conventional distillation techniques because of the residue left in the equipment when the distillation pot is empty.

Aromatic Distribution by $\mathrm{H}^{\mathrm{l}}$ and $\mathrm{Cl} 3 \mathrm{NMR}$. Brown and Ladner have developed a method for calculating several structural parameters of coal liquids based on the amounts of aromatic protons, aliphatic protons next to an aromatic ring and aliphatic protons not adjacent to an aromatic ring as measured by $\mathrm{H}^{1}$ NMR. (6) Several assumptions were made ${ }^{2 /}{ }^{\prime \prime}$ developing the equations which describe the molecular structures. They assumed that aromatic rings are not linked by $\mathrm{C}-\mathrm{C}$ bonds or by $\mathrm{C}-\mathrm{O}-\mathrm{C}$ bonds. Recent studies suggest that these are reasonably good assumptions in depolymerized coal liquids such as SRC II. (7) We also assumed that all of the oxygen present in the SRC II is present as phenolic oxygen and appears under the aromatics in the NMR as found by Schwager, et al. (8) We corrected for this using the oxygen concentrations from the elemental analysis provided by Westinghouse. The fractions of total hydrogen measured were: 
TABLE 2. COMPARISON OF DISTILLATION RESULTS USING WESTINGHOUSE SRC II

\begin{tabular}{|c|c|c|c|}
\hline \multirow{3}{*}{$\begin{array}{c}\text { Volume Distilled/ } \\
\text { wt } \% \\
\end{array}$} & \multicolumn{3}{|c|}{ Method } \\
\hline & Battelle & \multicolumn{2}{|c|}{ ASTM } \\
\hline & GC Simulation, ${ }^{\circ} \mathrm{C}$ & $\mathrm{D} 86,{ }^{\circ} \mathrm{C}$ & $2887,{ }^{\circ} \mathrm{C}$ \\
\hline$I B P$ & 114 & 104 & 136 \\
\hline 5 & 172 & 194 & 166 \\
\hline 10 & 183 & 207 & 181 \\
\hline 30 & 211 & 223 & 207 \\
\hline 50 & 235 & 237 & $229^{\prime \prime}$ \\
\hline 70 & 252 & 255 & 250 \\
\hline 90 & 293 & 303 & 282 \\
\hline 95 & 331 & 338 & 312 \\
\hline EP & 412 & 338 & 406 \\
\hline
\end{tabular}




$$
\begin{array}{ll}
0.36 & \mathrm{H}_{\mathrm{O}}=\text { aliphatic not adjacent to aromatic } \\
0.37 & \mathrm{H}_{\alpha}=\text { aliphatic adjacent to aromatic } \\
0.24 & \mathrm{H}_{\mathrm{arO}}=\text { aromatic } \\
0.03 & \mathrm{H} \\
\mathrm{OH} & =\text { phenolic. }
\end{array}
$$

sing these fractions, the elemental analyses and a molecular weight of 200 $g /$ mole (discussed in the next section) the following molecular structure parameters were calculated for the Westinghouse SRC II blend.

$$
\begin{aligned}
& f_{a}=\text { fraction of total carbon which is aromatic }=0.556 . \\
& \frac{H_{a r o}}{C_{a r o}}=\text { ratio of substitutable edge atoms to total aromatic } \\
& \alpha=0.998 \\
& C_{A}=\text { total number of aromatic carbon atoms per molecule }=7.95 \\
& R_{S}=\text { number of substituted aromatic ring carbons }=3.76 \\
& n=\text { number of carbon atoms per saturated substituent }=1.97 \\
& R_{n}=\text { number of aromatic rings per molecule }=1.01 \text {. }
\end{aligned}
$$

The molecular formula was calculated to be $\mathrm{C}_{14.3^{\mathrm{H}}} \mathrm{H}_{17.4} \mathrm{~N}_{0.15} \mathrm{~S}_{0.010_{0.54}}$.

These easy calculations provide sufficient characterization of the structures of the starting SRC II distillation fractions and pyrolysis and oxidation products to study the effects of aromaticity. These preliminary results suggested that almost all of the aromatics were single ring structures and that the substituents average two carbon atoms in length. In addition a sample was submitted for Cl3 NMR, which gives a measure of the ratio of aliphatic to aromatic carbon directly, and was used as a check on these calculations. The aromaticity by $C^{13}$ NMR was $f_{a}=0.60$. Other workers have also found that the Brown-Ladner equations agree very well with the cl3 results so C13 NMR analyses were not used on the other samples. (9)

Molecular Weight Measurements. Most molecular weight measurements for coal liquids reported in the literature are obtained by Vapor Pressure Osmometry (VPO) in either benzene or THF. A sample of the SRC II blend sent out for VPO measurement of molecular weight gave a molecular weight of 138 g/mole. Since these measurements involve a long lag time it was preferable to find a method for determining molecular weight in-house. VPO yields a number average molecular weight. Number average molecular weights have been 
obtained using two methods which could be done in-house: Gel Permeation Chromatography (GPC) and Gas Chromatography (GC).

GPC uses size exclusion of the adsorbed SRC II molecules dissolved in a solvent as they pass through a column containing a material with a known pore size distribution. Large molecules which cannot be adsorbed in the pores are eluted first. A polystyrene standard of known molecular weight distribution is run and used as an external standard to calibrate the molecular size distribution curve. Two problems occur. First, the results are based on molecular shape rather than weight and the polystyrene standard may have a different molecular size/weight ratio than the SRC II. Second, the SRC II must be totally soluble and must not be permanently adsorbed on the column. Both problems appeared to occur when the Westinghouse SRC II sample was analyzed using GPC. The number average molecular weight was found to be only $53 \mathrm{~g} / \mathrm{mole}$. This is clearly too low. Some of the SRC II was not eluted from the column and apparently the polystyrene polymer was not a good standard for SRC II as well.

GC was tried using the same column used for simulated distillation. This column elutes the compounds in order of their bolling point. The flame ionization detector (FID) used measures the mass of sample (carbon) passing through the flame. Standards of straight chain aliphatics of known boiling point and molecular welght were used to calibrate the results. The aliphatics mixture is not a good model for aromatics because aliphatics boil at lower temperatures for the same molecular weight compared to aromatics and phenols, as shown in Figure 3. The addition of aliphatic side chains to aromatics increases their boiling points, moving them into closer agreement with the n-allphatic standards.

The number average molecular weight obtained by the GC method was $190 \mathrm{~g} / \mathrm{mole}$. This also seemed low but number average molecular weights are heavily influenced by the concentration of low molecular weight species present. One set of published values for PAMCO SRC molecular weights (by VPO) are propane soluble 307, pentane insolubles-benzene solubles 352 , pentane soluble-propane insolubles 563, and carbon disulfide insolubles 600. These seem high considering the other properties of the Westinghouse SRC II such as viscosity $(1.19 \mathrm{cs}$ at $100 \mathrm{C})$ and pour point ( $-65 \mathrm{~F})$. 


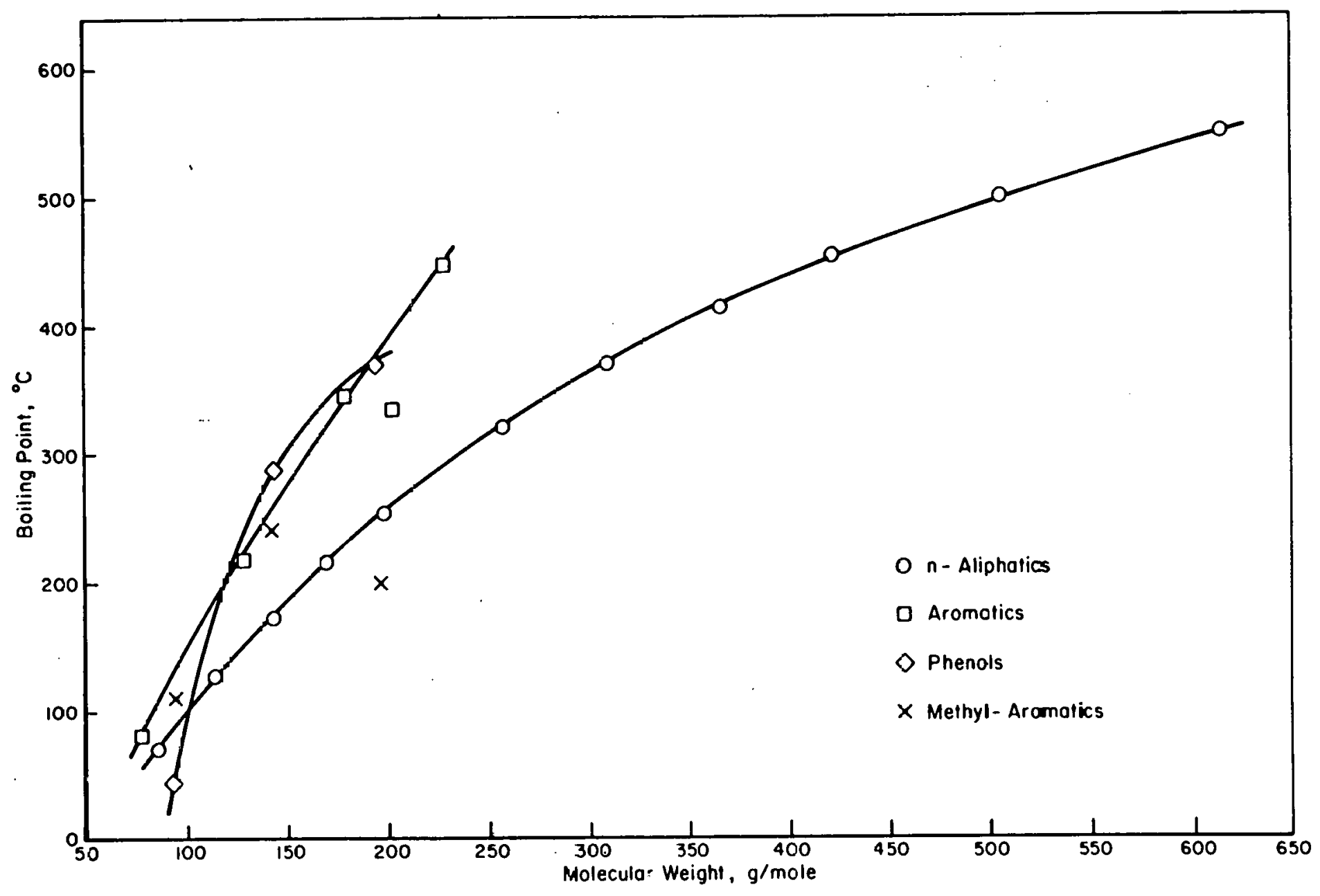

FIGURE 3. BOILING POINT VERSUS MOLECULAR WEIGHT IN VARIOUS TYPES OF AROMATLCS AND n-ALIPHATICS 


\section{Distillation of SRC II Samples}

Three 5-gallon samples of SRC II product fractions, one each of naphtha, middle distillate, and heavy distillate, were received from the Pittsburg and Midway Coal Mining Company. (The SRC II naphtha sample was not used in the current program.)

The SRC II middle distillate was distilled at atmospheric pressure to $266 \mathrm{C}$ and under reduced pressure (64 torr) from 264 to $304 \mathrm{C}$. Six fractions were obtained:

\begin{tabular}{|c|c|c|}
\hline Sample & $\begin{array}{c}\text { Boiling Point } \\
\text { Range, C, Corrected } \\
\text { to } 760 \mathrm{~mm} \mathrm{Hg}\end{array}$ & $\begin{array}{c}\text { Sample Weight, } \\
g / \%\end{array}$ \\
\hline $\begin{array}{l}\text { MD1 } \\
\text { MD2 } \\
\text { MD3 } \\
\text { MD4 } \\
\text { MD5 } \\
\text { MD6 }\end{array}$ & $\begin{array}{l}<150 \\
150-200 \\
200-250 \\
250-300 \\
300-304 \\
>304 \text { (residue) }\end{array}$ & $\begin{array}{c}6.0 / 0.7 \\
124.6 / 15.0 \\
356.4 / 43.0 \\
298.2 / 36.0 \\
9.0 / 1.1 \\
34.6 / 4.2\end{array}$ \\
\hline
\end{tabular}

The three largest fractions were analyzed for molecular weight, elemental analysis, hydrogen distribution, basic nitrogen and simulated distillation.

The SRC II heavy distillate sample was distilled under reduced pressure ( 3 torr). Five fractions were obtained:

\begin{tabular}{|c|c|c|}
\hline 3ample & $\begin{array}{l}\text { Boiling Point } \\
\text { Range, C, Corrected } \\
\text { to } 760 \mathrm{~mm} \mathrm{Hg}\end{array}$ & $\begin{array}{c}\text { Sample Weight, } \\
\mathrm{g} / \%\end{array}$ \\
\hline $\mathrm{HDI}$ & $<300$ & $82.1 / 8.2$ \\
\hline HD2 & $300-350$ & $334.2 / 33.3$ \\
\hline HD3 & $350-400$ & $293.9 / 29.3$ \\
\hline HD4 & $400-450$ & $149.6 / 14.9$ \\
\hline HD5 & $>450$ & $138.9 / 13.8$ \\
\hline
\end{tabular}

Fractions $H D-2, H D-3$, and $H D-4$ were also analyzed as described above. Fraction HD-1 is assumed to be identical to fraction MD-4 since the middle and heavy distillates are presumably cuts from the same distillation at the Tacoma SRC II pilot plant. 


\section{Analysis of Distillation Cuts}

The results of these analyses are listed in Tables 3-5. The results for a blend of middle and heavy SRC II distillate obtained previously from Westinghouse are also included.

The molecular weights obtained by VPO are number average molecular weights and are very sensitive to the low molecular weight compounds present. Thus, even though the HD-2 distillation fraction was obtained between 300 and $350 \mathrm{C}$, there are enough low molecular weight components to bring the number average molecular weight down to $177 \mathrm{~g} / \mathrm{mole}$. The molecular weights are plotted versus boiling point range in Figure 4. The boiling points of some typical aromatic compounds are included for comparison. Substitution of short aliphatic chains on a benzene ring raises the boiling point significantly. It is highly probable that virtually every compound in SRC II is a substituted aromatic.

The boiling point ranges as measured by GC (Table 4) do not fall entirely within the boiling point ranges measured during distillation. The boiling point ranges measured by GC are indicated in Figure 4 by dotted lines. When the boiling point ranges are extended the correlation of boiling point ranges with molecular weight agrees well with the known values for the substituted aromatics.

The elemental analyses listed in Table 3 show that carbon content insreases and hydọrogen content decreases with increasing molecular weight as expected. Nitrogen, sulfur and oxygen do not exhibit clear trends with increasing molecular weight. Basic nitrogen and the ratio of basic $\mathrm{N} /$ total $\mathrm{N}$ also do not follow clear trends with increasing molecular weight.

The fraction of aromatic hydrogen increases and the fractions of total aliphatic hydrogen and phenolic hydrogen decrease with increasing molecular weight (Table 3 ). The experimental variation in the NMR measurements is significant as shown by duplicate determinations.

The structural parameters calculated from the hydrogen distribution measurements are listed in Table 5. Aromaticity $\left(f_{a}\right)$ increases from about 40 percent to 70 percent with increasing molecular weight. The ratio of substitutable aromatic positions to total aromatic carbon ( $\mathrm{H}_{\text {aro }} / \mathrm{C}_{\mathrm{aro}}$ ) decreases with increasing molecular weight as would be expected as the number of condensed 
TABLE 3. ANALYTICAL DATA FOR WESTINGHOUSE AND GULF SRC II SAMPLES

\begin{tabular}{|c|c|c|c|c|c|c|c|}
\hline Sample & West Inghouse & $M D-2$ & MD-3 & MD-4 & HD-2 & HD-3 & $\mathrm{HD}-4$ \\
\hline Bp Range, ${ }^{\circ} \mathrm{C}$ & 、 & $150-200$ & $200-250$ & $250-300$ & $300-350$ & $350-400$ & $400-450$ \\
\hline$\frac{\text { Molecular Welght }}{\text { g/mole }}$ & 138 & 147 & 176 & 184 & 177 & 196 & 262 \\
\hline$\frac{\text { Elemental. Analyses }}{\text { (Wt. Per=ent) }}$ & & & & & & & \\
\hline Ash & 0.02 & 0.02 & 0.02 & 0.02 & -- & - & -- \\
\hline C & 85.9 & 82.6 & 83.4 & 87.3 & 90. & 90. & 90.1 \\
\hline H & 9.1 & 9.8 & 9.3 & 9.2 & 8.1 & 7.4 & 7.1 \\
\hline $\mathrm{N}^{(2)}$. & 1.0 & 0.9 & 1.5 & 1.7 & 1.0 & 1.4 & 1.4 \\
\hline $\mathbf{s}$ & 0.07 & 0.22 & 0.24 & 0.31 & 0.07 & 0.16 & 0.33 \\
\hline 0 & 3.9 & 6.5 & 5.5 & 1.5 & 0.8 & 1.0 & 1.1 \\
\hline Basic N & & 0.49 & 0.75 & 0.80 & 0.42 & 0.56 & 0.76 \\
\hline $\begin{array}{l}\text { Bas1c N/Total N } \\
\text { MMR Parameter }\end{array}$ & & 0.54 & 0.50 & 0.47 & 0.42 & 0.40 & 0.54 \\
\hline H $-\alpha$ to A=omatic & 0.37 & 0.31 & 0.42 & 0.43 & 0.40 & 0.36 & 0.37 \\
\hline Haliphatic & 0.36 & 0.48 & 0.32 & 0.34 & 0.27 & 0.26 & 0.25 \\
\hline Ha romatic & 0.24 & 0.17 & 0.21 & 0.22 & 0.32 & 0.37 & 0.37 \\
\hline H-Phenolie (3) & 0.03 & 0.04 & 0.05 & 0.01 & 0.01 & 0.01 & $0: 01$ \\
\hline
\end{tabular}

(1) Measured by Vapor Phase Osmometry.

(2) Measared by C-H-N analysis. Corrected results for MD-2, MD-3,

MD-4 and HD-2 are listed in Table 9.

(3) Based on the assumption $0=0 \mathrm{H}$. 
TABLE 4. ANALYTICAL DATA FOR WESTINGHOUSE AND GULF SRC II SAMPLES

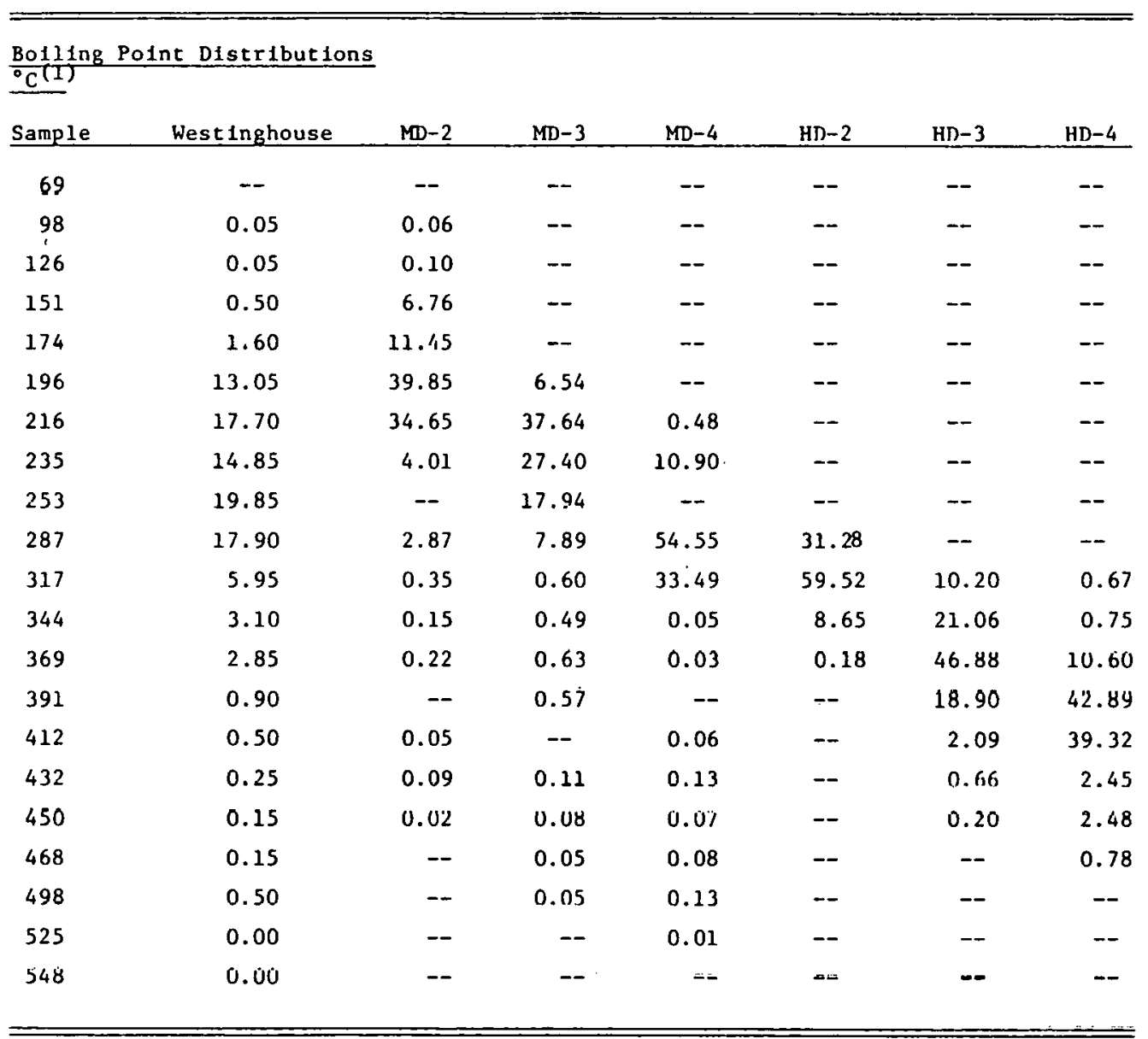

(1) Measured by GC simulation. 
TABLE 5. ANALYTICAL DATA FOR WESTINGHOUSE AND GULF SRC II SAMPLES

\begin{tabular}{|c|c|c|c|c|c|c|c|}
\hline Sample & Westinghouse & $\mathrm{MD}-2$ & $\mathrm{MD}-3$ & $\mathrm{MD}-4$ & HD-2 & $\mathrm{HD}-3$ & HD-4 \\
\hline$f_{a}(1)$ & 0.54 & 0.44 & 0.51 & 0.51 & 0.64 & 0.69 & 0.71 \\
\hline $\mathrm{H}_{\text {aro }} / \mathrm{C}_{\text {aro }}{ }^{(2)}$ & 1. & 1. & 1. & 1. & 0.88 & 0.78 & 0.74 \\
\hline$\sigma(3)$ & 0.50 & 0.60 & 0.59 & 0.52 & 0.40 & 0.34 & 0.35 \\
\hline$R_{s}(4,5)$ & 2.6 & 2.7 & 3.6 & 3.6 & 3.0 & 2.7 & 3.6 \\
\hline$n^{(6)}$ & 2.0 & 2.6 & 1.8 & 1.8 & 1.9 & 1.7 & 1.7 \\
\hline$c_{a}(7)$ & 5.3 & 4.4 & 6.2 & 6.9 & 8.5 & 10.2 & 13.9 \\
\hline$R_{a}(8)$ & 1. & 1. & 1. & 1.1 & 1.5 & 2.1 & 2.8 \\
\hline Molecular Formula & & & & & & & \\
\hline c & 9.88 & 10.1 & 12.2 & 13.4 & 13.3 & 14.7 & 19.7 \\
\hline H & 12. & 14.4 & 16.4 & 16.9 & 14.3 & 14.5 & 18.6 \\
\hline $\mathbf{N}$ & 0.10 & 0.09 & 0.19 & 0.22 & 0.13 & 0.20 & 0.26 \\
\hline s & 0.00 & 0.01 & 0.01 & 0.02 & 0.00 & 0.01 & 0.03 \\
\hline 0 & 0.34 & 0.61 & 0.61 & 0.17 & 0.09 & 0.13 & 0.18 \\
\hline
\end{tabular}

(1) $f_{a}=$ fraction of total carbon which is aromatic.

(2) Haro/Caro = ratio of substitutable aromatics.

(3) $\sigma=$ fraction of the avallable aromatic edge atoms occupled by substituents.

(4) $R_{S}=$ number of substituted aromat1c ring carbons.

(5) $\mathbf{R}_{S}$ was calculated by assuming $\mathrm{H}_{\text {aro }} / \mathrm{C}_{\text {aro }} \leq 1$.

(6) $\mathbf{n}=$ number of carbon atoms per saturated substituent.

(7) $C_{a}=$ total number of aromatic carbon atoms.

(8) $R_{a}=$ number of aromatic rings. 


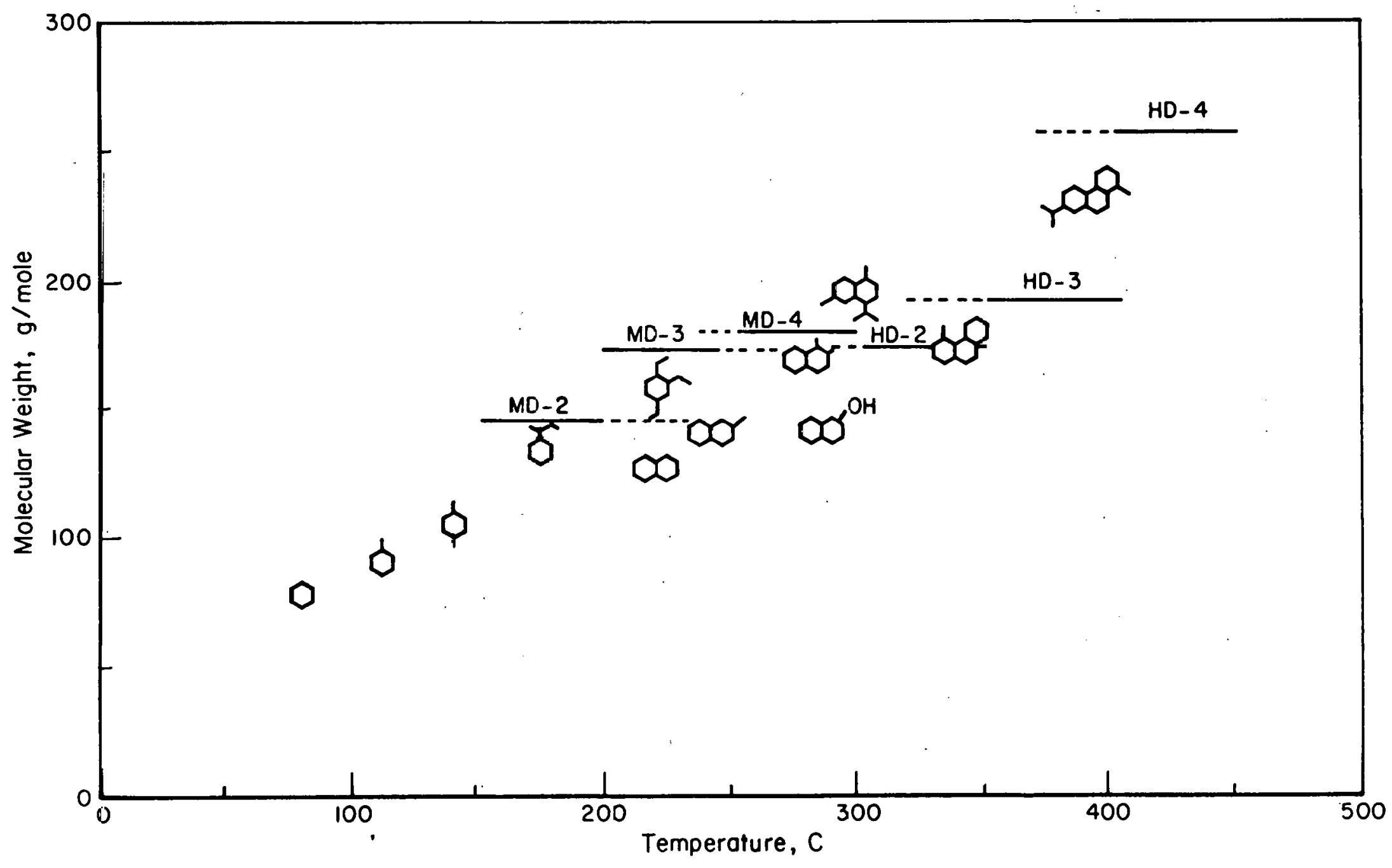

FIGURE 4. MOLECULAR WEIGHT - BOILING POINT DISTRIBUTION 
rings per molecule increases. The higher molecular weight molecules have a lower fraction of substituted aromatic carbon atoms $\alpha$, but about the same number of substituted aromatic carbon atoms per molecule $\left(R_{S}\right)$. This shows that coal is not "chickenwire" but is made up of aromatic centers connected to each other by a limited number of aliphatic and heteroatom bridges which are broken and capped during liquefaction. The number of substituents per aliphatic side chain $(n)$ does not change much with increasing molecular weight, remaining between one and two carbon atoms. This indicates that the connecting links are short, as would be expected for solid material such as coal. The number of aromatic carbon atoms $\left(C_{a}\right)$ and the number of aromatic rings $\left(R_{a}\right)$ per molecule increase with increasing molecular weight as expected.

The molecular formulas show that the molecules are largely hydrocarbons. Less than one in every $4-5$ molecules contains nitrogen and less than one molecule in 20-30 contains sulfur. Oxygen decreases with increasing molecular weight and is assumed to be entirely phenolic. More than half of the lower molecular weight molecules contain a phenolic functional group. Average molecular structures can be drawn for the various boiling point fractions. Some possibilities are shown in Figure 5. These structures contain 1-3 carbon aliphatic side chains. Alicyclic structures become more numerous as molecular weight increases. The number of aromatic rings per molecule is only 1-3 throughout the distillable range. These structures also correspond reasonably well with the structures of known boiling point shown in Figure 4.

\section{Improvement in the Measurement of Total Nitrogen}

The measurement of total nitrogen has been a problem in the past (10) and a number of papers have been written describing improved methods of analysis.(11-14) We were not satisfied with the total nitrogen analytical data supplied by Battelle's analytical staff and as a result, a series of standards were made up consisting of a pyridine-type compound in No. 2 fuel oil and a pyrrole-type compound in No. 2 fuel oil. Each standard was analyzed several times using both the $\mathrm{C}-\mathrm{H}-\mathrm{N}$ analyzer and the micro-Kjeldahl method of nitrogen analysis to characterize each method in terms of nitrogen recovery 


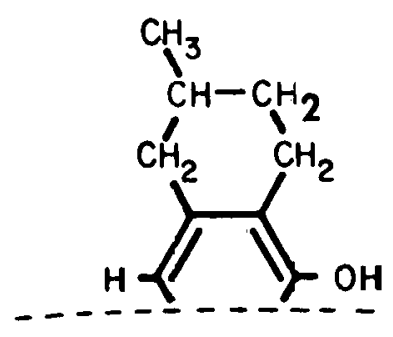

MD-2

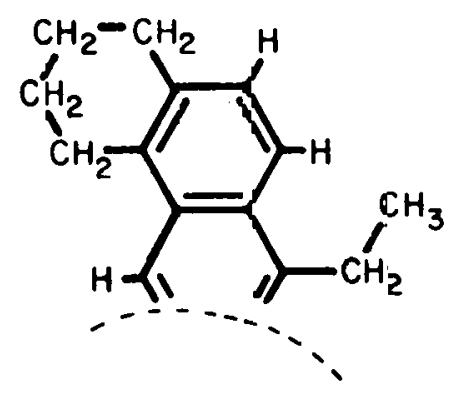

HD-?

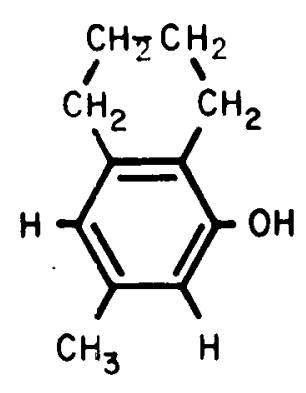

MD - 3

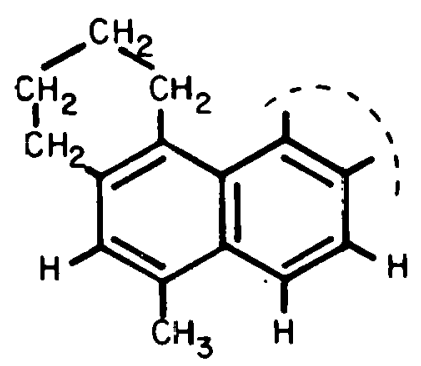

HD -3

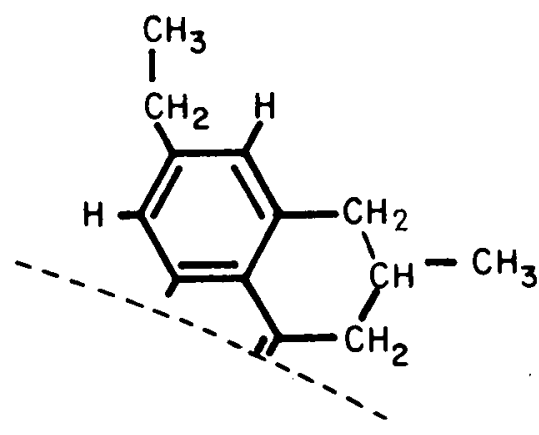

MD- 4

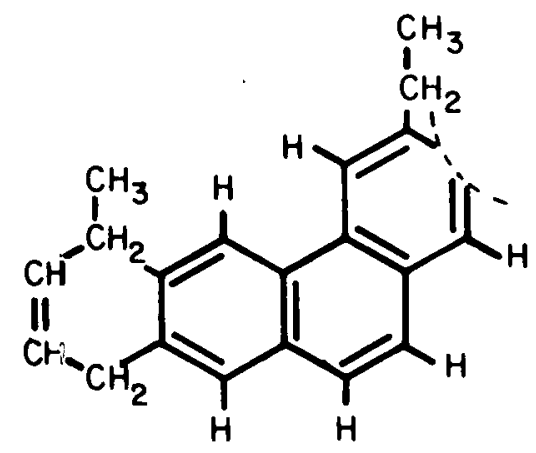

$\mathrm{HD}-4$ 
(accuracy) and standard deviation (precision). The results are listed in Table 6.

The nitrogen compounds used were pyrrole, quinoline and 4-benzyl pyridine. Pyrrole was found to be unstable and was not analyzed using the C$\mathrm{H}-\mathrm{N}$ analyzer. A freshly prepared mixture was analyzed by the micro-Kjeldahl method however. Nitrogen recoveries were 89-94 percent using the Kjeldahl method. The incomplete recoveries were apparently due to the stability of the compounds, particularly quinoline, which did not break down completely under the conditions used. Nitrogen recoveries were 107-112 percent using the $\mathrm{C}-\mathrm{H}-\mathrm{N}$ analyzer. The reasons for the high nitrogen recoveries are unknown, but the presence of air in the sample cup can lead to significant errors on the high side. The nitrogen levels used were around 1 percent and these errors could be expected to increase with typical samples from the pyrolysis-oxidation studies which contain less than $1 / 2$ percent nitrogen. It did not appear that these results were sufficiently accurate for use in this research program. The standard deviations were also too large.

It was therefore decided to send the samples outside Battelle for total nitrogen analyses. Several well known research groups, including those at Mobil and MIT, send their fuel samples to one outside laboratory for nitrogen analyses. A series of standard samples containing a stable pyrrole, 2,3dimethylindole, and quinoline in No. 2 fuel oil were sent to this outside laboratory for analysis of total nitrogen using the Kjeldahl method. The results are listed in Table 7.

Nitrogen recoveries were low (71-73 percent) for quinoline and high (100-118 percent) for 2,3-dimethylindole. Standard deviations were also ursatisfactory for the quinoline.

Energy and Environmental Research Corporation (EER) personnel suggested that we try Truesdail Laboratories, Inc. for total nitrogen analyses. They have studied the analytical methods available for total nitrogen analyses in fuel oil and have concluded that the Kjeldahl method is the best method overall, although care must be taken to insure complete digestion of refractory organics such as quinoline. (15) Their total nitrogen analyses appeared to be precise and accurate. The test samples consisted of No. 2 fuel oil spiked with quinoline (basic nitrogen) and 2,3-dimethylindole (nonbasic nitrogen). The results are shown in Table 8 . With the exception of the sample containing 
TABLE 5 . RESIJLTS OF TBE BATTELLE ANALYSES FOR NITROGEN USIRG KJELDAHL AND C-H-N METHODS

\begin{tabular}{|c|c|c|c|c|c|c|c|c|c|}
\hline \multirow[b]{3}{*}{ Sample } & \multirow{3}{*}{$\begin{array}{c}\text { Target } \\
\text { Conc., } \\
\%\end{array}$} & \multirow{3}{*}{$\begin{array}{c}\text { Analytical } \\
\text { Method }\end{array}$} & \multicolumn{7}{|c|}{ Nitrogen } \\
\hline & & & \multicolumn{3}{|c|}{ Replicates } & \multirow[b]{2}{*}{4} & \multicolumn{3}{|c|}{ Statistics } \\
\hline & & & 1 & 2 & 3 & & Std. Dev. & Mean & $\%$ Recovery \\
\hline Fuel 011 & -- & Kje1Jah1 & .02 & .02 & .02 & .02 & -- & -- & -- \\
\hline Fuel 011 & - & $\mathrm{CHN}$ & .02 & .07 & -- & -- & -- & - & -- \\
\hline Fuel 011 and Pyrrole(a) & 1.04 & Kjeldah1 & 0.99 & 0.98 & 0.95 & -- & .02 & 0.97 & 94.0 \\
\hline Fue1 011 and Quinoline & 1.02 & Kjeldahl & 0.91 & 1.0 & 0.82 & -- & .09 & 0.91 & 89. \\
\hline Fuel 011 and Quinoline & 1.02 & $\therefore \mathrm{CHN}$ & 1.17 & 1.12 & 1.02 & 1.11 & .06 & 1.1 & 107 \\
\hline $\begin{array}{l}\text { Fue1 } 011 \text { and } 4-\text { Benzy1- } \\
\text { pyridine }\end{array}$ & 0.84 & CHN & 0.96 & 0.84 & 1.01 & -- & .09 & 0.94 & 112 . \\
\hline
\end{tabular}

(a) Nitrogen was not determined on this samp-e by $\mathrm{C}-\mathrm{H}-\mathrm{N}$ because of the presence of two phases 
TABLE 7. RESULTS OF OUTSIDE LABORATORY ANALYSES FOR TOTAL NITROGEN

\begin{tabular}{|c|c|c|c|c|c|c|c|}
\hline \multirow{2}{*}{ Sample } & \multirow{2}{*}{$\begin{array}{c}\text { Target Conc, } \\
\mathrm{N} \%\end{array}$} & \multicolumn{3}{|c|}{ Replicates } & \multicolumn{3}{|c|}{ Statistics } \\
\hline & & $\overline{1}$ & 2 & $\overline{3}$ & Std, Dev. & Mean & $\%$ Recovery \\
\hline$\cdot$ & & & & $\cdots$ & & & \\
\hline Fuel 011 & -- & 0.016 & 0.015 & & .00071 & 0.0155 & --- \\
\hline Quinoline in Fuel 011 & 1.04 & 0.70 & 0.83 & 0.70 & .075 & 0.74 & 71.1 \\
\hline Quinoline in Fuel Dil & 0.54 & 0.50 & -- & & & & 92.6 \\
\hline 2,3-Dimethylindole in Fuel oil & 0.31 & 0.31 & & & & & 100.0 \\
\hline 2,3-D1methylindole in Fuel 011 & 0.11 & 0.14 & 0.12 & 0.13 & .01 & 0.13 & 118.2 \\
\hline
\end{tabular}


TABLE 8. RESULTS OF ANALYSES FOR TOTAL NIIROGEN BY TRUESDAIL LABORATORIES, INC.

\begin{tabular}{|c|c|c|c|c|c|c|c|}
\hline \multirow[b]{3}{*}{ Sample } & \multirow{3}{*}{$\begin{array}{c}\text { Target Conc., } \\
\% \mathrm{~N}\end{array}$} & \multirow{2}{*}{\multicolumn{3}{|c|}{ Replicates }} & \multicolumn{3}{|c|}{ Statistics } \\
\hline & & & & & & & Percent \\
\hline & & 1 & 2 & 3 & Stc. Dev. & Mean & Recovery \\
\hline Fuel 011 & - & 0.019 & 0.023 & & 0.0028 & 0.021 & - \\
\hline Quinoline in fuel oil & 1.04 & 1.05 & 1.05 & 1.05 & 0.0000 & 1.05 & 101.0 \\
\hline Quinoline in fuel oil & 0.54 & 0.56 & - & - & - & - & 103.7 \\
\hline 2,3-Dimethylindole in Euel ofl & 0.31 & 0.31 & 0.32 & & 0.0041 & 0.315 & 101.6 \\
\hline 2,3-Dimetrylindole fin fuel oil & 0.11 & 0.14 & 0.13 & & 0.19071 & 0.135 & 122.7 \\
\hline
\end{tabular}


a very low level of 2,3-dimethylindole, recoveries averaged 102 percent. The low level sample recovery was only 0.025 percent nitrogen above the actual value. The standard deviation on every sample was excellent.

The SRC II distillate fractions were submitted for total nitrogen analysis. The results, combined with the perchloric acid/acetic acid titation results for basic nitrogen are listed in Table 9. Total nitrogen content appears to peak in the 250-300 C boiling point range. Basic nitrogen is the principal component in all of the distillate samples but nonbasic nitrogen concentration increases with increasing boiling point.

The same samples were analyzed in-house using a gas chromatograph equipped with an effluent splitter leading to a FID detector, to measure total sample concentration, and a nitrogen specific thermionic detector to measure total nitrogen. The nitrogen specific detector conditions were optimized for nitrogen/carbon response. The results are shown in Figure 6. There is a significant difference in the detector response to basic and nonbasic nitrogen. Since it is likely that the basic $N /$ nonbasic $N$ ratio changes as pyrolysis or oxidative-pyrolysis progresses, our gas chromatograph was not used to determine total nitrogen.

Tests on the Method for Basic Nitrogen Determination

The precision of the perchloric acid titration procedure for basic nitrogen was checked by titrating one sample three times. The results were reproducible within 1 percent of the basic nitrogen percentage $( \pm 0.006$ percent absolute). Since the normality of the titrant is established by titrating pure pyridine samples under the standard titration conditions and since there is not an appreciable solvent blank, the accuracy of the method should also be good. The scatter in basic nitrogen content suggests that there are only a few basic $N$ compounds present in each SRC II distillation cut and that their concentrations vary widely from cut to cut.

The titration method for basic nitrogen(10) was also tested for selectivity on the same samples used for evaluation of total nitrogen analytical methods. Ideally, the titration method for basic nitrogen should recover 100 percent of the nitrogen in the samples containing quinoline but none of 
TABLE 9. NITROGEN DISTRIBUTION IN

SRC II DISTILLATION FRACTION

\begin{tabular}{ccccc}
\hline \hline Fraction & $\begin{array}{c}\text { Boiling Point } \\
\text { Range, }{ }^{\circ} \mathrm{C}\end{array}$ & Total N & Basic N & $\begin{array}{c}\text { Nonbasic N } \\
\text { (by diff.) }\end{array}$ \\
\hline MD-2 & $150-200$ & 0.55 & 0.49 & 0.06 \\
MD-3 & $200-250$ & 0.81 & 0.75 & 0.06 \\
MD-4 & $250-300$ & 1.05 & 0.80 & 0.25 \\
HD-2 & $300-350$ & 0.64 & 0.42 & 0.22 \\
\hline \hline
\end{tabular}




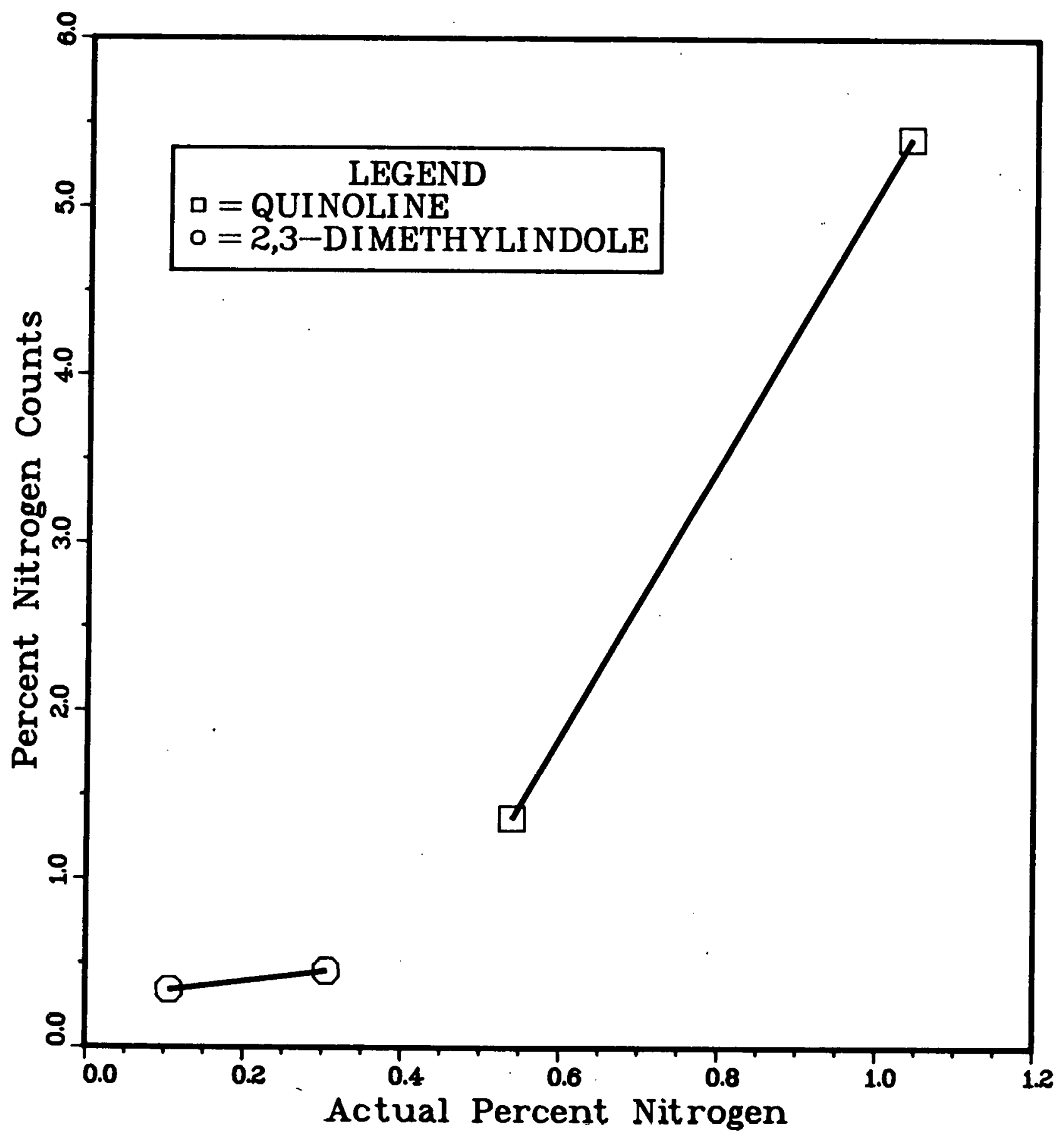

PIGURE 6. ACTUAL PERCENT NITROGEN

VERSUS PERCENT NITROGEN BY NITROGEN SPECIFIC DETECTOR / PID RESPONSE

USING GAS CHROMATOGRAPHY 
the nitrogen in the samples containing 2,3-dimethylindole. The results are shown in Table 10.

The standard deviations for all of the samples are good. Nitrogen recoveries are 102.3-102.5 percent for the basic nitrogen samples. The slightly high recoveries are apparently due to an error in the standardization of the perchloric acid titrant. The recoveries for nonbasic nitrogen are 0-2.1 percent, which is also good. It appears that basic nitrogen titration method is acceptable.

Improvement in the Simulated Distillation Method

A mixture of aromatics was prepared to use as a standard for the simulated distillation by gas chromatography (GC) analysis. The standard does not extend to boiling points as high as can be obtalned with the n-alkane standards. The aromatic standard mixture consists of the following:

$\begin{array}{lc}\text { Component } & \text { Boiling Point, C } \\ \text { Benzene } & 80 \\ \text { Toluene } & 111 \\ \text { p-Xylene } & 138 \\ \text { Indane } & 177 \\ \text { Naphthalene } & 218 \\ \text { Ditenzyl } & 285 \\ \text { Phenanthrene } & 340 \\ \text { Pyrene } & (395)\end{array}$

The boiling point of $395 \mathrm{C}$ for pyrene appears to be too high based on the curve of boiling point versus GC residence time. Other boiling polnts have been reported for pyrene.

An 18" $x$ 1/4" O.D. column had been used for the GC simulated distillation analysis. Most of the SRC II distillation cut which passed through the pyrolysis zone boiled in the same range as the starting material. Although there were many peaks of higher and lower boiling points, it was difficult to tell what changes had taken place in the region where the starting material boiled. Typical results are shown in Figure 7 . 
TABLE 10. RESULTS OF BATTELLE ANALYSES FOR BASIC NITROGEN USING TITRATION WITH PERCHLORIC ACID IN ACETIC ACID

\begin{tabular}{|c|c|c|c|c|c|c|c|}
\hline \multirow[b]{2}{*}{ Sample } & \multirow{2}{*}{$\underset{\mathrm{N} \%}{\text { Target Conc. }}$} & \multicolumn{3}{|c|}{ Replicates } & \multicolumn{3}{|c|}{ Statistics } \\
\hline & & 1 & 2 & $\overline{3}$ & Std. Dev. & Mean & N\% Recovery \\
\hline Fuel 0i1 & -- & 0.002 & 0.008 & $\cdot-$ & 0.0042 & 0.005 & -- \\
\hline Quinoline in Fuel oil & 1.04 & 1.075 & 1.068 & -- & 0.0049 & 1.072 & 102.5 \\
\hline Quinoline in Fuel oil & 0.54 & 0.555 & 0.555 & 0.562 & 0.0040 & 0.557 & 102.3 \\
\hline 2,3-Dinethylindole in Fuel $0 i 1$ & 0.11 & 0.000 & 0.007 & -- & 0.0049 & 0.00 & 0.0 \\
\hline
\end{tabular}




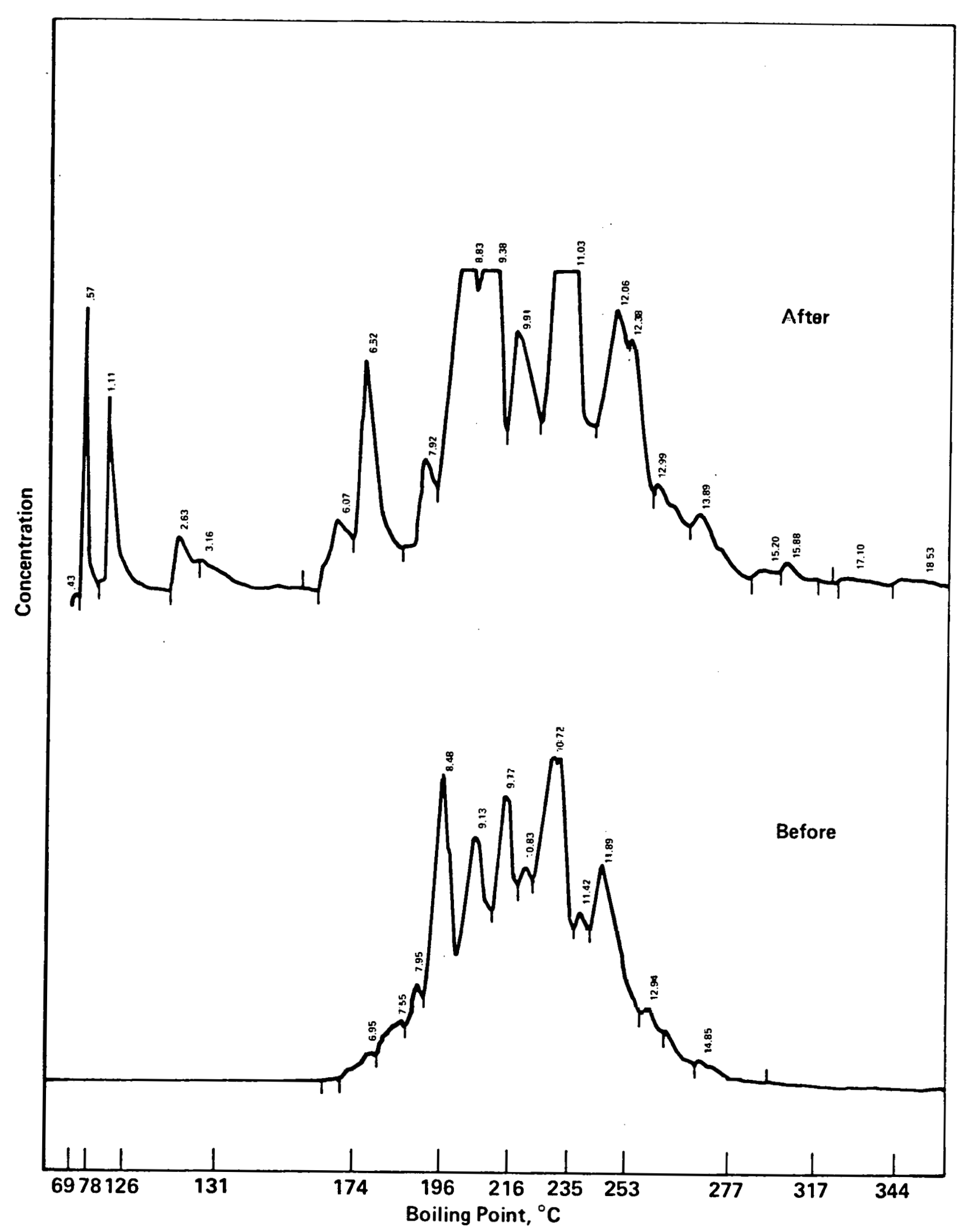

FIGURE 7. COMPARISON OF MD-3 (250-300 C) BOILING POINT DISTRIBUTION BEFORE AND AFTER PYROLYSIS AT. $800 \mathrm{C}$ (GC COLUMN $\left.18^{\prime \prime} \times 1 / 4^{\prime \prime}\right)$ (NUMBERS ABOVE PEAKS ARE GC ELUTION TIMES IN MINUTES) 
To improve the separation and to detect changes in composition occurring during pyrolysis, a 54" $\times 1 / 4 "$ O.D. column was prepared using the same packing, 10 percent UCW-982 on 60/80 Chrom-PAW. Simulated distillations using this column clearly showed the changes in the composition of the SRC II distillation cut taking place during pyrolysis, as shown in Figure 8.

Development of a Gas Chromatographic Method for the Determination of Molecular Weight

Molecular weight analyses by Vapor Phase Osmometry (VPO) have also been found to give some spurious results, particularly for the higher molecular weight materials in which some solids are probably present. The molecular weight of each sample has also been obtained by summing the area percent obtained by simulated distillation by gas chromatography using a series of aromatic standard compounds of known molecular weight to calibrate the curves. These results seem to be more consistent than the VPO results. Molecular weights obtained by the two methods are compared in Figure 9. There are differences between the two methods. The area percentages obtained by GC have not been corrected by using response factors. As a result, most of the VPO molecular weights are higher than those obtained by GC. The best fit between the data is given by the dashed line in Figure 9 (omitting the data shown as squares). This correlation allows a GC molecular weight to be substituted for a VPO molecular weight and may be a preferable method of obtaining molecular weight for the SRC II type samples.

\section{Comparison of Ardalytical Results With Literature Data}

The analytical results for the SR II distillation cuts agree well with detailed characterization of narrow boiling point cuts of SRC II reported by Gray, et al. (17): The most common structures they reported for the boiling point fractions used in this work are shown in Table 11. Tetralins, hydro-: phenanthrenes, and hydropyrenes predominate depending on the boiling point range of the sample.

The. Pittsburg and Midway Coal Mining Company sent analytical data on SRC II distillation cuts for comparison. The analyses are in good agreement. 


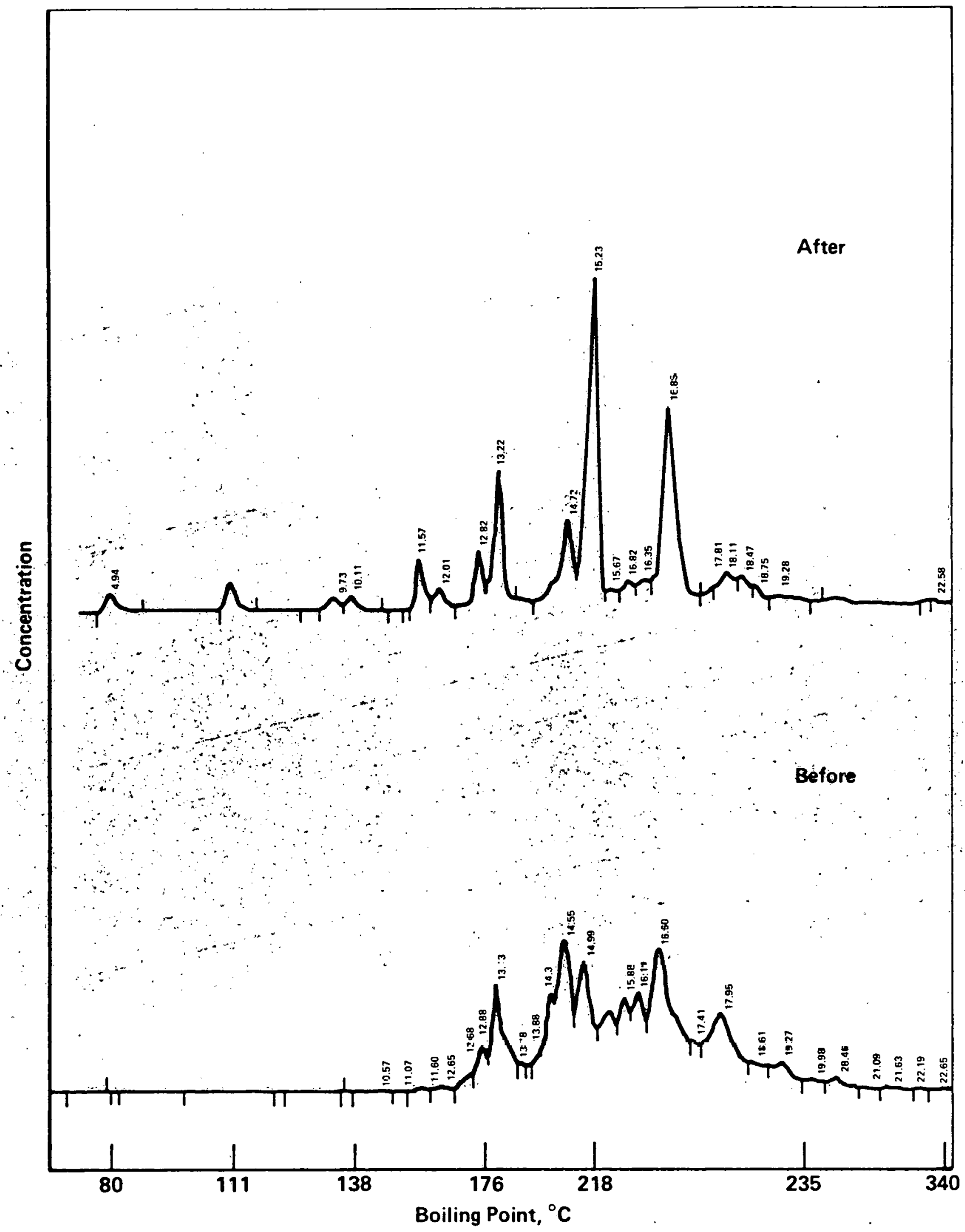

FIGURE 8. COMPARISON OF MD-3 (250-300 C) BOILING POINT DISTRIBUTION BEFORE AND AFTER PYROLYSIS AT $800 \mathrm{C}$ (GC COLUMN $\left.54^{\prime \prime} \times 1 / 4^{\prime \prime}\right)$ 


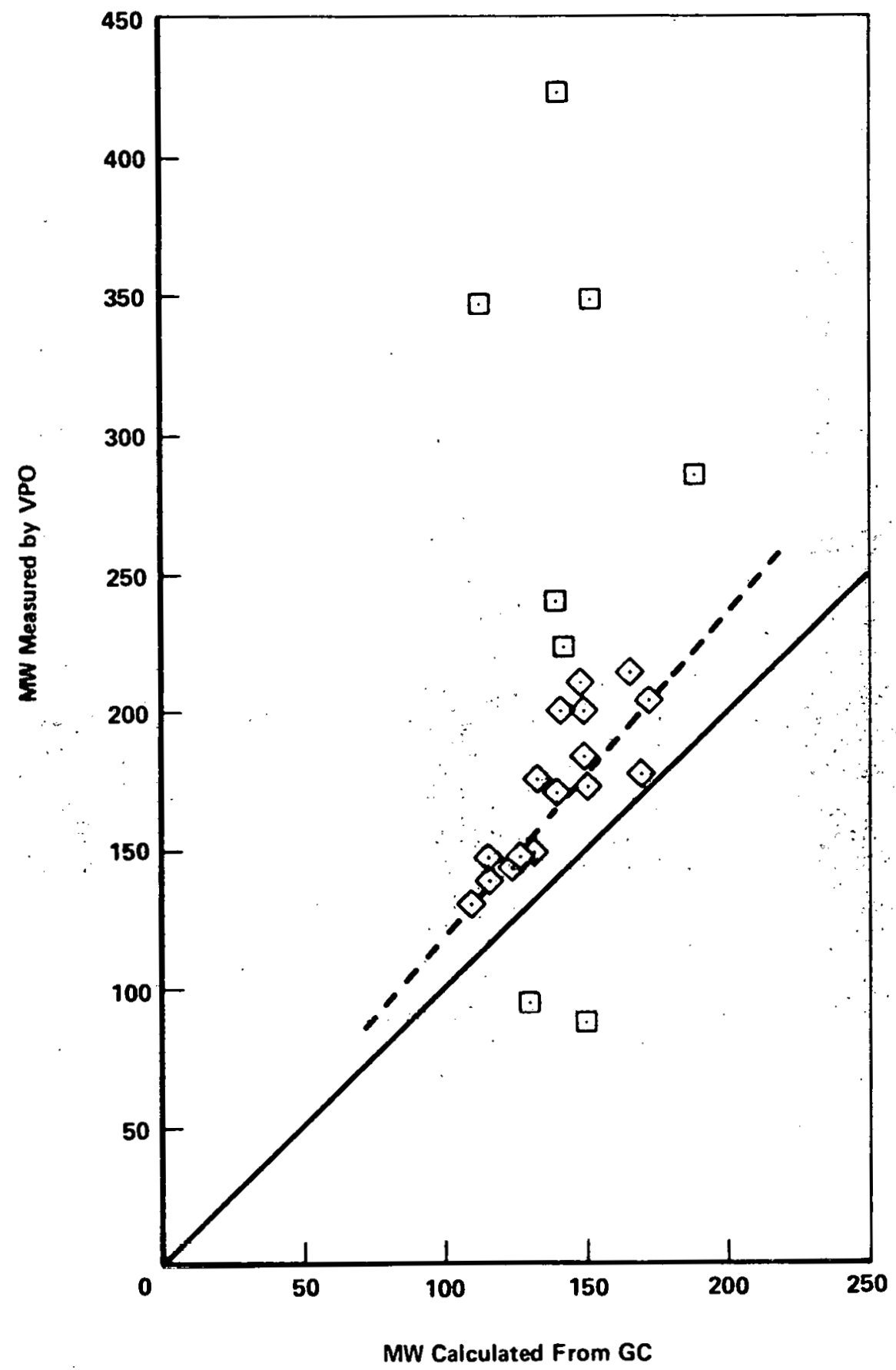

FIGURE 9. COMPARISON OF LIQUID PRODUCT MOLECULAR WF.TGHTS OBTATNED BY VAPOR PHASE OSMOMETRY AND SIMULATED DISTILLATION BY GAS CHROMATOGRAPHY 
TABLE 11. STRUCTURAL TYPES VERSUS BOILING POINT OF SRC II FRACTIONS

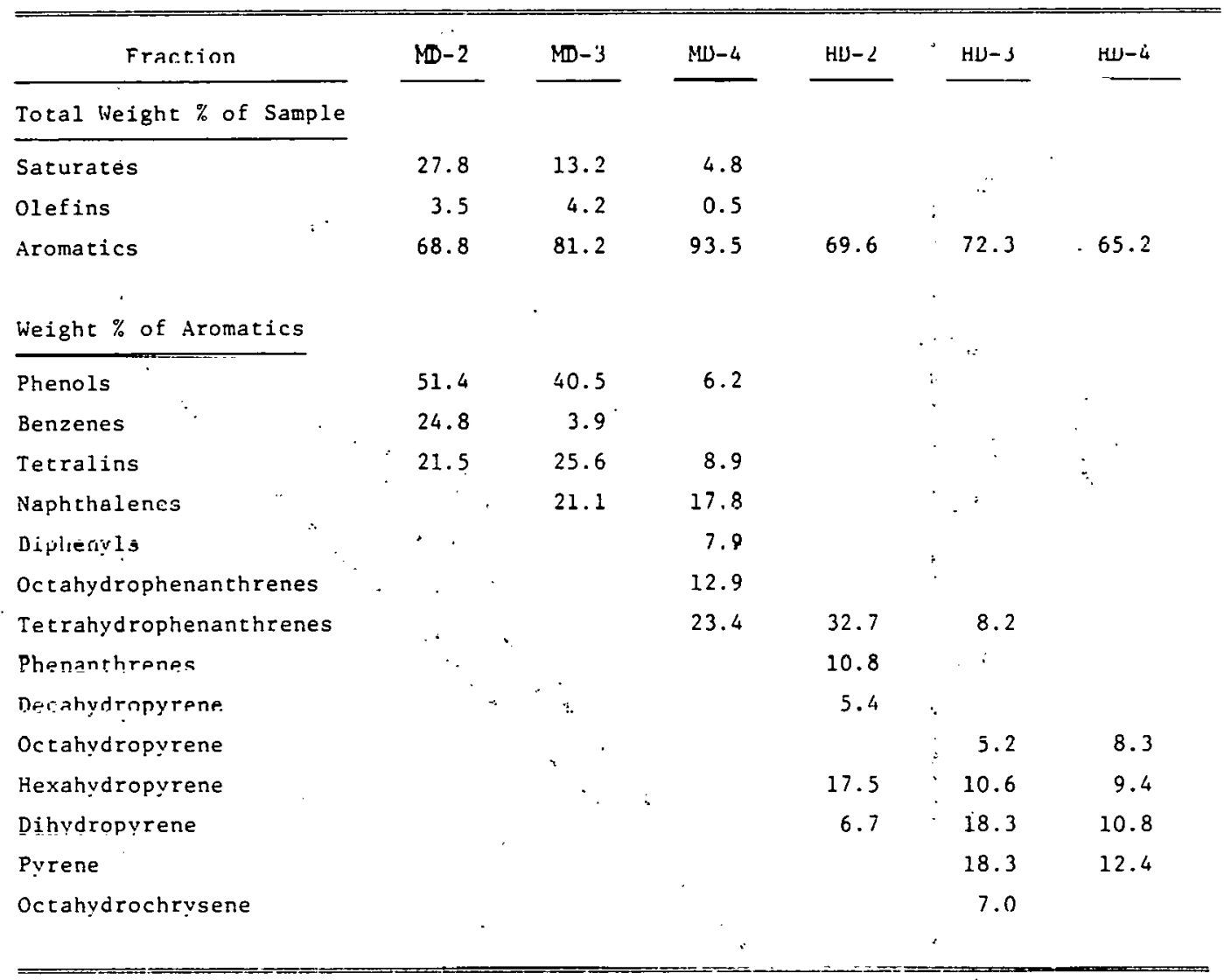


Their data were obtained using Powhatan No. 5 coal; the SRC II samples supplied to Battelle were prepared using Powhatan No. 6 coal. The significance of slightly different coals on the SRC II elemental analyses is unknown, but presumed to be minor.

The number average molecular weight of the distillation cuts were obtained by VPO. For the P\&M samples, which correspond most closely in boiling point range to the Battelle samples, the molecular weights correspond fairly well, as shown in Figure 10. The use of separate middle and heavy distillates to obtain the Battelle samples accounts for the largest variation between molecular weight which occurs in the fourth distillation cut.

The trends in carbon, hydrogen, and oxygen content in the SRC II cuts with increasing boiling point are the same for the Gulf and Battelle samples as shown in Figures 11-13. It should be noted that the contents of carbon and oxygen do not increase or decrease smoothly with increasing boiling point due to the large peak in oxygen content at $200 \mathrm{C}$.

The H/C atomic ratio decreases with increasing boiling point and the sulfur content is low but increases slowly with increasing boiling point as shown in Figure 14.

The total and basic nitrogen contents are shown in Figure 15. The total nitrogen content measured by Gulf increases gradually with increasing boiling point. The circled Battelle results in Figure 15 were obtained when the samples were sent out for analysis using the Kjeldahl method as discussed previously. The agreement between these results and the Gulf data is quite good.

Summary -- Task 1. Characterization of SRC II Samples

Five analytical tests were selected to analyze the SRC II before and after partial oxidation and pyrolysis, emphasizing characterization of the nitrogen species present and the aromatic structure. The analytical methods were tested and refined with the following results.

Vapor Pressure Osmometry (VPO) was first tried to obtain molecular weights but was found to be slow, expensive, and inaccurate in cases where some SRC II components were insoluble in the solvent used (THF). In addition, 


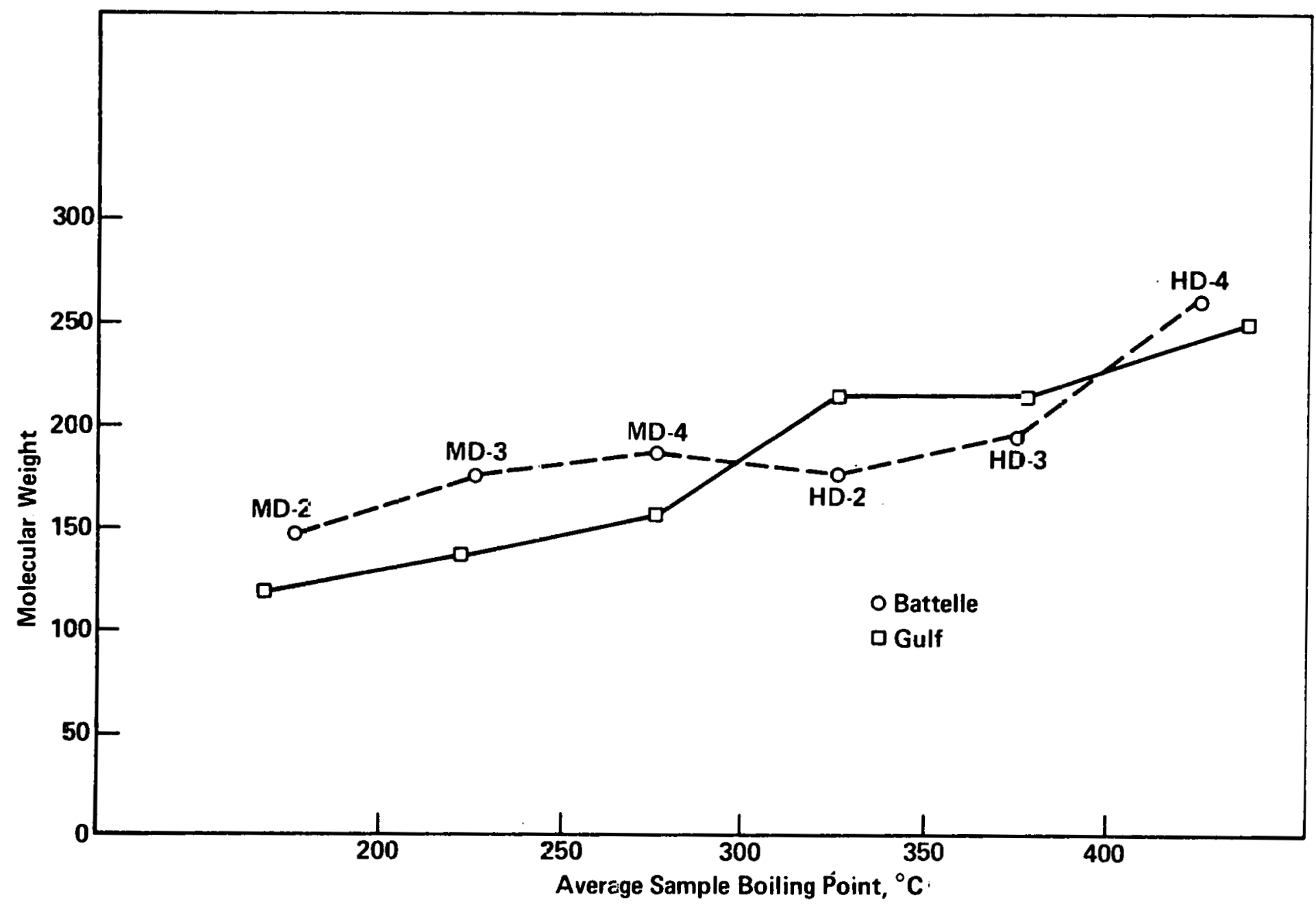

F-GURE 10. MOLECLLAR WEIGHT VERSUS AVERAGE BOILING POINT 


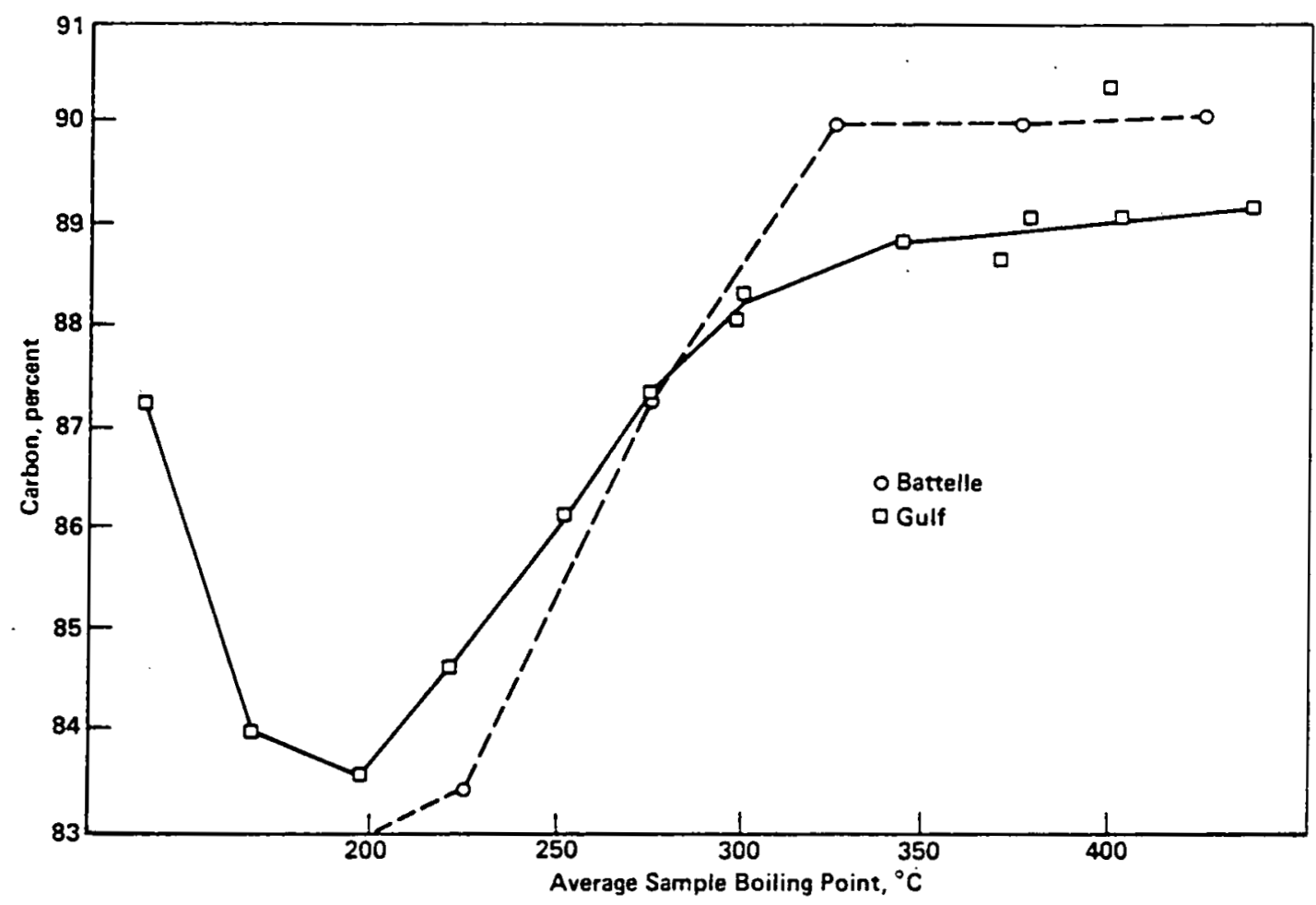

FIGURE 11. PERCENT CARBON VERSUS AVERAGE BOILING POINT

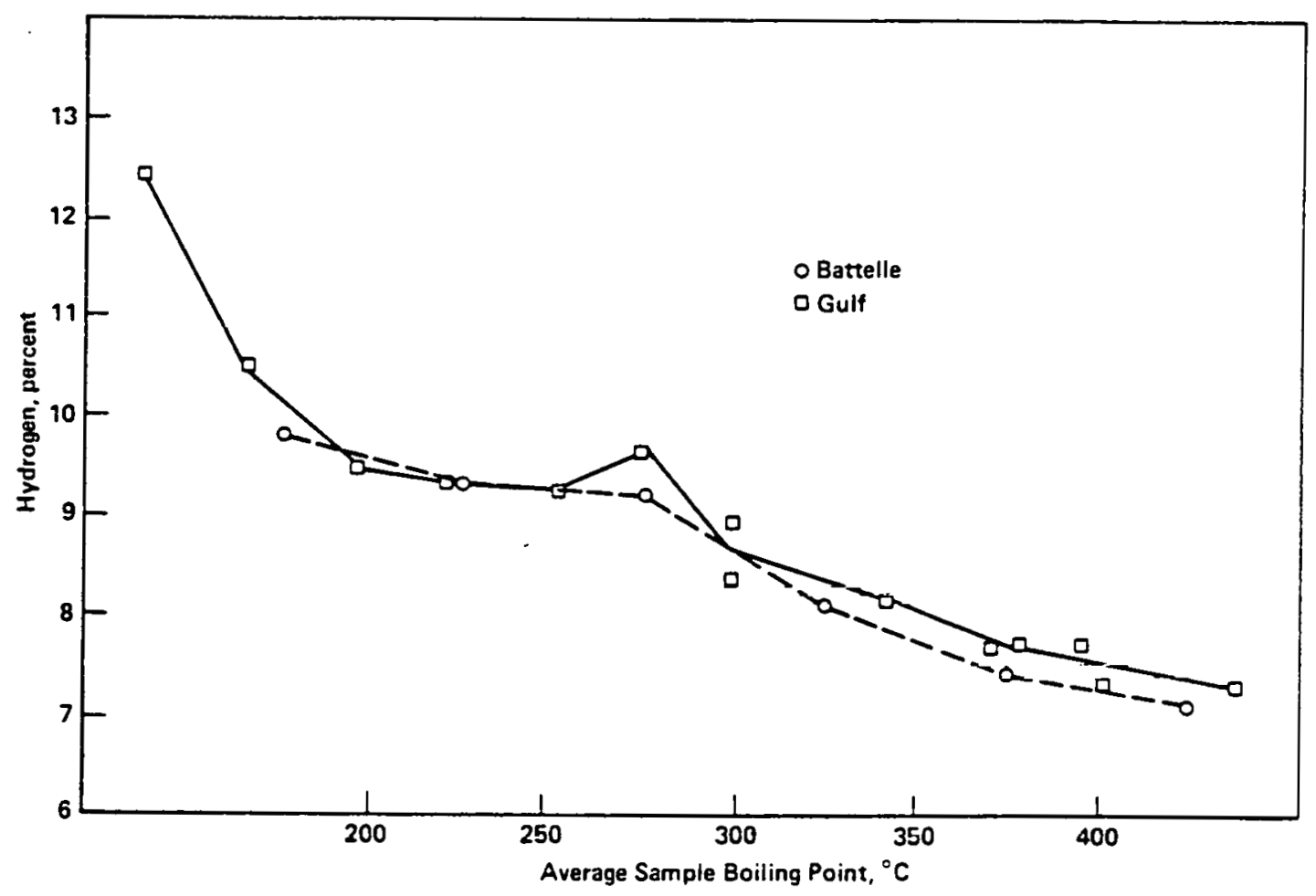

FIGURE 12. PERCENT HYDROGEN VERSUS AVERAGE BOILING POINT 


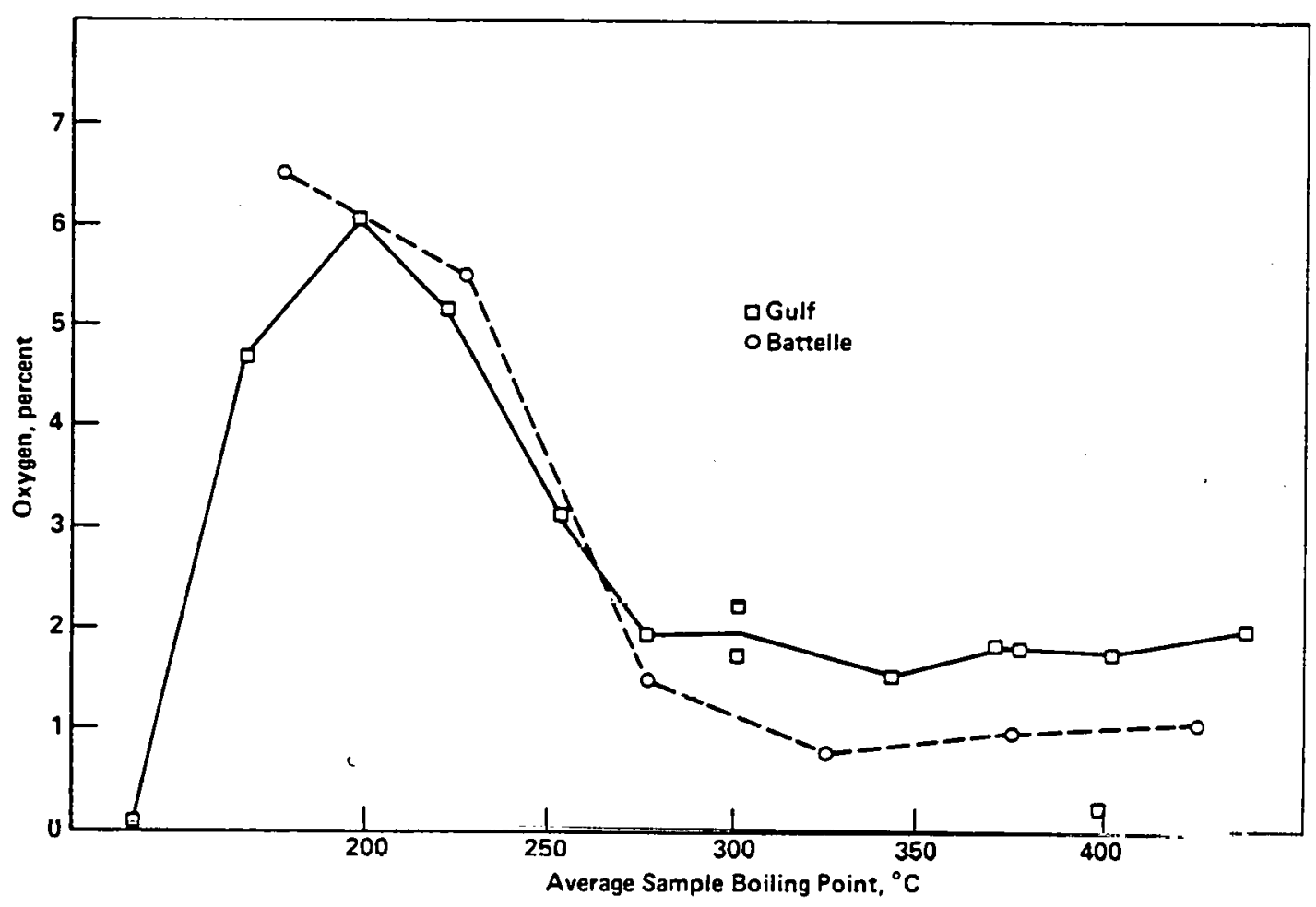

FIGURE 13. PERCENT OXYGEN VERSUS AVERAGE BOILING POINT

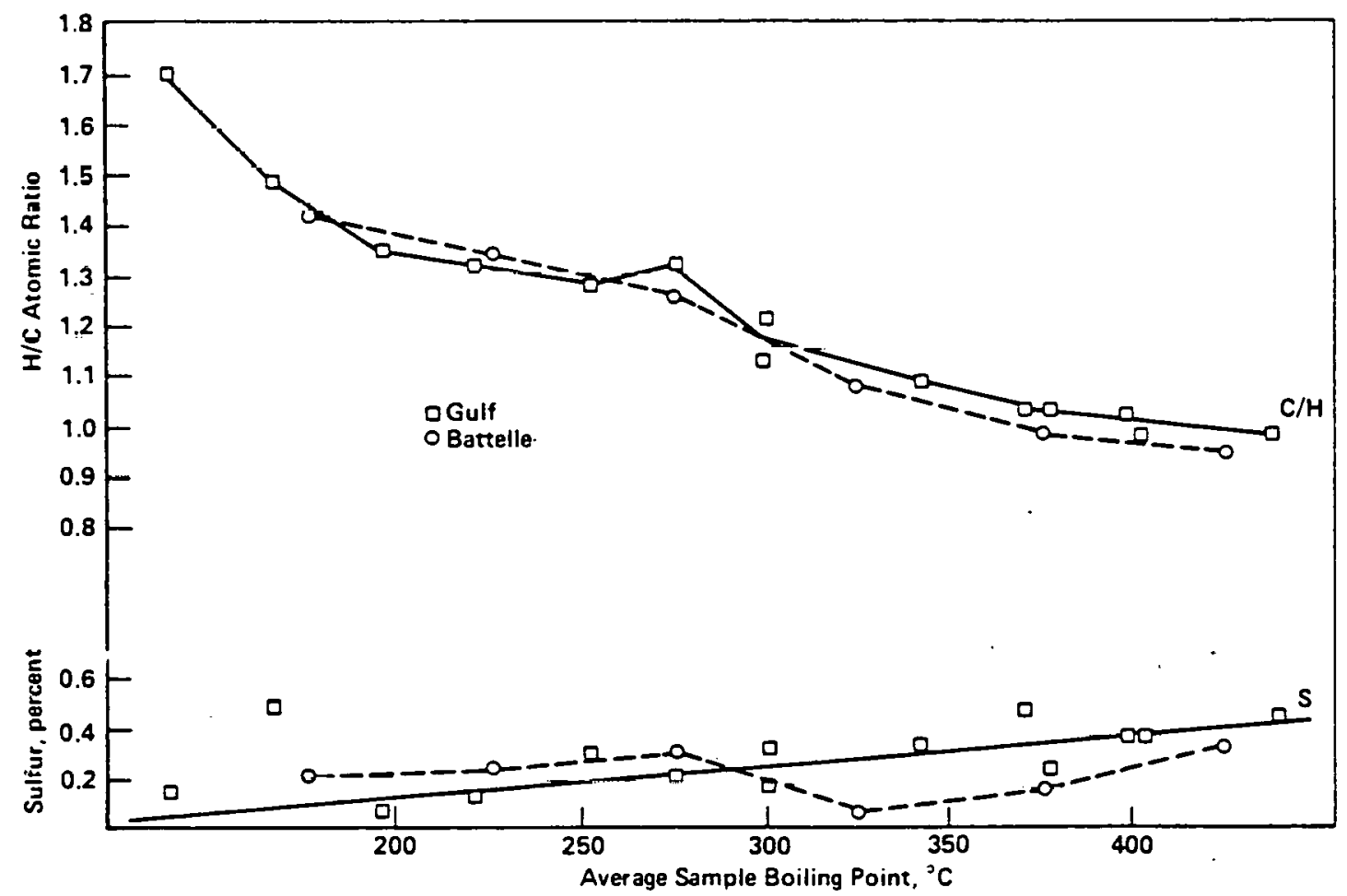

FIGURE 14. H/C ATOMIC RATIO AND PERCENT SULFUR VERSUS AVERAGE BOILING POINT 


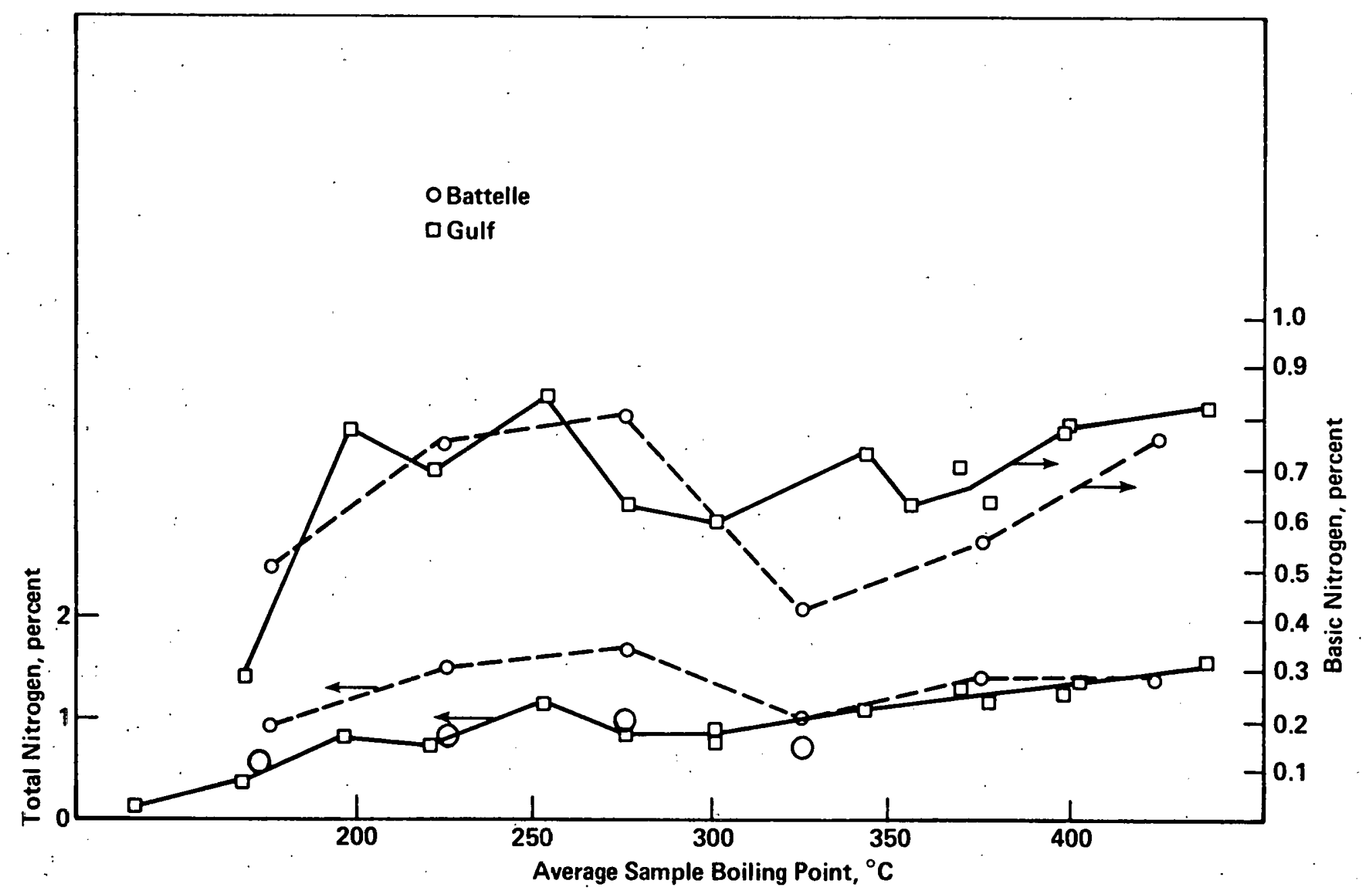

FIGURE 15. BASIC AND TOTAL NITROGEN VERSUS AVERAGE BOILING POINT 
the number average molecular weights which result from VPO analysis were found to be heavily influenced by low molecular weight components in the mixtures. A method using the summation of molecular weights of components separated by gas chromatography (GC) was found to give more realistic and consistent values of molecular weight and was chosen as the preferred method. It could be done cheaply and quickly in-house with the same data used to obtain simulated distillation measurements. The GC curves were standardized using a mixture of aromatics of known molecular weight and boiling point.

Elemental analyses were done using microcombustion for $\mathrm{C}$ and $\mathrm{H}$. Total nitrogen proved to be dif'ficult to measure accurately on these samples and was obtained by sending the samples to an outside laboratory. The results obtained seemed to be precise and accurate, using a modified Kjeldah1 technique, but the procedures required approximately 5 grams of sample.

Basic nitrogen was measured by titrating with perohloric acid in anhydrous acetic acid. The technique was found to be precise and accurate. Aromatic structure was characterized by applying the Brown-Ladner correlations to hydrogen distribution data obtained by $\mathrm{H}^{1} \mathrm{NMR}$. Using this data, the molecular weight and the elemental analyses, average structures could be drawn for each bolling point fraction of SRC II. These agreed well with more detailed structural studies done on SRC II fractions by other investigators.

Samples of middle and heavy SRC II distillate fractions obtained from Pittsburg and Midway Coal Mining Company were distilled into $50 \mathrm{C}$ boiling point range fractions and characterized using the tests developed in this Task for use in the oxidative-pyrolysis studies in Tasks 2 and 3.

TASKS 2 AND 3 - BENCH SCALE OXIDATIVE-PYROLYSIS STUDIES

Objective

The objective of this task was to determine the pyrolysis and oxidation behavior of the Task 1 SRC II distillate fractions as a function of temperature, time and oxygen level. The distribution of arumatics and fuel-N constituents in the fractions before and after pyrolysis was of particular interest. 
Development of a Bench Scale Oxidative-Pyrolysis Apparatus

Steady-state or dynamic nonsteady-state procedures can be used to do bench-scale studies of the pyrolytic oxidative stability of SRC II distillate fractions. An advantage of the latter is the obvious similarity to what a droplet sees on entering the combustion zone. A disadvantage is the difficulty in carrying out informative experiments. If we compare these two approaches to the volatility problem in coal one notes that both procedures tend to lead to the same type of results. This is emplified by the steadystate analysis of Solomon and Colket(18) and the rapid pyrolysis experiments of Suuberg, Peters, and Howard(19). Preliminary evidence obtained by Beér, et al. (20), shows a much higher fuel nitrogen loss per unit mass of the liquid fuel evaporated when $150 \mu \mathrm{m}$ droplets of a residual petroleum fuel oil were rapidly pyrolyzed, whereas when the fuel oil was vaporized under normal distillation conditions, more nitrogen was retained in the residue. Also of consequence to this study are the facts that the dynamic system provides a better representation of the real combustor and independent variables in a flow reactor are more easily controlled.

Drop Tube Furnace. A drop tube apparatus was assembled as shown in the schematic in Figure 16. A two-inch-diameter quartz tube was positioned vertically and heated by a two-foot-long electric furnace. A smaller quartz tube was permanently attached to the top of the reactor, one end of which was sealed with a serum cap. The liquid flow rate was held constant by means of a syringe pump. Inlet gases were passed through the reactor via a connection on top. Product gases were conled and separatcd from the cundensables in the collector before passing into the analyzing instruments. The pyrolyzed droplets were collected in one of four sample bottles. The residence time of the fuel droplets was controlled solely by varying the drop size.

Preliminary experiments were carried out with the Westinghouse SRC II fuel oil sample blend. The purpose of these experiments was to determine the collection efficienny, the importanoe of drop size and the effect of gas flow. The collection efficiency was close to 100 percent when $2.65-\mathrm{mm}$ diameter droplets were passed through the reactor at room temperature. The 


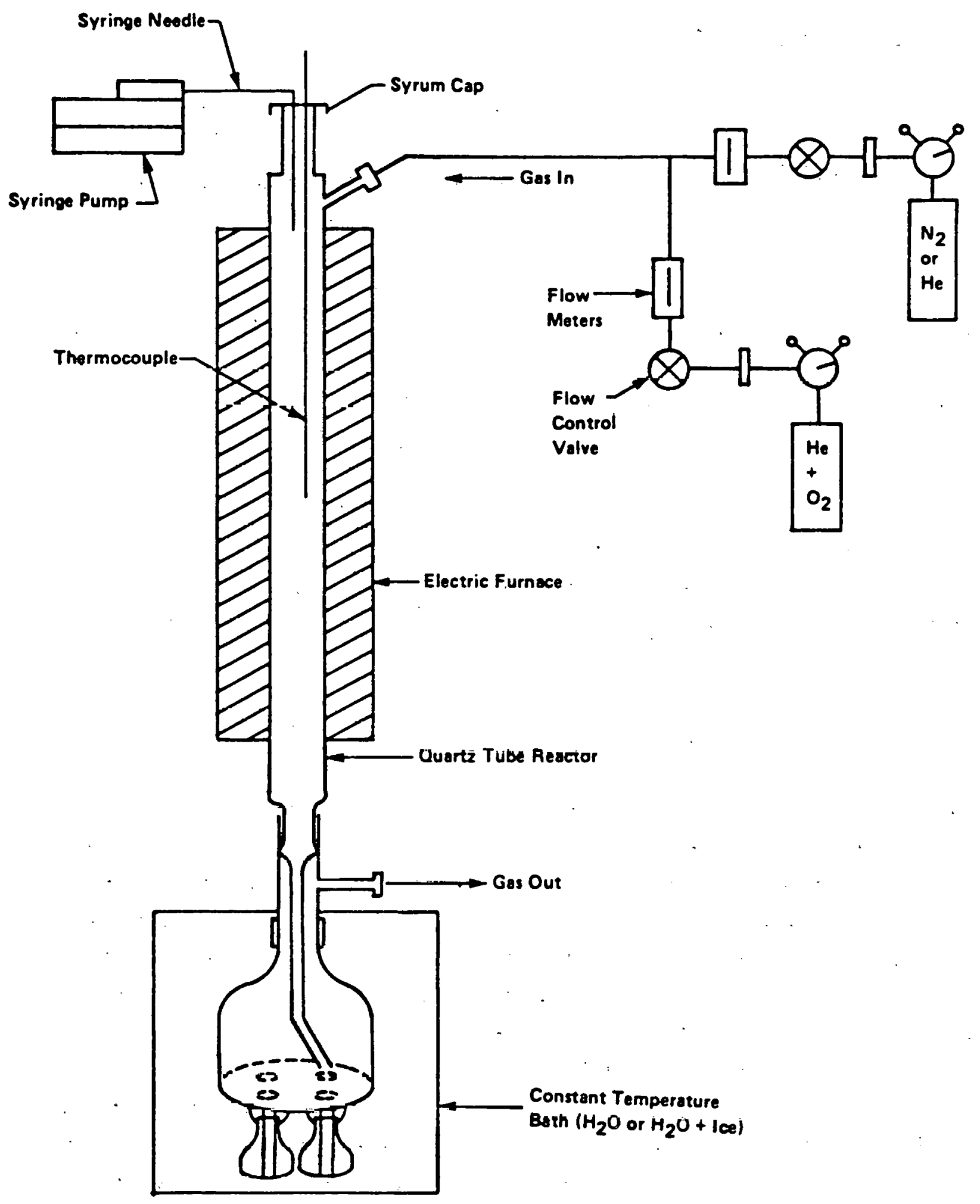


experiments were also repeated at 800,1000 and $1200 \mathrm{~K}$ under either a constant stream of nitrogen or a no-flow condition. Due to the large drop size used, only a maximum of 6 percent weight loss was recorded at $1200 \mathrm{~K}$. Based on chromatographic analysis it appeared that the fuel was unchanged in these experiments. The residue collected at $1200 \mathrm{~K}$ and under a stagnant $\mathrm{N}_{2}$ medium showed the same boiling point distribution, the same concentration of basic nitrogen and the same overall composition as the original oil. The percent weight loss was the same for the two cases of fuel oil dropping through a 5 liter/min $\mathrm{N}_{2}$ stream or through a stagnant medium.

Gas flow, however, may have an effect on soot formation by limiting contact with the walls of reactor. When the reactor was purged with a constant stream of nitrogen during the pyrolysis experiments, carbon deposition on the reactor walls was not observed. However, under a no-flow condition, a layer of black residue, presumably soot, coated the heated section of the quartz tube. Parts of the residue were hard and parts were flaky. It burned off easily in the presence of oxygen.

Calculations assuming a uniform gas and droplet temperature and for the case of a droplet falling through a stagnant medium showed that the time required to heat a $2.65-\mathrm{mm}$ diameter liquid fuel drop to within 63 percent of the gas temperature is approximately $40 \mathrm{sec}$. If the drop size is decreased by an order of magnitude, i.e., $265 \mu \mathrm{m}$, the heating time reduces to only $0.4 \mathrm{sec}$.

Additional computations also indicated that the pyrolysis of the full droplet is controlled by heat transfer from the gas to the droplet. If all the heat convected to the drop were used solely to vaporize the oil, the time for complete evaporation of a $2.65-\mathrm{mm}$ diameter droplet was calculated to be 5 and $9 \mathrm{sec}$ for gas temperatures of 1200 and $800 \mathrm{~K}$, respectively. Similar calculations gave a value of approximately $5 \mathrm{sec}$ for the center of the drop to reach 63 percent of the outer surface temperature (assumed to be the same as the gas temperature). Both values are significantly smaller than the estimated $40 \mathrm{sec}$ heat transfer time between the gas and the drop.

Additional pyrulysis experiments were conducted at 400, 500 and $850 \mathrm{C}$ with SRC II middle distillate and a 200-250 C cut (MD-3). Although it was desired to pass small drops, $<200 \mu \mathrm{m}$, through the furnace, efforts were unsuccessful. Due to surface tension, drop size produced by a fine needle 
having diameters less than $200 \mu \mathrm{m}$ was not significantly smaller than those produced from larger needles. For this reason and because extremely high flow resistance was encountered when fine needles were used and because the fuel was fairly volatile, preliminary experiments were carried out with a large needle which had an opening of $508 \mu \mathrm{m}$. Approximately 2-mm diameter drops were generated with this needle size. Fuel was fed via the syringe pump at rates between 0.1-0.9 8/min. The percent fuel vaporized increased with temperature, but the heating rates were insufficient to vaporize the drops, except at $850 \mathrm{C}$. At $400 \mathrm{C}$ there was essentially no change in the properties of the MD-3 distillation cut. This was also the situation when 5.3 percent $\mathrm{O}_{2}$ was added to the helium stream carrying the drops through the furnace.

Modification to Prevaporize the Fucl. $\Lambda$ system was set. up similar to that of Blazowski(21) in which the fuel is vaporized in an aluminum block heater, mixed with a preheated gas stream, and then passed into the furnace region. The fuel feed rate in this system was also maintained by the syringe pump.

The collection system was also modified. The vapor emitting from the furnace region was passed through a cold trap system to a gas chromatograph for analysis of the low molecular weight (gaseous) decomposition products. A schematic of the modified experimental system is shown in Figure 17.

Proliminary Fixperimental Results. The 200-250 C (MD-3) SRC II distillation fraction was vaporized at $300 \mathrm{C}$ and the helium/vapor mixture was passed through a $300 \mathrm{C}$ pyrolysis zone. Under these conditions there was no change in the composition of the distillation cut. Analysis by simulated distillation using gas chromatography showed that the distribution of compourds in the distillation cut was identical before and after vaporization at $300 \mathrm{C}$. No other analyses were done on this product. Reaction conditions for this (Run 1) and all other preliminary experiments dune with a verticel roaotor are listed in Table 12.

The boiling point distribution from a pyrolysis experiment at $800 \mathrm{C}$ clearly showed changes in product composition (Run 2). Three experiments (Runs 3, 4, and 5), at $800 \mathrm{C}$ nominal temperature and three residence times, 


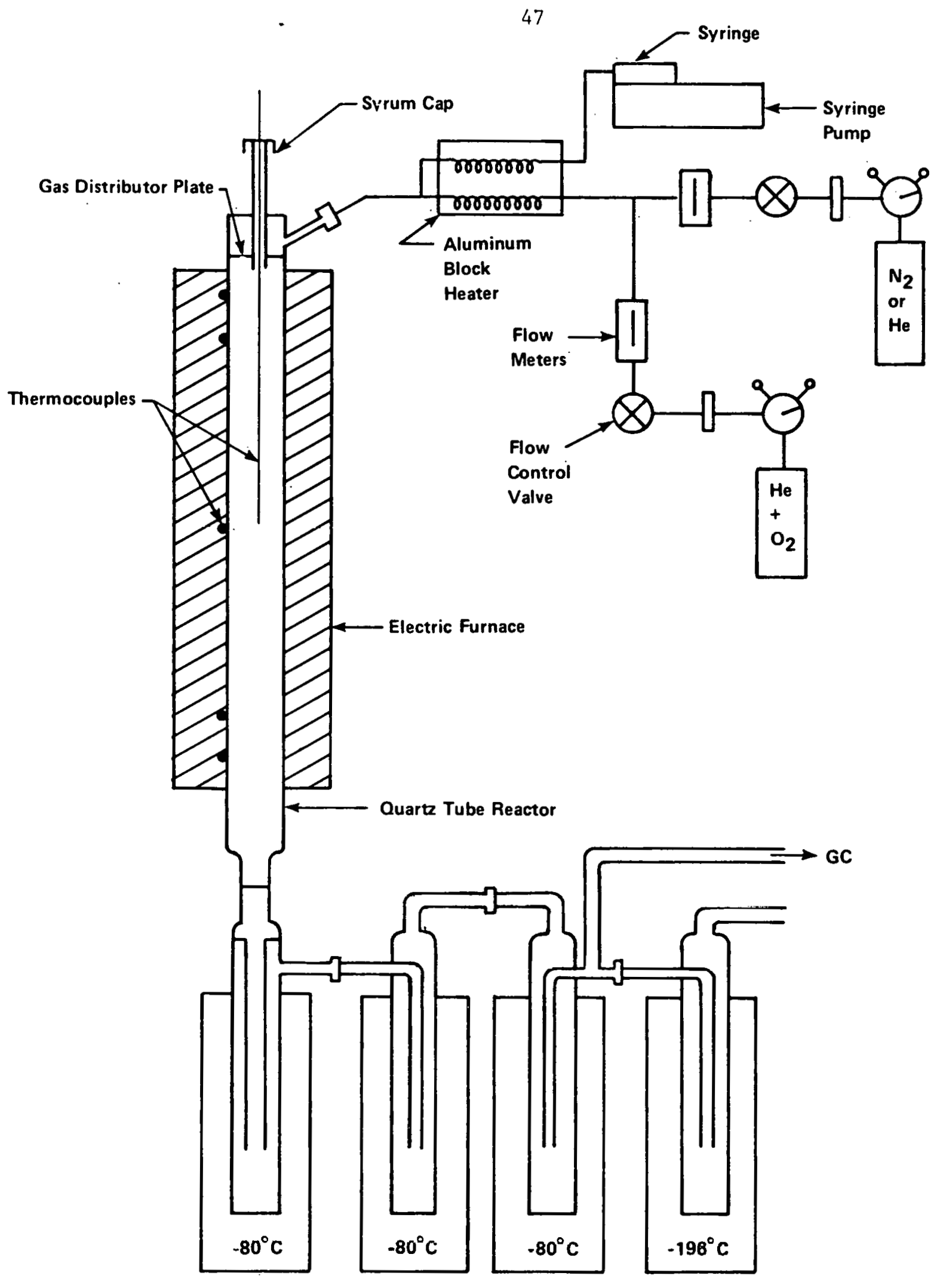

FIGURE 17. A SCHEMATIC DIAGRAM OF THE MODIFIED EXPERIMENTAL SET-UP 
TABLE 12. EXPERIMENTAL CONDITIONS FOR INITIAL PYROLYSIS EXPERIMENTS

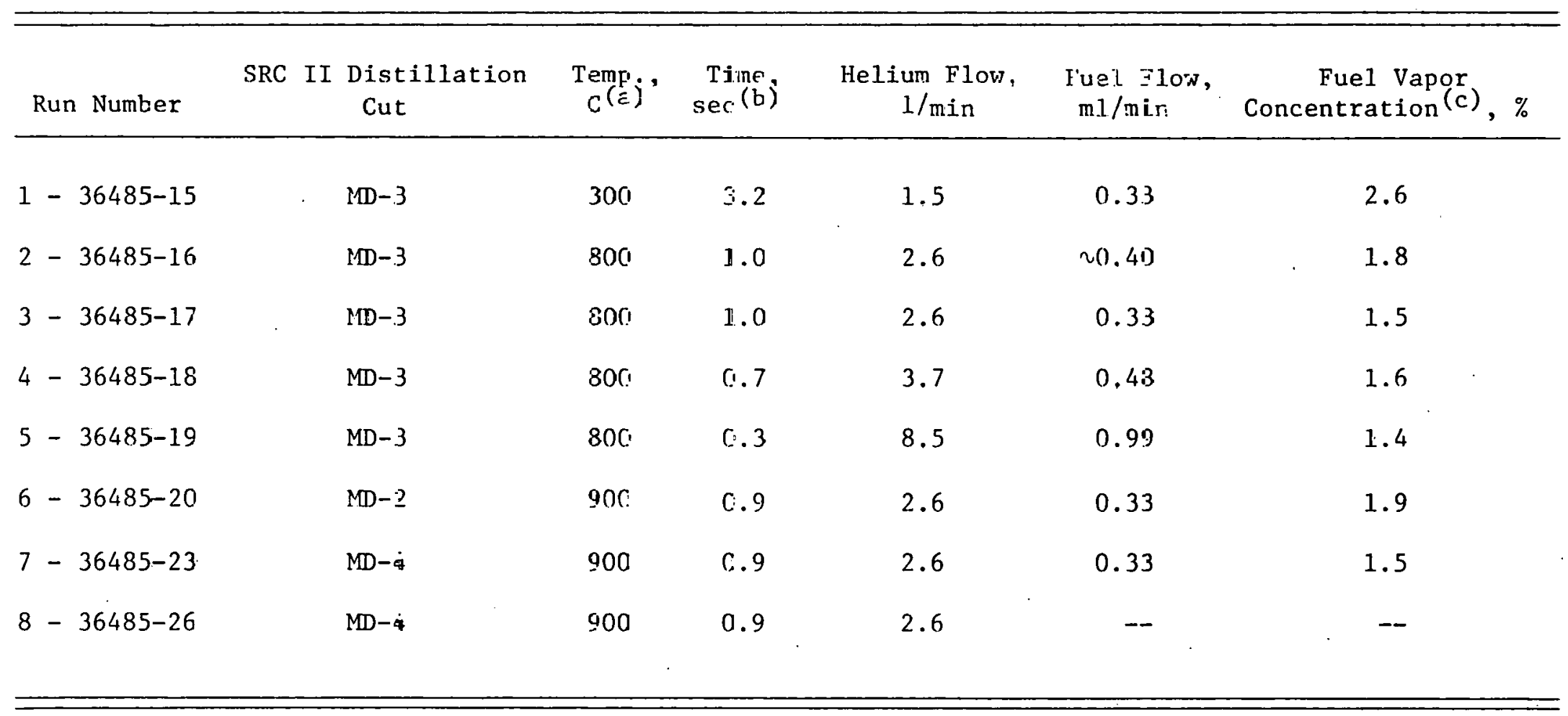

(a) Nominal temperatures, measured on outside of reactor tube wall at center of zone 3.

(b) Nominal times: based on gas-flow thru hottest zone.

(c) Calculated, based on density and average molecular weight of distillation cut. 
were carried out to obtain more specific information about the changes taking place in the pyrolyzed liquids. The products from Runs 3 and 5 were subjected to a complete set of analyses.

At $0.3-\mathrm{sec}$ residence time and $800 \mathrm{C}$, no apparent change in boiling point distribution took place as shown by the GC simulated distillation (Figure 18). At 1.0-sec residence time, large amounts of benzene, toluene, and xylenes were produced as well as many materials of higher boiling point than the starting material. The results are listed in Table 13 and compared. to MD-3 starting material.

Although the GC simulated distillations showed no changes in the product composition at $0.3 \mathrm{sec}$ and extensive changes at $10 \mathrm{sec}$ residence time, the molecular weights of the $0.3 \mathrm{sec}$ (Run 5) and $1.0 \mathrm{sec}$ (Run 3) residence time products were about the same.

As the extent of pyrolysis was increased, the liquid products contained increasing amounts of oxygen and nitrogen and decreasing amounts of carbon and hydrogen. The products were virtually sulfur free. Basic nitrogen remained approximately constant and the basic $\mathrm{N} /$ total $\mathrm{N}$ ratio decreased sharply. However, these total $\mathrm{N}$ results were obtained by $\mathrm{C}-\mathrm{H}-\mathrm{N}$ analysis. The NMR parameters showed that most of the aliphatic hydrogen, $\alpha$ or farther from an aromatic ring, was removed and total aliphatic hydrogen decreased sharply. As a result the percentages of aromatic and phenolic hydrogen increased.

The structural parameters derived from NMR data showed that aromaticity $\left(f_{a}\right)$, number of aromatic carbons $\left(C_{a}\right)$, and number of aromatic rings $\left(R_{a}\right)$ increased as expected while the number of carbons per saturated substitucnt $(n)$ decreased.

The gaseous species in the pyrolyzed products were identified by means of gas chromatography and Dräeger tubes. The experiments were carried out with the 150-200 C (MD-2, Run 6) and the 250-300 C (MD-4, Run 7) cuts at a nominal furnace temperature of $900, \mathrm{C}$ and a residence time of 1 sec. Gas chromatographic analysis showed the presence of $\mathrm{H}_{2}, \mathrm{C}_{2} \mathrm{H}_{6}, \mathrm{C}_{2} \mathrm{H}_{4}, \mathrm{~N}_{2}$, and $\mathrm{CH}_{4}$ in the flue gas with methane as the predominant gaseous product. Both distillate cuts gave the same gaseous products. In Run 8 with MD-4 under similar conditions, $\mathrm{HCN}$ and a smaller amount of $\mathrm{NH}_{3}$ were identified with the Dräeger tubes. 


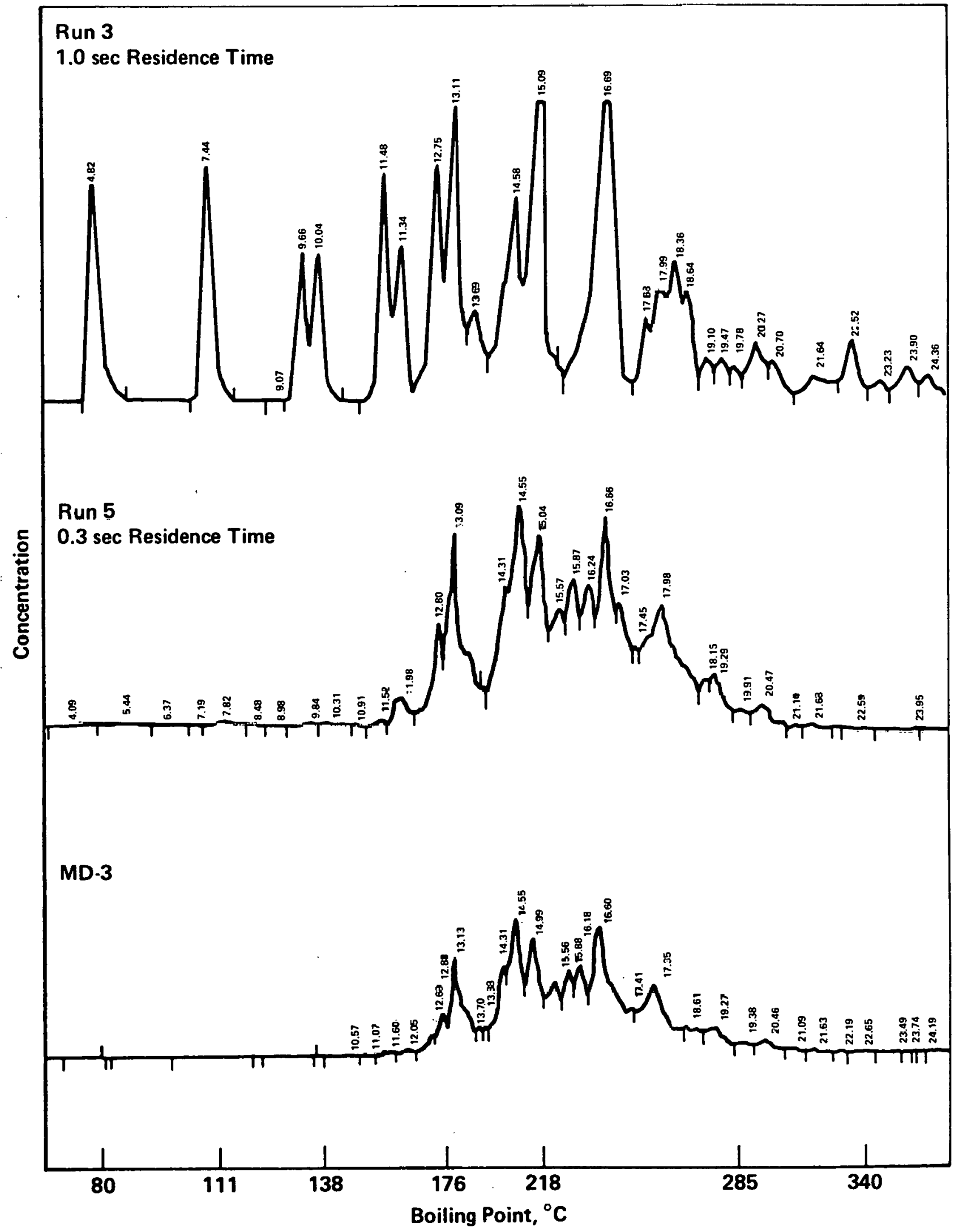

FIGURE 18. COMPARISON OF BOILING POINT DISTRIBUTION IN MD-3 (250-300 C) BEFORE AND AFTER PYROLYSIS AT 800 C FOR 0.3 AND 1.0 SECONDS IN HELIUM 
TABLE 13. ANALYTICAL DATA FOR MD-3 PYROLYSIS EXPERIMENTS $(\mathrm{T}=800 \mathrm{C})$

\begin{tabular}{|c|c|c|c|}
\hline Run No. & $\begin{array}{l}\text { Starting } \\
\text { Material }\end{array}$ & 5 & 3 \\
\hline Residence time, sec & -- & 0.3 & 1. \\
\hline Sample No. 36510- & $\mathrm{MD}-3$ & $49-8,9$ & $49-12$ \\
\hline Molecular Weight, g/mole & 176 & 148 & 147 \\
\hline \multicolumn{4}{|c|}{ Elemental Analyses, wt. percent } \\
\hline Ash & 0.02 & & \\
\hline $\mathrm{C}$ & 83.4 & 80.2 & 75.5 \\
\hline $\mathrm{H}$ & 9.3 & 8.3 & 5.9 \\
\hline $\mathrm{N}$ & 1.5 & 3.6 & 4.3 \\
\hline s & 0.24 & 0.055 & 0.065 \\
\hline 0 (difference) & 5.5 & 7.8 & 14.2 \\
\hline Basic $\mathrm{N}$ & 0.75 & 0.75 & 0.83 \\
\hline Basic N/Total N & 0.50 & 0.21 & 0.19 \\
\hline \multicolumn{4}{|c|}{ Hydrogen Distribution, fraction } \\
\hline $\mathrm{H} \alpha^{(\mathrm{a})}$ & 0.42 & 0.46 & 0.28 \\
\hline H aliphatic & 0.32 & 0.33 & 0.02 \\
\hline H aromatic & 0.22 & 0.15 & 0.55 \\
\hline H phenolic (b) & 0.037 & 0.059 & 0.15 \\
\hline \multicolumn{4}{|c|}{ Simulated Distillation (see Figure 9) } \\
\hline \multicolumn{4}{|l|}{ Structural Parameters } \\
\hline$f_{a}(c)$ & 0.51 & 0.51 & 0.86 \\
\hline \multirow{2}{*}{$\mathrm{H}_{\sigma^{\text {aro }}} / \mathrm{C}_{\text {aro }}(\mathrm{d})$} & 0.77 & 0.93 & 0.75 \\
\hline & 0.57 & 0.76 & 0.42 \\
\hline$R_{s}(f)$ & 2.69 & 3.56 & 2.50 \\
\hline$n(g)$ & 1.76 & 1.72 & 1.07 \\
\hline$c_{a}(h)$ & 6.2 & 5.04 & 7.95 \\
\hline$R_{a}(i)$ & 1.70 & 1.18 & 1.99 \\
\hline \multicolumn{4}{|l|}{ Molecular Formula } \\
\hline C & 12.2 & 9.9 & 9.2 \\
\hline H & 16.4 & 12.3 & 8.7 \\
\hline $\mathrm{N}$ & 0.19 & 0.38 & 0.45 \\
\hline $\mathbf{s}$ & 0.01 & 0.00 & 0.00 \\
\hline 0 & 0.61 & 0.72 & 1.30 \\
\hline
\end{tabular}

(a) Aliphatic a to aromatic ring.

(b) Based on the assumption $0=0 \mathrm{H}$.

(c) $\mathrm{f}_{\mathrm{a}}=$ fraction of total carbon which is aromatic.

(d) $\mathrm{H}_{\text {aro }} / \mathrm{C}_{\text {aro }}=$ ratio of substitutable aromatics.

(e) $\sigma=$ fraction of the available aromatic edge atoms occupied by substituents.

(f) $R_{s}=$ number of substituted aromatic ring carbons.

(g) $n=$ number of carbon atoms per saturated substituent.

(h) $C_{a}=$ total number of aromatic carbon atoms.

(i) $R_{a}=$ number of aromatic ringc. 
Horizontal Furnace Modifications. With the preliminary identification of the pyrolysis products clarified and prior to carrying out more quantitative pyrolysis experiments, additional modifications were made to the experimental apparatus. Since the pyrolyses were more effectively conducted as vapor phase pyrolyses the reaction furnace was placed in a horizontal position. To specify the temperature and residence time more accurately, a set of thermocouples was introduced into the reactor volume. These two modifications allowed for a flatter temperature profile than with the vertical setup. Figure 19 is a schematic of the modified experimental apparatus. Figure 20 shows a schematic of the fuel vaporizor. The larger volume in the new vaporizor was designed to allow the fuel vapor to be fed, vaporized, and mixed with helium with no fractionation.

\section{Experimental Results}

The focus of this study was the chemistry of the partially pyrolyzed and oxidized liquid fuel which survives as pyrolysis and oxidative pyrolysis proceed. The experiments were designed so that these products were not completely destroyed and could be recovered for analysis.

Each of the four SRC II distillation cuts was pyrolyzed at 500, 700, and $900 \mathrm{C}$ for approximately $5 \mathrm{sec}$ residence time in helium. The fuel vapor concentration averaged 1.45 volume percent in helium in these experiments.

Recoveries of liquid products averaged 95 percent at $500 \mathrm{C}, 74$ percent at $700 \mathrm{C}$, and 54 percent of fuel weight fed at $900 \mathrm{C}$. Visually, there appeared to be very little reaction at $500 \mathrm{C}$. No solids were deposited on the pyrolysis tube and virtually no gases were detected. Chemically; the most notable change at $500 \mathrm{C}$ was a decrease in sulfur content from an average of 0.21 weight percent in the distillation cuts to 0.06 weight percent in the liquid products. Other chemical changes were small.

The initial oxidation experiments were conducted with MD-4 at two substoichiometric levels of oxygen in the helium flow gas.. These corresponded 


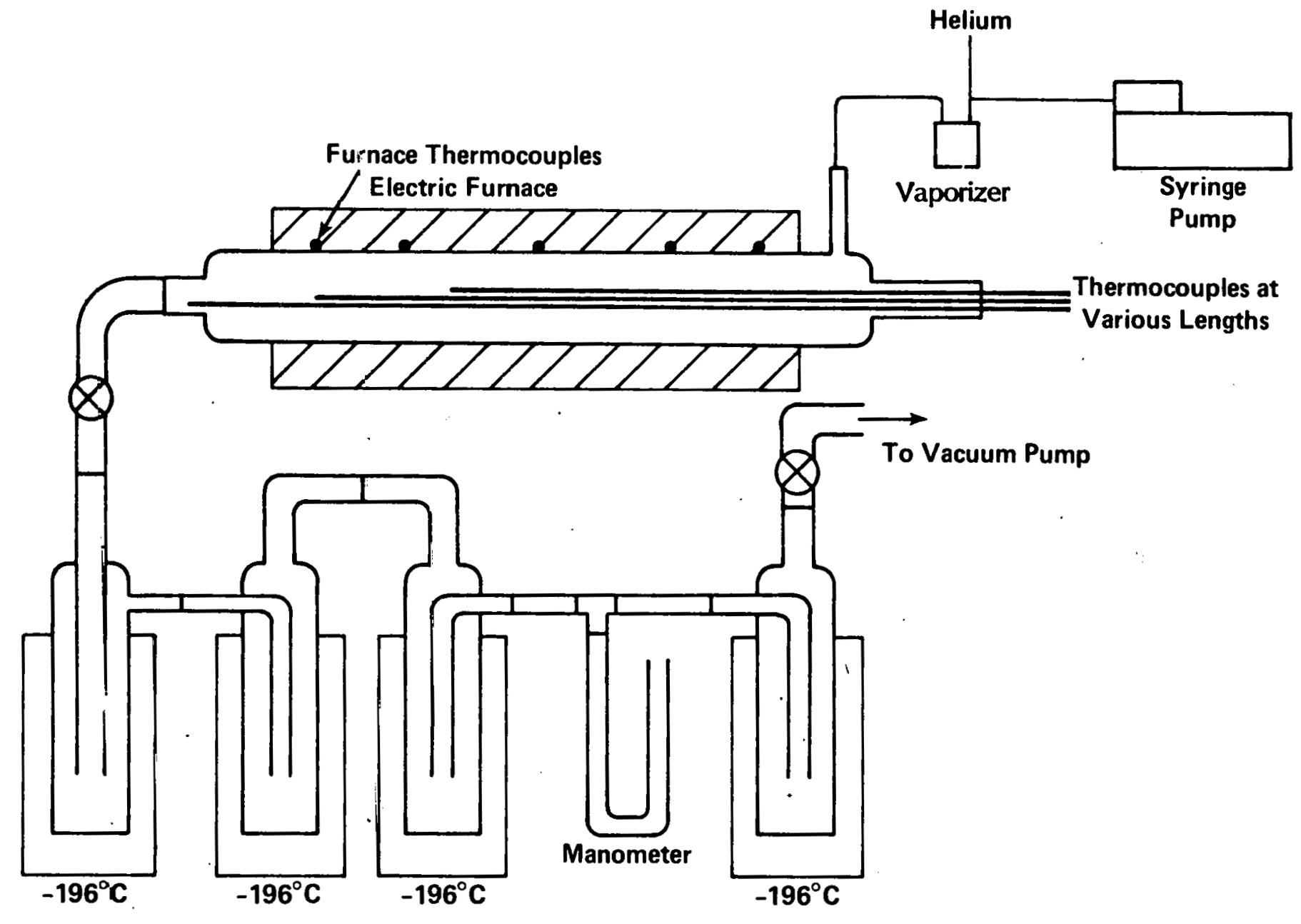

FIGURE i9. SCHEMATIC OF THE MODIFIED EXPERIMENT APPARATUS 


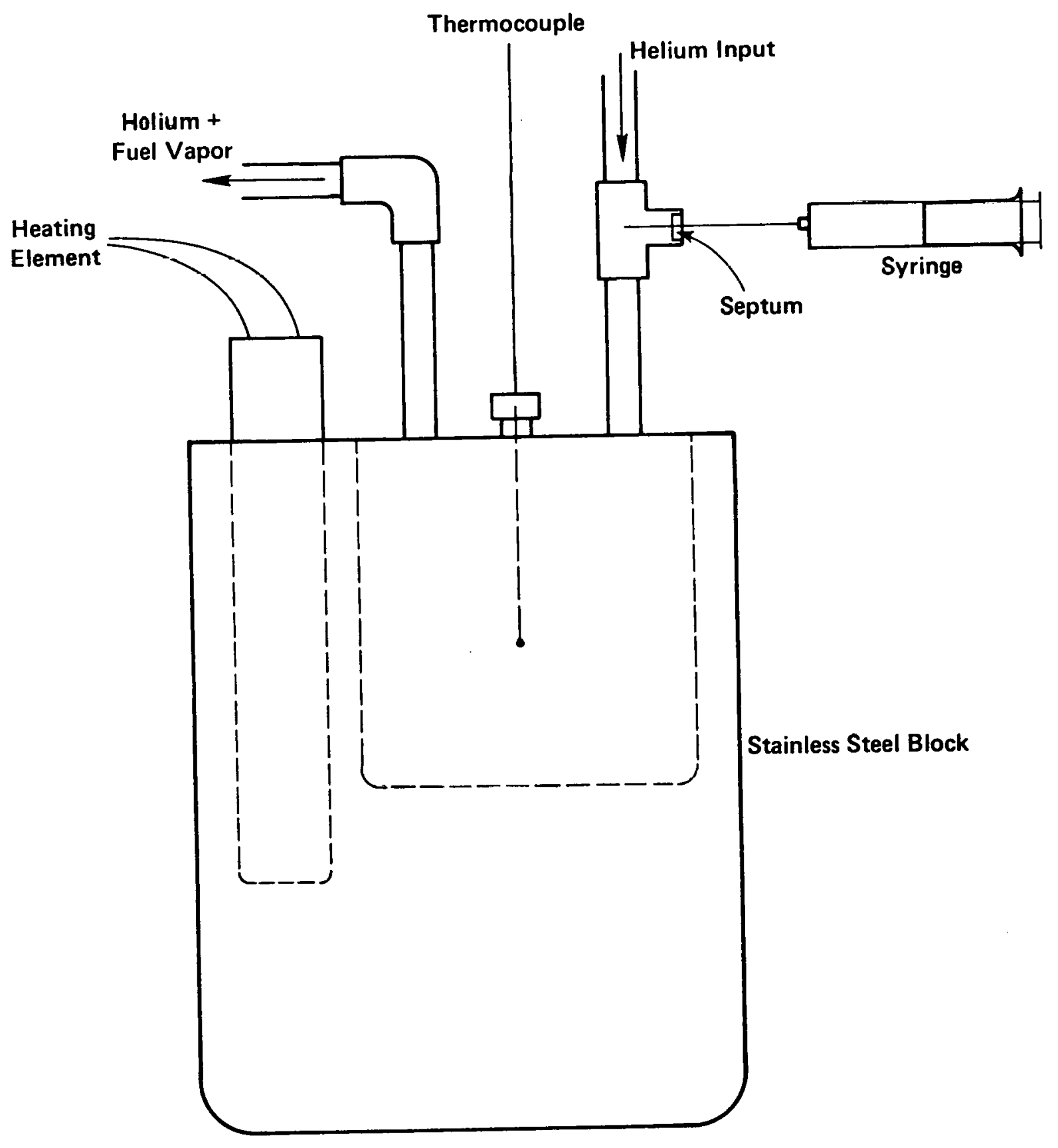

FIGURE 20. SCHEMATIC OF THE FUEL VAPORIZER 
to about 8 and 24 percent of the oxygen required to convert the fuel to $\mathrm{CO}_{2}$ and $\mathrm{H}_{2} \mathrm{O}$. (a) Temperatures of 500,700 , and $900 \mathrm{C}$, at about $5 \mathrm{sec}$ residence times, were used to compare with the corresponding pyrolysis experiment results to study the effects of oxygen.

A series of experiments were carried out to extend the reaction temperature to $1100 \mathrm{C}$ and the oxygen level to almost 100 percent stoichiometric oxygen.

Problems were encountered with these conditions which necessitated some changes and limitations in the usual analytical procedures. The products obtained at $1100 \mathrm{C}$ were nonvolatile solids. The only analyses which could be run on these samples were elemental analyses including total nitrogen and cl3 NMR for aromaticity. Basic nitrogen determinations using the perchloric acid/ acetic acid titration technique were tried and the results are reported but recoveries are unknown. The solids were not soluble in the titration system.

The samples obtained at approximately 100 percent stoichiometric oxygen contained large quantities of water. These were dried before analysis by evacuating at room temperature in a dessicator charged with Drierite until a constant weight was obtained. The liquid samples were then analyzed routinely although limited sample sizes decreased the precision of some analyses.

The average residence time for these experiments was $6.6 \pm 1.7 \mathrm{sec}$. Average substoichiometric oxygen concentrations were $6.6,20.4$, and 73.0 percent at the three levels of oxygen used. However, the range at each level was quite large. Fuel vapor concentrations averaged $1.43 \pm 0.33$ volume percent.

Since the products at $1100 \mathrm{C}$ were entirely solids and gases, this was an upper temperature limit for these experiments. At the lower limit of $500 \mathrm{C}$, relatively little chemical reaction was found to occur at the residence times used. At approximately 100 percent of stoichiometric oxygen required for formation of $\mathrm{CO}_{2}$ and $\mathrm{H}_{2} \mathrm{O}$ small amounts of organic products survived but sample sizes were limited.

(a) $\mathrm{MD}-4$ - molecular formula assumed $=\mathrm{C}_{13} 3^{\mathrm{H}} 16$

Stoichiometric $\left(\frac{\text { Fuel, moleo }}{0_{2}, \text { moles }}\right)=.006$

Stoichiometric oxygen $=17$ moles $\mathrm{O}_{2}$

$\mathrm{C}_{13} \mathrm{H}_{16}+17 \mathrm{O}_{2}+13 \mathrm{CO}_{2}+8 \mathrm{H}_{2} \mathrm{O}$ 
Summary of Tasks 2 and 3 Reaction Conditions

Table 14 is a summary of reaction conditions for the Tasks 2 and 3 experiments and Table 15 is a summary of product recoveries and mass balances. These include the weight of fuel fed, the weight of condensed liquid products, the weight of solids deposited on the reactor tube (based on collected weights of $\mathrm{CO}_{2}$ resulting from the carbon burnoff), the weight of gas condensed and revolatilized (based on the assumption that all of the gas is methane and the PVT relationship for the vapor collection system), and the weight of uncondensed gases (based on the volume of gas fed to the system and periodic analyses of the noncondensed gases by gas chromatography). The gas shromatngraphic analyses are also shown.

For some experiments, Dräeger tubes were used to obtain approximate concentrations of $\mathrm{HCN}, \mathrm{NH}_{3}$, and $\mathrm{NO}$ in the conderised gases.

Mass balances (for the seven completely analyzed experiments)

averaged 96.4 percent.

Oxygen conversions were also calculated for the pyrolysis-oxidation experiments based on the level of oxygen remaining in the uncondensed gas stream.

Average total gas, liquid, and solid recoverles are sliown in Table 16 on a normalized basis. The data show definite trends. Gas production increased with increasing temperature at all oxygen concenlralions. Solida formation also increased with increasing temperature. It was assumed that there were no solids left on the tube at 100 percent stoichiometric oxygen. Liquid production declined with increasing temperature at all oxygen concentrations.

solids frimation dcoreased with insreasing nxygen concentration at 700,900 , and $1100 \mathrm{C}$. At $500 \mathrm{C}$ no solids were formed. Liquid product formation decreased and gaseous product formation increased with increasing oxygen concentration at all temperatures. The overall trends are as expected.

Summary of Liquid Product Properties

Table 17 summarizes the molecular weights, elemental analyses, and nitrogen-type analyses for the condensed products. The molecular weights obtained by GC are considered to be more accurate. 
TABLE 14. OXIDATIVE-PYROLYSIS REACTION CONDITIONS

\begin{tabular}{|c|c|c|c|c|c|c|c|c|c|}
\hline $\begin{array}{l}\text { Kun } \\
\text { No. }\end{array}$ & Fue L & $\begin{array}{l}\text { Vaporizer/ } \\
\text { Reactor } \\
\text { Temp., C }\end{array}$ & $\begin{array}{l}\text { Total Gas } \\
\text { Flow, } \\
\text { Q/min }\end{array}$ & $\begin{array}{l}\text { Fuel } \\
\text { Flow, } \\
\mathrm{ml} / \mathrm{mln}\end{array}$ & $\begin{array}{c}\mathrm{O}_{2} \\
\text { Conc. , } \\
\% \text { (iC) }\end{array}$ & $\begin{array}{l}\text { Fuel (1) } \\
\text { Vapor } \\
\text { Conc., \% }\end{array}$ & $\begin{array}{c}\text { Residence } \\
\text { Tíme, } \\
\text { sec }\end{array}$ & $\begin{array}{l}\text { Stoic. } \\
\mathrm{O}_{2},(2) \\
\%\end{array}$ & $\begin{array}{c}\text { Fuel Equiv. } \\
\text { Rat1o, (3) } \\
\phi\end{array}$ \\
\hline 21 & $M D-\ddot{z}$ & $265 / 502$ & 3.9 & 0.32 & 0 & 1.23 & 7.2 & --- & -- \\
\hline 18 & $M D-\tilde{z}$ & $247 / 699$ & 3.1 & 0.34 & 0 & 1.48 & 7.2 & --- & -- \\
\hline 22 & $M U-2$ & $252 / 896$ & 2.6 & 0.33 & 0 & 1.87 & 7.1 & --- & -- \\
\hline 25 & $M D-3$ & $303 / 505$ & 3.9 & 0.47 & 0 & 1.62 & 7.2 & -- & -- \\
\hline 24 & $M D-3$ & $243 / 698$ & 3.1 & 0.39 & 0 & 1.69 & 7.2 & -- & ' -- \\
\hline 23 & MD-3 & $288 / 896$ & 2.6 & 0.33 & 0 & 1.70 & 7.1 & --- & -- \\
\hline $60-28$ & MD-4 & $344 / 493$ & 3.9 & 0.33 & 0 & 1.04 & 7.3 & -- & -- \\
\hline $58-24$ & MD -4 & $/(700)$ & 3.4 & 0.32 & 0 & 1.15 & 6.6 & $-\cdots$ & $-\infty$ \\
\hline 1.9 & MO-4 & $343 / 898$ & 2.6 & 0.33 & 0 & 1.55 & 7.1 & -- & --- \\
\hline 32 & $M D-4$ & $332 / 1104$ & 2.2 & 0.35 & 0 & 1.99 & 7.1 & --- & --- \\
\hline 17 & HD-2 & $389 / 500$ & 3.9 & 0.37 & 0 & 1.08 & 7.2 &.- & -.- \\
\hline 16 & HD-2 & $404 / 699$ & 3.1 & 0.35 & 0 & 1.28 & 7.2 & $\ldots$ & $\ldots$ \\
\hline 14 & HD-2 & $399 / 905$ & 2.6 & 0.33 & 0 & 1.44 & 7.1 & -- & --- \\
\hline 26 & $M D-4$ & $293 / 513$ & 4.25 & $(0.33)$ & 1.6 & 0.98 & 6.5 & 9.5 & 11 \\
\hline 27 & MD-4 & $293 / 704$ & 3.32 & 0.31 & 1.4 & 1.18 & 6.7 & 6.9 & 14 \\
\hline 28 & MD-4 & $347 / 897$ & 2.82 & 0.34 & 1.5 & 1.51 & 6.6 & 5.7 & 18 \\
\hline 34 & MD-4 & $371 / 1066$ & 1.92 & 0.31 & 1.5 & 2.02 & 8.4 & 4.3 & 23 \\
\hline 31 & $M D-4$ & $357 / 513$ & 3.92 & 0.41 & 5.0 & 1.32 & 7.1 & 22.0 & 4.5 \\
\hline 30 & MD-4 & $338 / 710$ & 3. $3 i$ & 0.30 & 4.6 & 1.14 & 6.7 & 23.5 & 4.2 \\
\hline 29 & $M D-4$ & $343 / 899$ & 3.25 & 0.32 & 4.9 & 1.24 & 5.7 & 22.9 & 4.4 \\
\hline 35 & $M D-4$ & $349 / 1096$ & 2.19 & 0.34 & 4.4 & 1.94 & 7.2 & 13.1 & 7.6 \\
\hline 39 & $M D-4$ & $(300) / 515$ & 3.80 & 0.32 & 15.5 & 1.06 & 7.3 & 84.8 & 1.2 \\
\hline 38 & MD-4 & $329 / 704$ & 3.80 & 0.25 & 15.6 & 0.83 & 5.9 & 109. & .91 \\
\hline 40 & $M D-4$ & $352 / 899$ & 2.80 & 0.35 & 15.2 & 1.57 & 6.6 & 56.0 & 1.8 \\
\hline 36 & $M D-4$ & $343 / 1096$ & 2.20 & 0.33 & 14.1 & 1.88 & 7.2 & 43.3 & 2.3 \\
\hline
\end{tabular}

(1) MD-4, molecular formula assumed $=C_{13^{H}}{ }_{16} ; M W=172$, density $=0.98 \mathrm{~g} / \mathrm{ml}$.

(2) Stolchfometric oxygen for $\mathrm{MD}-4=17$ moles $\mathrm{O}_{2}$ /mole.

(3) Fuel equivalence ratio, $=\frac{\text { FueliAir, actual }}{\text { FueliAir, stoichiometric }}=\frac{100}{\text { stolchlometric oxygen }}$ 
TABLE 15. FYROLYSIS AND OXIDATIVE PYROLYSIS PRODUCT RECOVERIES AND BALANCES

\begin{tabular}{|c|c|c|c|c|c|c|c|c|c|c|c|c|c|c|}
\hline \multirow{2}{*}{$\begin{array}{l}\text { KuII } \\
\text { Non. }\end{array}$} & \multirow{2}{*}{$\begin{array}{c}\text { linel/ } \\
\text { Tump., } \\
6 \\
\end{array}$} & \multirow{2}{*}{$\begin{array}{c}\text { Wt. } \\
\text { red, } \\
B\end{array}$} & \multirow{2}{*}{$\begin{array}{c}\text { Wt. } \\
\text { Cas } \\
\text { Trapped, } \\
\text { g Methiane } \\
\end{array}$} & \multirow{2}{*}{$\begin{array}{c}\text { Wt. } \\
\text { Curbon } \\
\text { Deposiction, } \\
\text { g }\end{array}$} & \multirow{2}{*}{$\begin{array}{c}\text { We. } \\
\text { Liquids } \\
\text { Trapped, } \\
g\end{array}$} & \multirow{2}{*}{$\begin{array}{l}\text { Measurec } \\
\text { Mass } \\
\text { Bualance, } \\
\text { Onst/In }\end{array}$} & \multirow{2}{*}{$\begin{array}{c}\text { Noncondensed } \\
\text { Cases, } \\
\text { H }\end{array}$} & \multirow{2}{*}{$\begin{array}{c}\% \mathrm{O}_{2} \\
\text { Conversion } \\
\end{array}$} & \multicolumn{3}{|c|}{$\begin{array}{c}\text { Noncondenstble } \\
\text { Gas Concentrat luns, } \\
\text { vol. } \% \\
\end{array}$} & \multicolumn{3}{|c|}{$\begin{array}{l}\text { Condensed } \\
\text { NItrogen } \\
\text { Gilses, Dem }\end{array}$} \\
\hline & & & & & & & & & $\mathrm{CO}_{2}$ & $\mathrm{CH}_{4}$ & C) & $\mathrm{HCN}$ & $\mathrm{NIH}_{3}$ & AO \\
\hline 21 & $M()-2 / 500$ & 21.41 & 0.89 & 0.0 & 20.24 & 98.6 & NM & -- & NM & NM & MM & NM & NM & NM \\
\hline 18 & 1700 & 25.85 & 1.1 .1 & 0.0 & 19.41 & 79.5 & NM & -- & NM & NM & NM & NM & NM & NM \\
\hline 22 & 1900 & 21.34 & 0.96 & 2.35 & 11.38 & 68.8 & NM & - & NM & NM & NM & NM & NM & NM \\
\hline 25 & MIIJ-3/500 & 20.59 & $1.1 \mathrm{i}$ & 0.0 & 19.29 & 99.1 & 1.30 & - & NM & NM & NM & NM & NM & INM \\
\hline 24 & 1700 & 19.7 & 0.64 & 1.28 & 11.51 & 68.1 & NM & -- & NM & NM & NM & NM & NM & IM \\
\hline 23 & 19100 & 32.56 & 1.16 & 4.77 & 18.42 & 74.5 & $\mathrm{NNI}$ & -- & NM & NM & NM & NM & NM & INM \\
\hline $60-28$ & $\mathrm{M}(\mathrm{J})-4 / 500$ & 10.47 & 0.0 & NM & 8.49 & 81.2 & MM & -- & NM & NM & NM & NM & NM & NiM \\
\hline $58-24$ & 1700 & 12.72 & $\mathrm{NH}$ & NM & 9.68 & 76.1 & NM & -- & NM & $\mathrm{NH}$ & NM & NM & NM & NM \\
\hline 19 & 1900 & 29.93 & $0.8 ?$ & 5.4 & 16.17 & 75.0 & NM & -- & NM & NM & NM & NM & NM & NM \\
\hline 32 & 11100 & 21.89 & 0.83 & 5.81 & 8.72 & 70.3 & NM & -- & NM & NM & NM & $>150$ & 4000 & 0 \\
\hline 1.7 & $(11)-2 / 500$ & 13.66 & 0.02 & 0.0 & 9.11 & 66.8 & NM & -- & NM & NM & NM & NM & NM & $\mathrm{NMI}$ \\
\hline 16 & 17000 & 25.95 & 0.86 & NM & 20.68 & 83.0 & NM & -- & NM & NM & NM & NM & NM & NM \\
\hline 14 & $19 i j 0$ & 22.26 & 1.13 & NM & 10.54 & 52.4 & NM & -- & NM & NM & NM & NM & NM & NM \\
\hline 26 & $(01)-4 / 500)$ & 30.45 & 0.2 & 0.0 & 29.44 & 100.6 & 1.04 & 25 & NM & NM & NM & NM & NM & NM \\
\hline 27 & 1700 & 23.22 & 1.28 & 0.76 & 19.1 & 108.3 & 3.94 & 100 & 1.34 & 0.63 & 0.98 & $>150$ & 21.50 & NIs \\
\hline 28 & 1900 & 29.24 & 1.26 & 4.05 & 17.19 & 97.4 & 5.96 & 100 & 1.24 & 1.21 & 1.96 & 150 & 7000 & NI) \\
\hline 34 & 11100 & 14.015 & 0.2 & NM & 4.59 & 56.4 & 3.15 & 97 & 2.59 & 0.60 & 3.74 & $N M$ & NM & NM \\
\hline 31 & $M(1)-4 / 5(10$ & 22.73 & 0.6 & 0.0 & 15.15 & 69.8 & 0.14 & Low & 0 & 0 & 0.31 & NM & NM & NM \\
\hline 30 & 1700 & 0.14 .1 & NNI & NM & 10.16 & NM & NM & NM & ND & $\mathrm{Tr}$ & 2.4 & $\mathrm{Pr}$ & $\operatorname{Pr}$ & I'r \\
\hline 29 & 1900 & 18.84 & 1.28 & 1.88 & 9.97 & 94.2 & 4.62 & 100 & 0.72 & 1.16 & 2.8 & $>150$ & 27000 & NM \\
\hline 35 & 11100 & 18.7 & $0.4 ?$ & 3.87 & 6.70 & 85.5 & 4.95 & 97 & 2.06 & 0.65 & 5.45 & NM & NMI & NM \\
\hline 39 & (1) $-4 / 500$ & 24.81 & 1.4 .7 & 0.0 & 20.92 & 90.0 & 0 & 33 & ND & NI) & ND & NM & NM & NMI \\
\hline 38 & 1700 & 28.29 & 0.19 & NM & 36.83 & 181.6 & 14.33 & 100 & ND & 0.67 & 5.93 & NM & NM & NM \\
\hline 40) & 1900 & 28.44 & 0.0 & NN & 13.65 & 96.2 & 13.7 & 99.5 & 0.75 & 0.67 & 9.82 & NM & NM & NM \\
\hline 36 & 11100 & 16.97 & 1.1 & NM & 4.98 & 87.3 & 8.73 & 99 & 1.31 & 0.44 & 12.73 & NM & NM & NM \\
\hline
\end{tabular}

Tr - Trace

Pr - Present

S - Sollds trapped 
TABLE 16. NORMALIZED AVERAGE RECOVERIES OF SOLIDS, LIQUIDS AND GASES FROM PYROLYSIS AND OXIDATIVE-PYROLYSIS OF SRC II DISTILLATE FRACTIONS

\begin{tabular}{|c|c|c|c|c|c|c|c|c|c|c|c|c|}
\hline \multirow{2}{*}{$\begin{array}{l}\text { Av. Ptucent of } \\
\text { Stojch. Oxygen } \\
\text { Temp, CC }\end{array}$} & \multicolumn{3}{|c|}{$0 \%$} & \multicolumn{3}{|c|}{$7 \%$} & \multicolumn{3}{|c|}{$20 \%$} & \multicolumn{3}{|c|}{$73 x$} \\
\hline & Cras & Llquid & Solid & Gas & I.1quid & Solid & Gas & Liquid & Solld & Cas & Liquid & Sol1d \\
\hline 500 & 3.2 & 96.8 & 0.0 & 4.0 & 96.0 & 0.0 & 4.6 & 95.4 & 0.0 & 6.3 & 93.7 & 0.0 \\
\hline 700 & 4.4 & 87.7 & 7.9 & 20.8 & 76.2 & 3.0 & $(24.6)^{(1)}$ & 72.1 & $(3.4)^{(1)}$ & 28.3 & 71.7 & $(0.0)^{(2)}$ \\
\hline$y 00$ & 4.8 & 74.7 & 20.5 & 25.4 & 60.4 & 14.5 & 33.2 & 56.2 & 10.6 & 50.1 & 49.4 & $(0.0)^{(2)}$ \\
\hline 1100 & 5.5 & 0.0 & $94.5^{(3)}$ & 23.8 & 0.0 & $(76.2)^{(3,4)}$ & 33.9 & 0.0 & $66.1^{(3)}$ & 66.3 & 0.0 & $(33.7)^{(2,3)}$ \\
\hline
\end{tabular}

(1) Bised on averages of data at conditfons of higher and lower oxygen concentrations.

(2) Based on assumption thit no solifs remained in tube at high oxygen levels.

(3) Sullds caughit in condenser traps comblned with solids left on reactor wall.

(4) By difference. 
TABLE 17. MOLECULAR WEIGHTS AND ELEMENTAL ANALYSES OF PYROLYSIS AND PYROLYSIS-OXIDATION PRODUCTS

\begin{tabular}{|c|c|c|c|c|c|c|c|c|c|}
\hline \multirow[b]{2}{*}{$\begin{array}{l}\text { Run } \\
\text { No. }\end{array}$} & \multicolumn{2}{|c|}{ frol ecular } & \multicolumn{7}{|c|}{ Elemencal Allalyses, \% } \\
\hline & $\frac{\text { We iglut }}{\text { VPo }}$ & $\frac{g / \ln U 1 \mathrm{e}}{\mathrm{CC}}$ & $\mathbf{C}$ & H & $\mathbf{S}$ & $\begin{array}{c}n \\
(D+f f .)\end{array}$ & $\begin{array}{c}\text { Tirtal } \\
\mathrm{N}\end{array}$ & $\begin{array}{c}\text { Basic } \\
N\end{array}$ & $\begin{array}{c}\text { Nonbasic N } \\
\text { (Diff. })\end{array}$ \\
\hline $\begin{array}{l}21 \\
18 \\
22\end{array}$ & $\begin{array}{c}117 \\
\text { J } 38 \\
(423)\end{array}$ & $\begin{array}{l}139 \\
137 \\
167\end{array}$ & $\begin{array}{l}82.7 \\
84.7 \\
84.2\end{array}$ & $\begin{array}{l}9.6 \\
8.0 \\
5.6\end{array}$ & $\begin{array}{l}0.05 \\
0.04 \\
0.12\end{array}$ & $\begin{array}{l}7.08 \\
11.8 \\
10.1\end{array}$ & $\begin{array}{l}0.59 \\
0.67 \\
0.37\end{array}$ & $\begin{array}{l}0.36 \\
0.37 \\
0.15\end{array}$ & $\begin{array}{l}0.23 \\
0.30 \\
0.22\end{array}$ \\
\hline $\begin{array}{l}25 \\
24 \\
23\end{array}$ & $\begin{array}{c}130 \\
143 \\
(347)\end{array}$ & $\begin{array}{l}129 \\
147 \\
136\end{array}$ & $\begin{array}{l}80.5 \\
84.0 \\
87.5\end{array}$ & $\begin{array}{l}8.8 \\
7.1 \\
5.4\end{array}$ & $\begin{array}{l}0.07 \\
0.07 \\
0.21\end{array}$ & $\begin{array}{r}10.6 \\
8.8 \\
6.9\end{array}$ & $\begin{array}{l}0.77 \\
1.01 \\
0.92\end{array}$ & $\begin{array}{l}0.48 \\
0.54 \\
0.24\end{array}$ & $\begin{array}{l}0.29 \\
0.47 \\
0.68\end{array}$ \\
\hline $\begin{array}{r}60-28 \\
58-24 \\
19 \\
32\end{array}$ & $\begin{array}{c}211 \\
200 \\
94 \\
\mathrm{NM}(\mathrm{a})\end{array}$ & $\begin{array}{l}176 \\
167 \\
153 \\
N M(a)\end{array}$ & $\begin{array}{l}86.2 \\
88.9 \\
81.0 \\
97.8\end{array}$ & $\begin{array}{l}9.1 \\
6.9 \\
5.0 \\
0.9\end{array}$ & $\begin{array}{l}0.09 \\
0.09 \\
0.21 \\
\mathrm{NM}^{(\mathrm{b})}\end{array}$ & $\begin{array}{r}2.3 \\
1.6 \\
12.5 \\
1.0\end{array}$ & $\begin{array}{l}1.04 \\
1.25 \\
0.95 \\
0.31\end{array}$ & $\begin{array}{l}0.54 \\
0.62 \\
0.23 \\
0.03^{(c)}\end{array}$ & $\begin{array}{l}0.50 \\
0.63 \\
0.72 \\
0.28(c)\end{array}$ \\
\hline $\begin{array}{l}17 \\
3.6 \\
14\end{array}$ & $\begin{array}{l}213 \\
203 \\
285\end{array}$ & $\begin{array}{l}147 \\
172 \\
223\end{array}$ & $\begin{array}{l}89.2 \\
87.7 \\
77.0\end{array}$ & $\begin{array}{l}8.4 \\
6.5 \\
3.8\end{array}$ & $\begin{array}{l}0.04 \\
0.08 \\
0.41\end{array}$ & $\begin{array}{r}1.3 \\
3.8 \\
25.8\end{array}$ & $\begin{array}{l}0.63 \\
0.73 \\
0.65\end{array}$ & $\begin{array}{l}0.29 \\
0.33 \\
0.08\end{array}$ & $\begin{array}{l}0.34 \\
0.40 \\
0.57\end{array}$ \\
\hline $\begin{array}{l}26 \\
27 \\
28 \\
34\end{array}$ & $\begin{array}{l}172 \\
170 \\
(87) \\
\mathrm{NM}^{2}(\mathrm{a})\end{array}$ & $\begin{array}{l}179 \\
165 \\
1 / 8 \\
N y_{1}(a)\end{array}$ & $\begin{array}{l}87.6 \\
85.0 \\
79.4 \\
98.9\end{array}$ & $\begin{array}{l}8.9 \\
7.1 \\
4.6 \\
0.7\end{array}$ & $\begin{array}{l}0.10 \\
0.13 \\
0.46 \\
N M\end{array}$ & $\begin{array}{r}2.3 \\
6.4 \\
14.6 \\
0.1\end{array}$ & $\begin{array}{l}1.05 \\
1.20 \\
0.95 \\
0.28\end{array}$ & $\begin{array}{l}0.52 \\
0.47 \\
0.28 \\
0.01 \text { (c) }\end{array}$ & $\begin{array}{l}0.53 \\
0.73 \\
0.67 \\
0.27(c)\end{array}$ \\
\hline $\begin{array}{l}31 \\
30 \\
29 \\
35\end{array}$ & $\begin{array}{c}199 \\
240 \\
(349) \\
N N(a)\end{array}$ & $\begin{array}{l}176 \\
166 \\
182 \\
\text { NM(a) }\end{array}$ & $\begin{array}{l}87.0 \\
87.2 \\
84.8 \\
95 .\end{array}$ & $\begin{array}{l}8.6 \\
6.9 \\
6.5 \\
1.0\end{array}$ & $\begin{array}{l}0.15 \\
0.17 \\
0.32 \\
\mathrm{NM}^{2}(\mathrm{~b})\end{array}$ & $\begin{array}{l}3.0 \\
4.4 \\
7.4 \\
3.7\end{array}$ & $\begin{array}{l}1.00 \\
0.97 \\
0.83 \\
0.28\end{array}$ & $\begin{array}{l}0.44 \\
0.37 \\
0.29 \\
0.02 \text { (c) }\end{array}$ & $\begin{array}{l}0.56 \\
0.60 \\
0.54 \\
0.26 \text { (c) }\end{array}$ \\
\hline $\begin{array}{l}39 \\
38 \\
40 \\
36\end{array}$ & 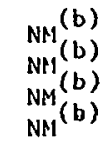 & $\begin{array}{l}141 \\
129 \\
241 \\
\mathrm{NM}(a)\end{array}$ & $\begin{array}{l}77.8 \\
83 . \\
57.2 \\
96 .\end{array}$ & $\begin{array}{l}6.5 \\
5.0 \\
3.9 \\
1.9\end{array}$ & $\begin{array}{l}N M^{(b)} \\
N M_{(b)}^{(b)} \\
N{ }^{(b)}(b) \\
N H^{\prime}(b)\end{array}$ & $\begin{array}{r}14.6 \\
9.3 \\
38.3 \\
2.5\end{array}$ & $\begin{array}{l}1.12 \\
2.72 \\
0.56 \\
0.29\end{array}$ & $\begin{array}{l}0.49 \\
0.92 \\
0.11 \\
0.10(c)\end{array}$ & $\begin{array}{l}0.63 \\
1.80 \\
0.45 \\
0.19 \text { (c) }\end{array}$ \\
\hline
\end{tabular}

(a) Not measurable due to sol1d sample.

(b) Not masured.

(c) Value in doubt - solid sample. 
Basic nitrogen analyses for the $1100 \mathrm{C}$ experiments were based on the perchloric acid/acetic acid titration method on the solid samples obtained in the condensers, but the accuracy of these results is questionable because the samples were not soluble in the titration solvent.

In Table 18 the hydrogen distributions measured by $\mathrm{H}^{1}$ NMR are listed. The structural parameters obtained by the Brown-Ladner correlations and molecular formulas derived from the elemental analyses and GC molecular weights are listed in Table 17. Only aromaticity, obtained by C13 NMR, could be obtained for the solid samples obtained in the condensate traps at $1100 \mathrm{C}$.

The amounts of representative unsubstituted aromatics in the liquid products, as measured by gas chromatography, are listed in Table 19. These results are not corrected for response factors and are percentages of total liquid product peak areas. These analyses also could not be done on the solids obtained at $1100 \mathrm{C}$.

Aromaticity. Aromaticity, the ratio of aromatic carbons to total carbon, increases from an average of 0.53 in the starting material and 0.56 at $500 \mathrm{C}$ to 0.83 at $700 \mathrm{C}$ and 0.95 at $900 \mathrm{C}$, as shown in Figure 21. The number of aromatic rings increases proportionately. There is almost uniform behavior between the different boiling point fractions. Aromatization of the ring systems is an important reaction during pyrolysis.

Figure 22 shows the relationship between aromaticity of the unburned products at each temperature and the stoichiometric amount of oxygen available during oxidative pyrolysis. Aromaticity does not appear to increase with increasing concentration of oxygen at any temperature.

The number of aromatic ring substituents and the average substituent length decreases with increasing pyrolysis temperature as shown in Figures 23 and 24 , respectively. These numbers include aliphatic rings attached to aromatic rings at two points, such as in tetralin-type molecules. The number of substituents decreases from approximately three per ring in the starting material and at 500 c. to approximately one per ring at 900 C. The aliphatic substituents are very short, ranging from an average of less than two carbon atoms at low temperature to less than one carbon atom per substituent at 900 C. (Phenolic substituents are counted as 0-carbon substituents.) 
62

TABLE 18, HYDRoGEN DISTRIBUTION, STRUCTURAL PARAMETERS AND MOLECULAR FORMULAS FOR PYROLYSIS
AND OXIDATIVE PYROLYSIS PRODUCTS OF SRC II DISTILLATION FRACTIONS

\begin{tabular}{|c|c|c|c|c|c|c|c|c|c|c|c|c|c|c|c|c|c|c|c|c|c|c|c|c|c|}
\hline Run No. & 21 & 18 & 22 & 25 & 24 & 23 & $60-28$ & $58-24$ & 19 & 17 & 16 & 14 & $32^{(b)}$ & 26 & 27 & 28 & $34^{(b)}$ & 31 & 30 & 29 & $35^{(b)}$ & 39 & 38 & 40 & $36^{(\mathrm{b})}$ \\
\hline \multicolumn{26}{|l|}{ Hydrogen Distribution, \% } \\
\hline Aliphatic H & 39 & 3 & 5 & 32 & 2 & 11 & 32 & 8 & 23 & 32 & 13 & 19 & мM & 34 & 4 & 16 & NM & 27 & 1 & 3 & NM & 25 & 5 & s1 & NM \\
\hline a to Aromatic $H$ & 31 & 32 & 0 & 38 & 32 & 0 & 44 & 28 & 0 & 33 & 21 & 0 & NM & 40 & 26 & 4 & NM & 39 & 19 & 0 & NM & 47 & 31 & 1 & NM \\
\hline Aromatic $H$ & 24 & 65 & 95 & 26 & 61 & 89 & 23 & 64 & 77 & 35 & 66 & 81 & NM & 2.5 & 69 & 80 & MM & 31 & 00 & 97 & NM & $3^{8}$ & niti & १!. & MM \\
\hline Phenolic $\mathrm{H}$ & 5 & 0 & 0 & 4 & 5 & 0 & 1 & 0 & 0 & 0 & 0 & 0 & NM & $?$ & 0 & 0 & NM & 3 & 0 & $n$ & $m$ & 0 & $a$ & 4 & $\mathrm{MM}$ \\
\hline \multicolumn{26}{|l|}{ Structural Parameters } \\
\hline Arumialicicily, $f_{a}$ & 0.51 & 0.80 & 0,98 & 0.54 & 0.83 & 0,96 & 0.52 & 0,83 & 0,91 & 0.63 & 0.85 & 0,94 & 0.97 & 0.55 & 0.81 & 0,93 & 1.: 0 & 0.61 & 0,91 & 0.99 & NM & 0.64 & 0,87 & 0,79 & 1.0 \\
\hline Aro. Edge/Total aro,, Haro $/ \mathrm{C}_{\text {aro }}$ & 1: & 1. & 0,77 & 1: & 0.94 & 0.69 & 1. & 0,87 & 0.63 & 0.92 & 0,80 & 0,56 & NM & 1. & 0,97 & 0.69 & MM & 1. & 0,94 & 0,90 & NM & 0,81 & 0.67 & 0,46 & NM \\
\hline Substituted edge/total edge, $\sigma$ & 0.51 & 0.32 & 0.12 & 0.59 & 0.31 & 0,09 & 0.52 & 0,31 & 0.20 & 0,34 & 0,19 & 0,54 & MM & 0.48 & 0.23 & 0,27 & NM & 0,43 & 0.1 .5 & 0.80 & NM & 0,73 & 0,34 & & NM \\
\hline Substituted ring carbons, $R_{S}$ & 2.5 & 2.3 & 1.1 & 2.8 & 2.5 & 0.6 & 3.4 & 2.8 & 1.2 & 2.9 & 1.6 & 3.7 & NM & $3: 3$ & $2, ?$ & 2.0 & NM & 3,8 & 1,6 & 0.9 & $\mathrm{NM}$ & 3.5 & 1,8 & & Nм \\
\hline Garbon atoms/substituent, $n$ & 1,9 & 0.8 & 0.2 & 1.4 & 0.7 & $0: 7$ & 1,8 & 0.8 & 0,8 & 1,9 & 1.2 & $0: 2$ & m & $1: 9$ & 1.2 & 5 & NM & 1.7 & 1,1 & & NM & 1,5 & 1.2 & & MM \\
\hline Total aromatic carbons, $C_{a}$ & 4.9 & 7,2 & 11,5 & 4.7 & 8,5 & 9.5 & 6.5 & 10,3 & 9,3 & 9,2 & 10.7 & 12.2 & NM & 6,9 & 9,8 & 12,0 & MM & 8.8 & 11,0 & $12: 7$ & $\mathrm{NM}$ & 5.9 & 7.8 & 9.1 & NM \\
\hline No aromatic rings, $R_{a}$ & 1. & 1. & 2,3 & 1. & 1.3 & 2.5 & 1 & $1, ?$ & $2: 7$ & $1: 4$ & $2: 1$ & 3.7 & NM & $1:$ & 1.2 & 2.7 & $M$ & 1: & 1.3 & 1,6 & NM & 1,6 & 2,3 & 3.5 & $M$ \\
\hline \multicolumn{26}{|l|}{ Molecular Formula ${ }^{(a)}$} \\
\hline c & 9.6 & 9,7 & 11,7 & 8.7 & 10.3 & 9.9 & 12,6 & $12: 4$ & 10.3 & 14,6 & 12.6 & $1.4: 3$ & NM & $13: 1$ & 11.7 & 11,8 & NM & 12.8 & 12,1 & 12,9 & 쏘 & 9,1 & $8: 9$ & 14,5 & MM \\
\hline H & 13.6 & 11.0 & 9.4 & 11,4 & 10,4 & $7: 3$ & $16 ; 0$ & 11.5 & $7: 7$ & 16.5 & 11,2 & 8.5 & $N M$ & 15.9 & 11,7 & 8.2 & NبM & $15: 1$ & 11,5 & 11.8 & NM & 9,2 & 6.5 & 9.1 & $M M$ \\
\hline $\mathrm{N}$ & 0.06 & 0,07 & 0.04 & $0.0 ?$ & 0,11 & 0,09 & 0.13 & 0.15 & 0.10 & 0.04 & $0,0.9$ & $: 10$ & NM & 0,13 & $0: 14$ & $n: 12$ & $N M$ & 0.13 & $n: 17$ & $n: 11$ & NM & 9.11 & 0,25 & 0,10 & $M$ \\
\hline s & 0.00 & 0,00 & 0.01 & 0.00 & 0.00 & 0,01 & 0.00 & 0.00 & 0.01 & 0.00 & 0.00 & 0,03 & NM & 0,01 & $n, n_{1}$ & $n, n n$ & мب̣ & 0.01 & 0.01 & 0,92 & NM & NM & NM & NM & NM \\
\hline 0 & 0.6 & 1.0 & 1,1 & 0.9 & 0.8 & 0.6 & 0.3 & 0.2 & 1.8 & $n, ?$ & $n:$ & 3.6 & PMP & 0.3 & 0,7 & 1,7 & $m$ & 0,3 & $0: 3$ & $y, y$ & NM & 1,1 & 0,5 & 5.9 & $\mathrm{NM}$ \\
\hline
\end{tabular}

(a) Based on GC molecular weights:

(b) Solid, 
TABLE 19. UNSUBSTITUTED AROMATICS IN PRODUCTS OF PYROLYSIS AND OXIDATIVE-PYROLYSIS OF SRC II DISTILLATION FRACTIONS (PERCENTAGES)

\begin{tabular}{|c|c|c|c|c|}
\hline $\begin{array}{l}\text { Run } \\
\text { No. }\end{array}$ & Benzene & Naphthalene & Phenanthrene & Pyrene \\
\hline 21 & 0.0 & 3.4 & 1.2 & 0.0 \\
\hline 18 & 6.1 & 6.6 & 0.4 & 0.1 \\
\hline 22 & 26.9 & 19.8 & 6.8 & 1.5 . \\
\hline 25 & 0.0 & 3.7 & 0.0 & 0.0 \\
\hline 24 & 4.1 & 16.7 & 1.0 & 0.2 \\
\hline 23 & 52.9 & 18.2 & 2.6 & 0.8 \\
\hline $60-28$ & 0.0 & 0.3 & 1.6 & 0.0 \\
\hline $58-24$ & 1.0 & 7.8 & 3.5 & 0.3 \\
\hline 19 & 25.2 & 31.8 & 10.3 & 2.6 \\
\hline 32 & $\mathrm{NM}(\mathrm{a})$ & NM & NM & NM \\
\hline 17 & 0.0 & 0.0 & 31.5 & 0.5 \\
\hline 16 & 0.5 & 1.3 & 20.8 & 1.3 \\
\hline 14 & 4.3 & 18.4 & 43.7 & 5.6 \\
\hline 26 & 0.0 & 1.1 & 2.7 & 0.1 \\
\hline 27 & 2.9 & 9.1 & 3.8 & 0.4 \\
\hline 28 & 11.5 & 30.9 & 8.9 & 4.0 \\
\hline 34 & $\mathrm{NM}^{(a)}$ & $\mathrm{NM}$ & $\mathrm{NM}$ & $\mathrm{NM}$ \\
\hline 31 & 0.0 & 1.4 & 2.1 & 0.0 \\
\hline 30 & 4.5 & 12.3 & 4.5 & 0.5 \\
\hline 29 & 5.4 & 27.8 & 7.1 & 2.5 \\
\hline 35 & $N M(a)$ & NM & $\mathrm{NM}$ & $\mathrm{NM}$ \\
\hline 39 & 15.0 & 0.0 & 0.0 & 0.0 \\
\hline 38 & 10.0 & 0.0 & 3.8 & 0.0 \\
\hline 40 & 0.0 & 0.0 & 0.0 & 0.0 \\
\hline 36 & $\mathrm{NM}(\mathrm{a})$ & NM & $\mathrm{NM}$ & $\mathrm{NM}$ \\
\hline
\end{tabular}

(a) Solid sample. 


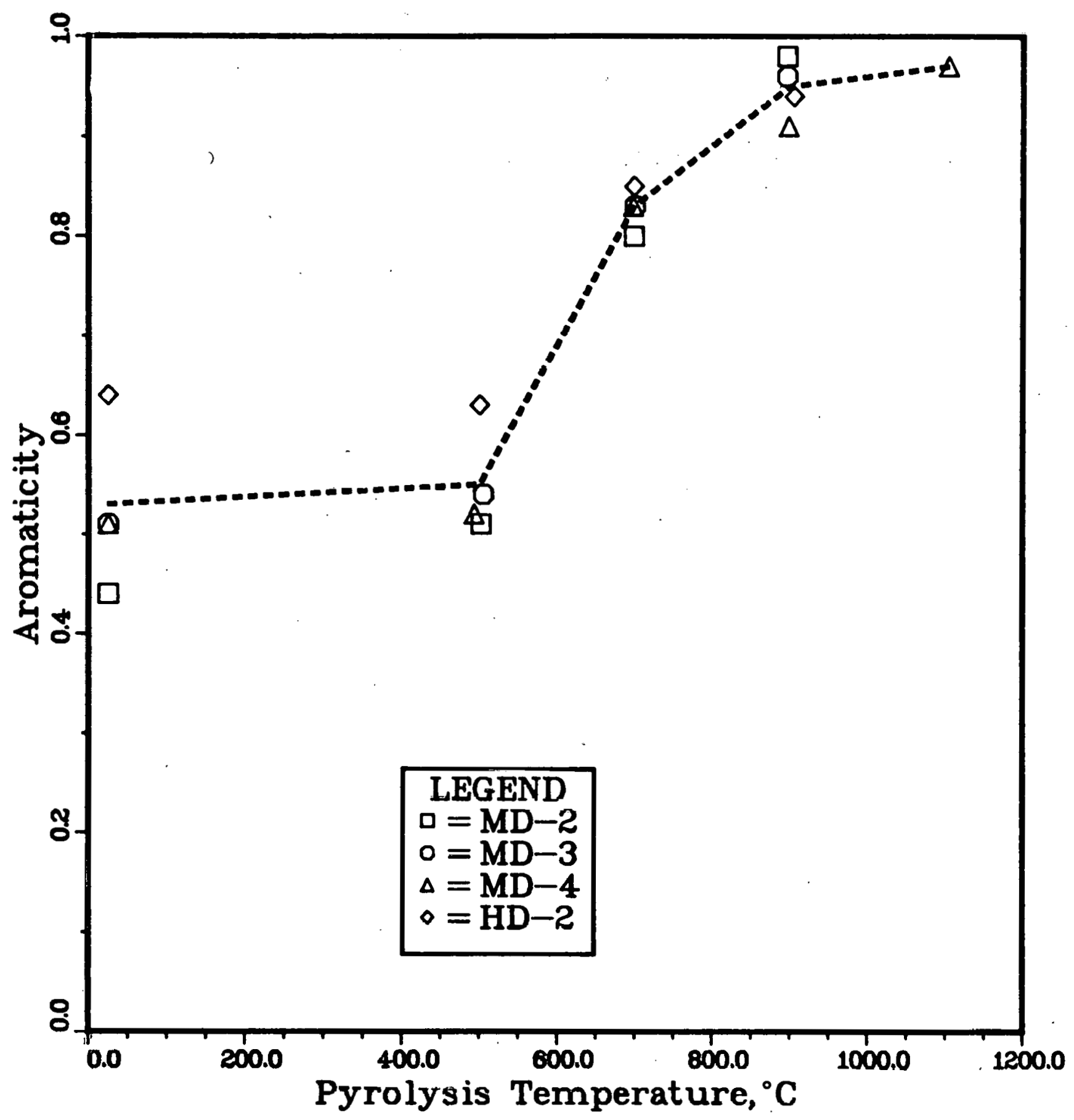

FIGURE 21. AROMATICITY OF LIQUID PRODUCTS VERSUS PYROLYSIS TEMPERATURE 


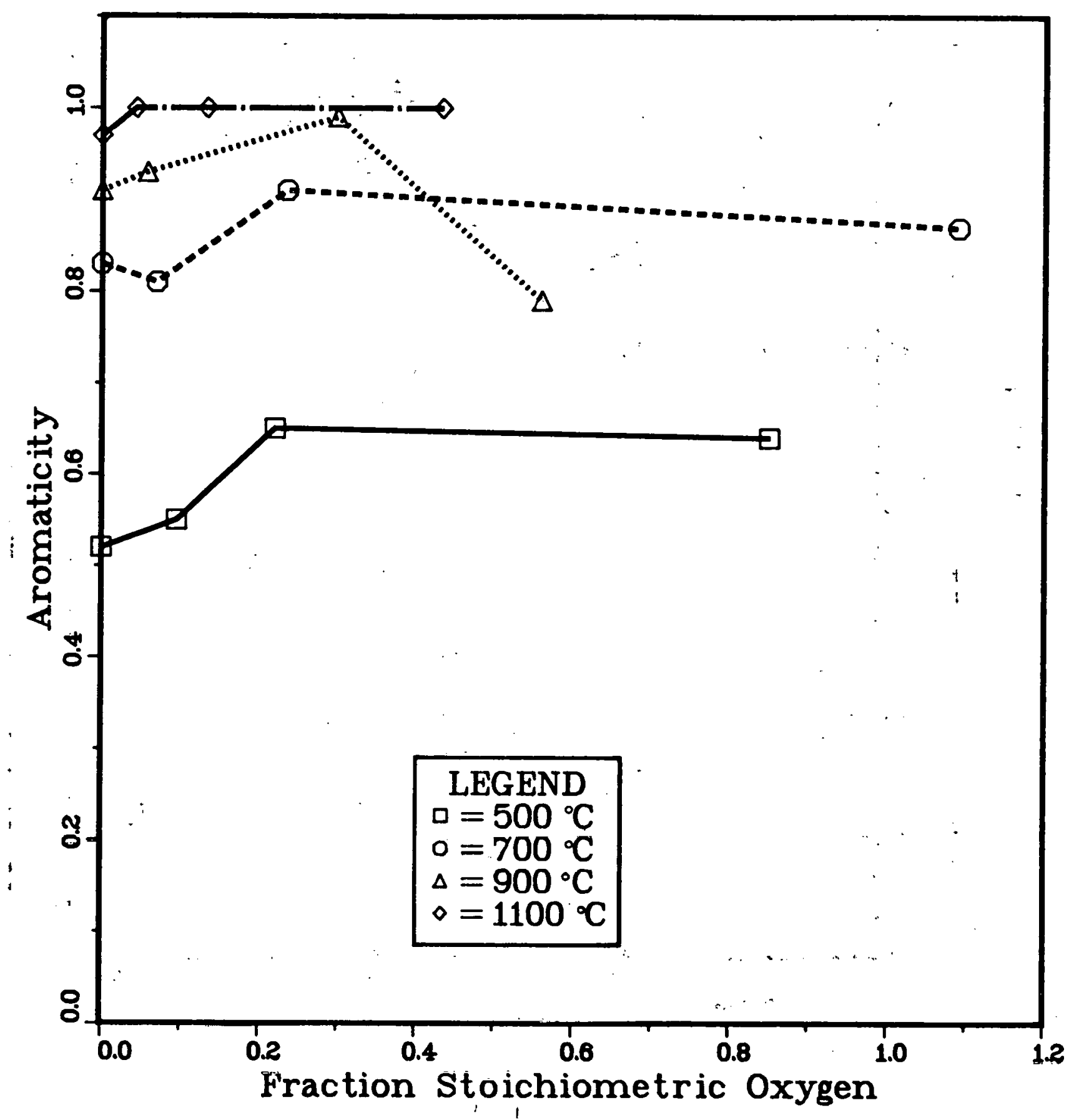

FIGURE 22." AROMATICITY VERSUS FRACTION OF STOICHIOMETRIC OXYGEN 


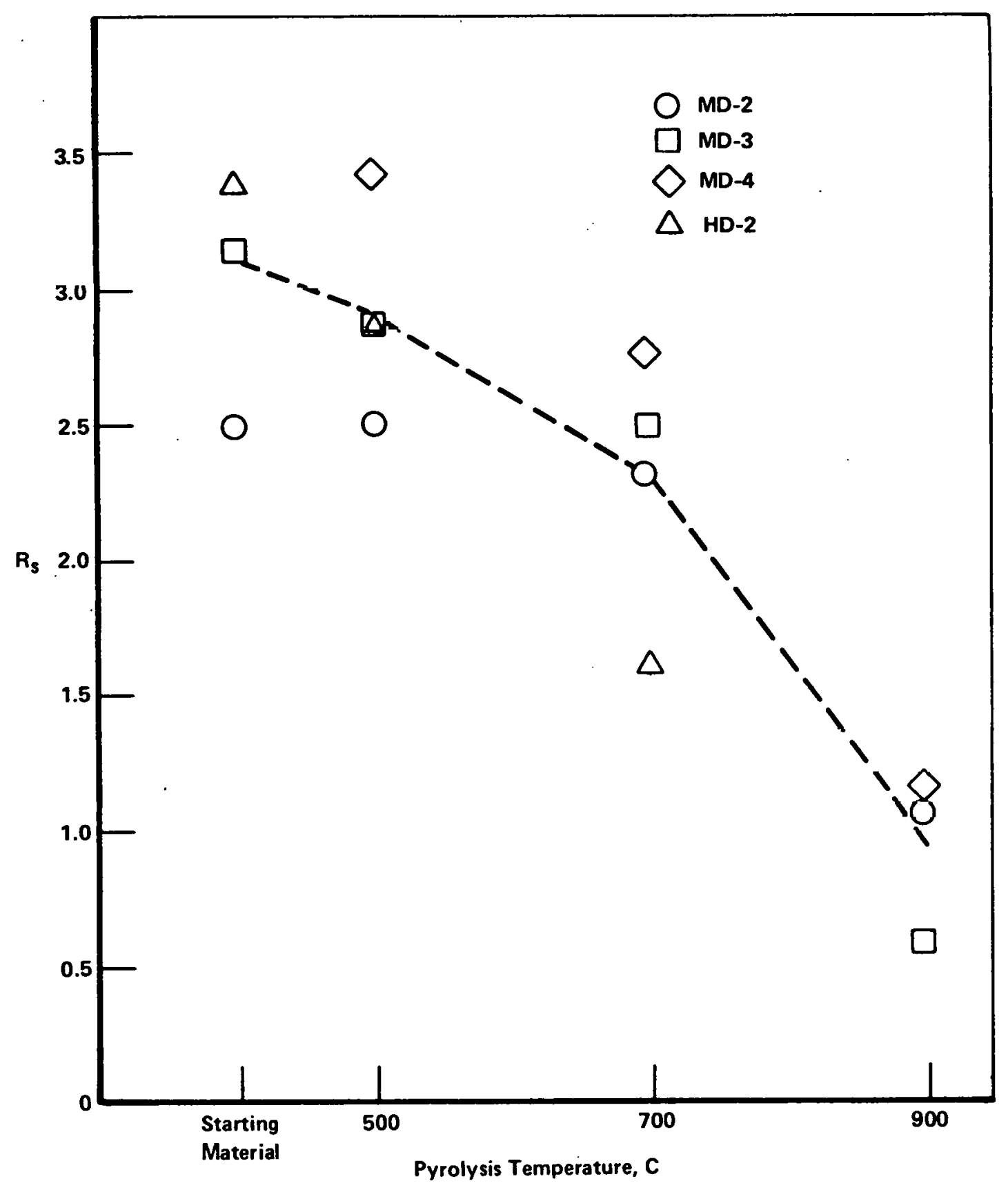

FIGURE 23. NUMBER OF AROMATIC RING SUBSTITUENTS $\left(R_{S}\right)$ VERSUS PYROLYSIS TEMPERATURE 


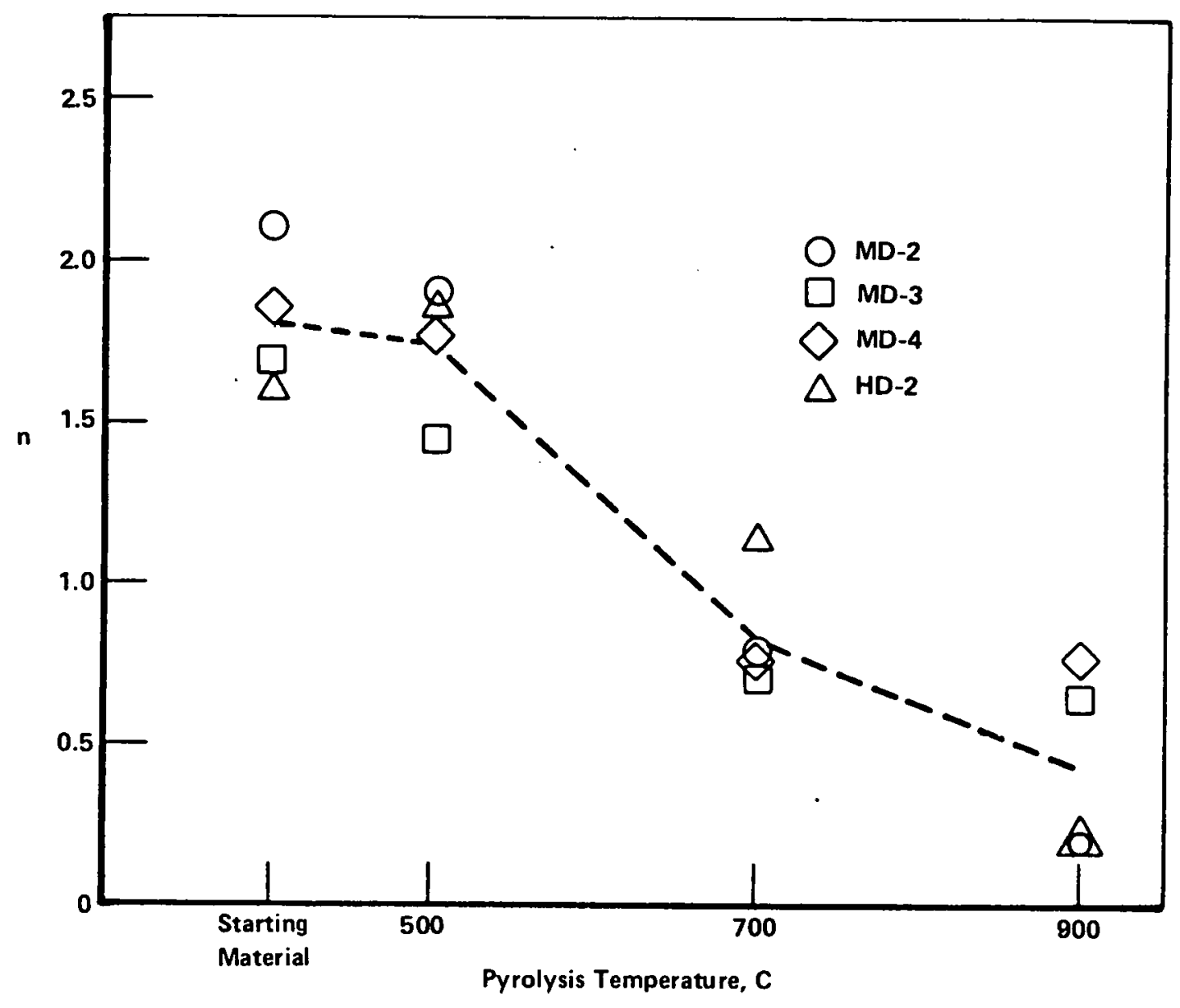

FIGURE 24. SUBSTITUENT LENGTH ( $n$ ) VERSUS PYROLYSIS TEMPERATURE 
Molecular Weight. Aromatization, involving $\mathrm{C}-\mathrm{H}$ bond breakage, rather than removal of aliphatic substituents, which involves aromatic carbonaliphatic carbon bond breakage is suggested to explain the observations because the weight per molecule remains approximately constant with increasing temperature, as shown in Figure 25. The molecular weight measurements were determined by summation of the peak areas in the simulated distillation by gas chromatography analysis. Molecular weight could not be extended to $1100 \mathrm{C}$ because the products formed at $1100 \mathrm{C}$ were solids. However, the solids may be assumed to represent a significant increase in molecular weight above the 150$170 \mathrm{~g} /$ mole range obtained from 500-900 C.

The relationship between molecular weight and fraction of stoichiometric oxygen is shown in Figure 26. At 500 and $700 \mathrm{C}$ molecular weight declines, but at $900 \mathrm{C}$ the molecular weight increases with increasing fraction of stoichiometric oxygen. At $900 \mathrm{C}$ oxygen appears to cause a relative increase in ring condensation. No data could be obtained at $1100 \mathrm{C}$.

Elemental Composition. The weight percent of carbon is roughly constant from 500 to $900 \mathrm{C}$ but jumps significantly at $1100 \mathrm{C}$, as shown in Figure 27. The $1100 \mathrm{C}$ sample was collected in the condensers and was probably obtained in approximately the same residence time as the samples obtained at lower temperatures. Hydrogen drops to less than one weight percent and oxygen (by difference) also drops to about one weight percent at $1100 \mathrm{C}$. Compounds containing oxygen and hydrogen are destroyed between 900 and $1100 \mathrm{C}$ at the residence times used in these experiments (about $7 \mathrm{sec}$ ). A highly carbonaceous material, presumably with a graphitic structure, is obtained at $1100 \mathrm{C}$. There appears to be little difference in the carbonaceous products obtained at $1100 \mathrm{C}$ from the different SRC II distillation fractions.

Up to $900 \mathrm{C}$ there is a significant increase in the concentration of other elements. Direct oxygen determinations were not made, but this material is assumed to be primarily oxygen since the liquid products are nearly ash and sulfur free and the nitrogen content did not change significantly. The oxygen increase must result from preferential retention in the liquid products of the oxygen in the SRC II distillation cuts. There is no other source of oxygen in the system. This is not surprising since the nonliquid products consist of 


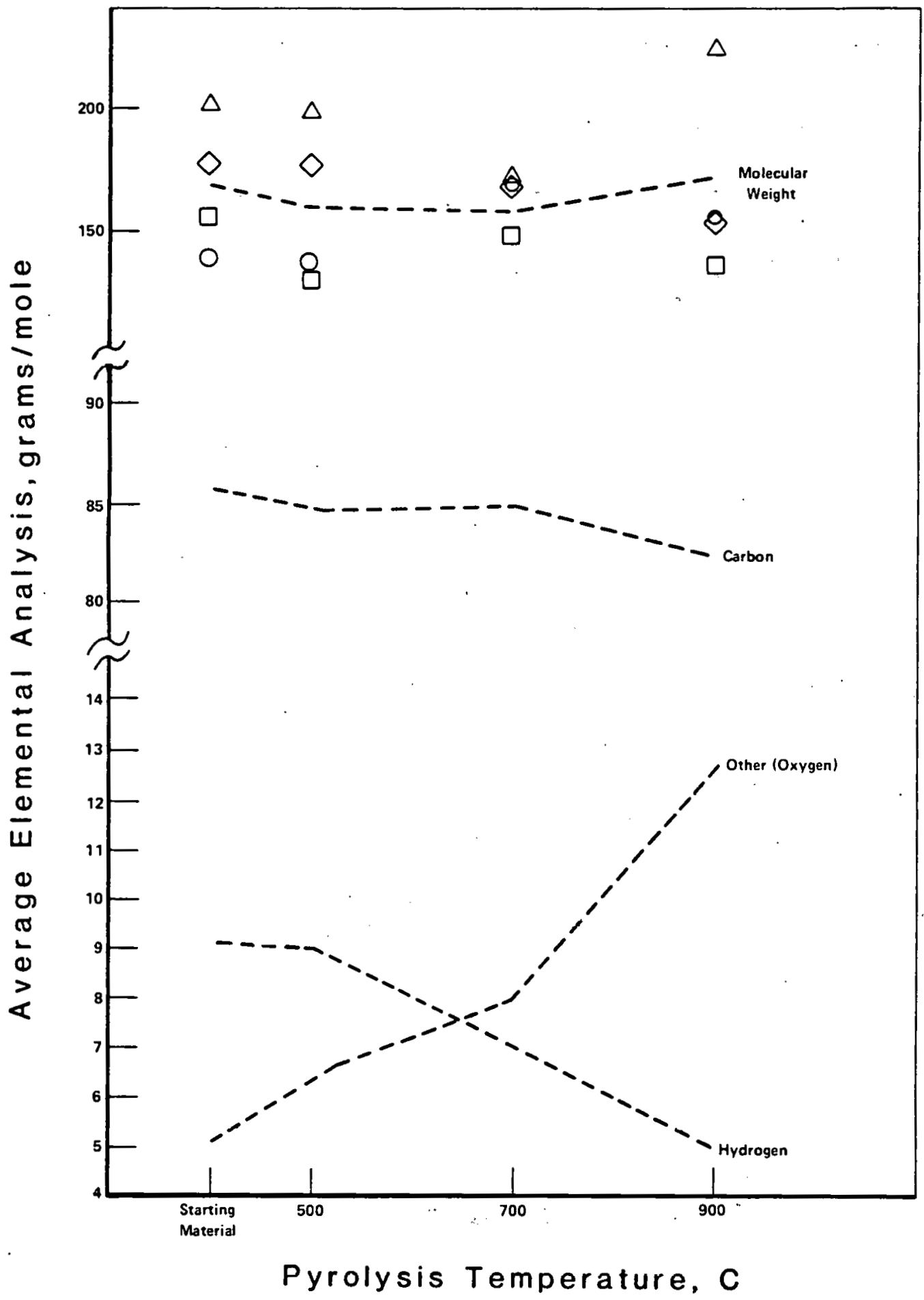

FIGURE 25. MOLECULAR WEIGHT AND ELEMENTAL COMPOSITION VERSUS PYROLYSIS TEMPERATURE 


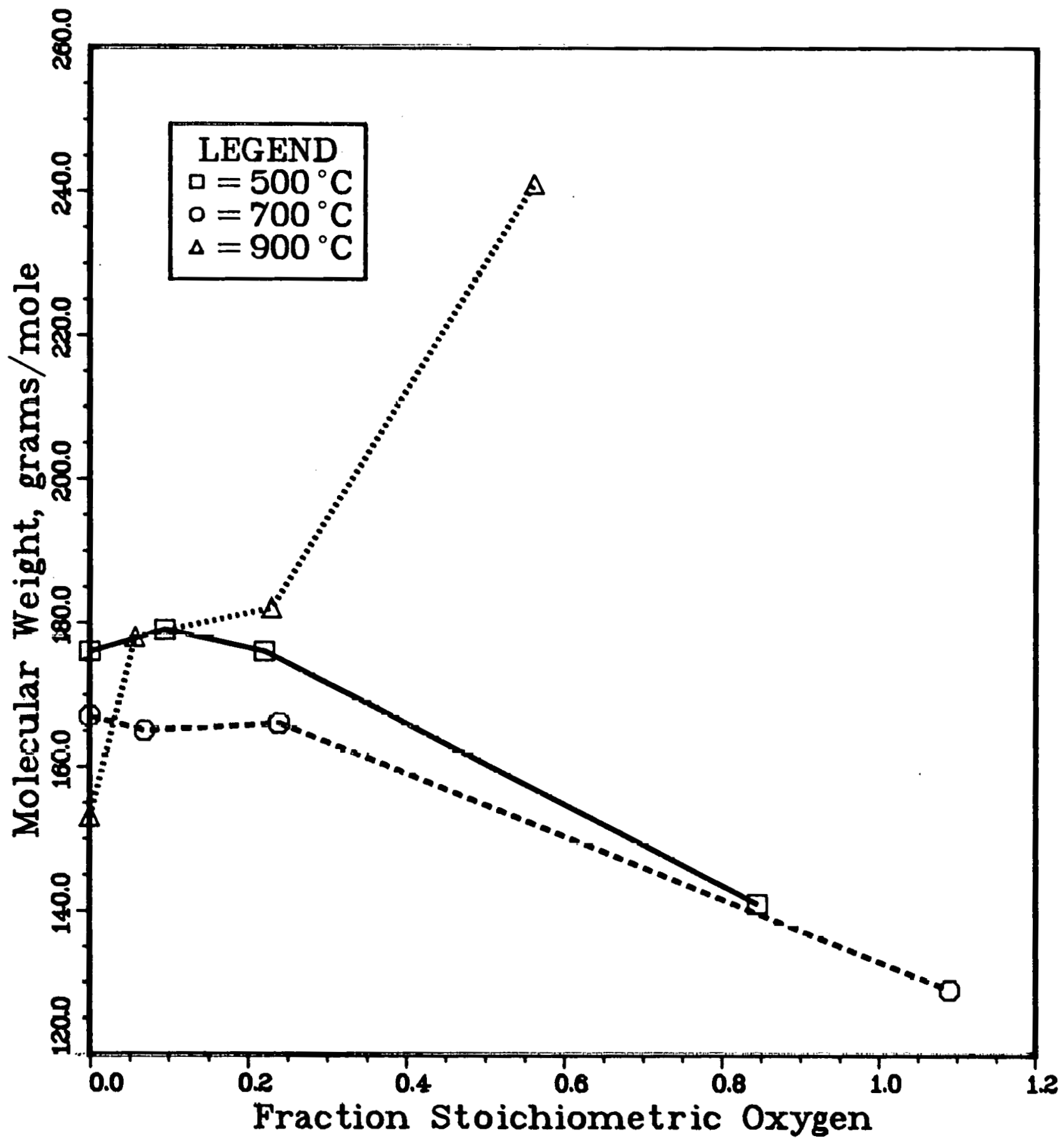

FIGURE 26. MOLECULAR WEIGHT VERSUS FRACTION OF STOICHIOMETRIC OXYGEN 


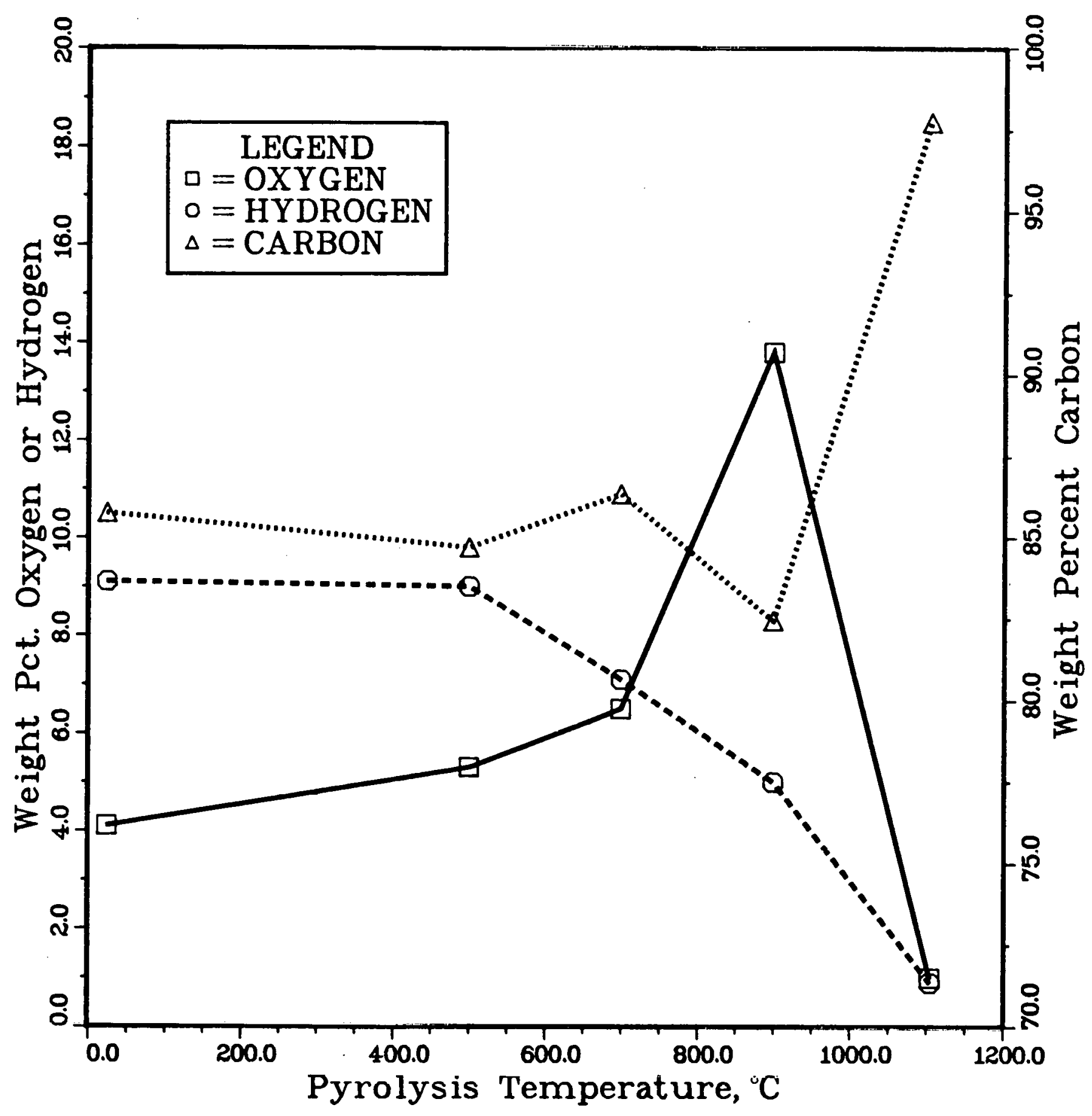

FIGURE 27. CARBON, HYDROGEN AND OXYGEN CONTENT VERSUS PYROLYSIS TEMPERATURE 
soot (carbon) and light gases (primarily methane). Most or all of the oxygen in the SRC II distillation cuts is phenolic. The phenolic substituent apparently inhibits soot formation, possibly by quenching free radicals formed thermally during pyrolysis.

The hydrogen distribution is shown in more detail versus temperature in Figure 28. The average number of hydrogen atoms per molecule decreases and aliphatic hydrogen decreases to no more than one per molecule at $900 \mathrm{C}$. There is an increase in the number of aromatic hydrogens per molecule.

The changes in elemental composition of the partially pyrolyzed and oxidized fuel with increasing fraction of stoishinmetris oxygen are shown in Figures 29-31. Carbon and hydrogen decline slightly while oxygen content increases. This is apparently due to oxygen incorporation in the molecules by oxidation. A mechanism such as the one described by Santoro and Glassman, in which dihydroxy benzenes are intermediates, is in agreement with this observation. (22)

Nitrogen Concentration. As shown in Figure 32, nitrogen is unchanged from room temperature to $500 \mathrm{C}$, is preferentially retained in the unpyrolyzed liquids between 500 and $700 \mathrm{C}$ and is destroyed at an increasing rate from 700 to $1100 \mathrm{C}$. There is a conversion of basic to nonbasic nitrogen below $500 \mathrm{C}$ and basic nitrogen appears to be less stable than nonbasic nitrogen at ali temperatures. This is a surprising result when the simplistic view is taken that basic nitrogen is primarily pyridine and quinoline-type compounds, which are relatively stable, and nonbasic nitrogen is pyrrole and similar compounds which are generally thought to be less stable. These assumptions are apparently not correct and this is an area where more research is needed.

Figure 33 indicates that nitrogen distribution remains approximately constant as the level of stoichiometric oxygen is increased.

Unsubstituted Aromatics. The data indicate that the liquid product evolves during pyrolysis until it consists primarily of unsubstituted aromatics such as benzene, naphthalene, phenanthrene, and pyrene and phenolics. of course, aromatization is not the only mechanism occurring since liquid products with both higher and lower molecular weights than the starting 


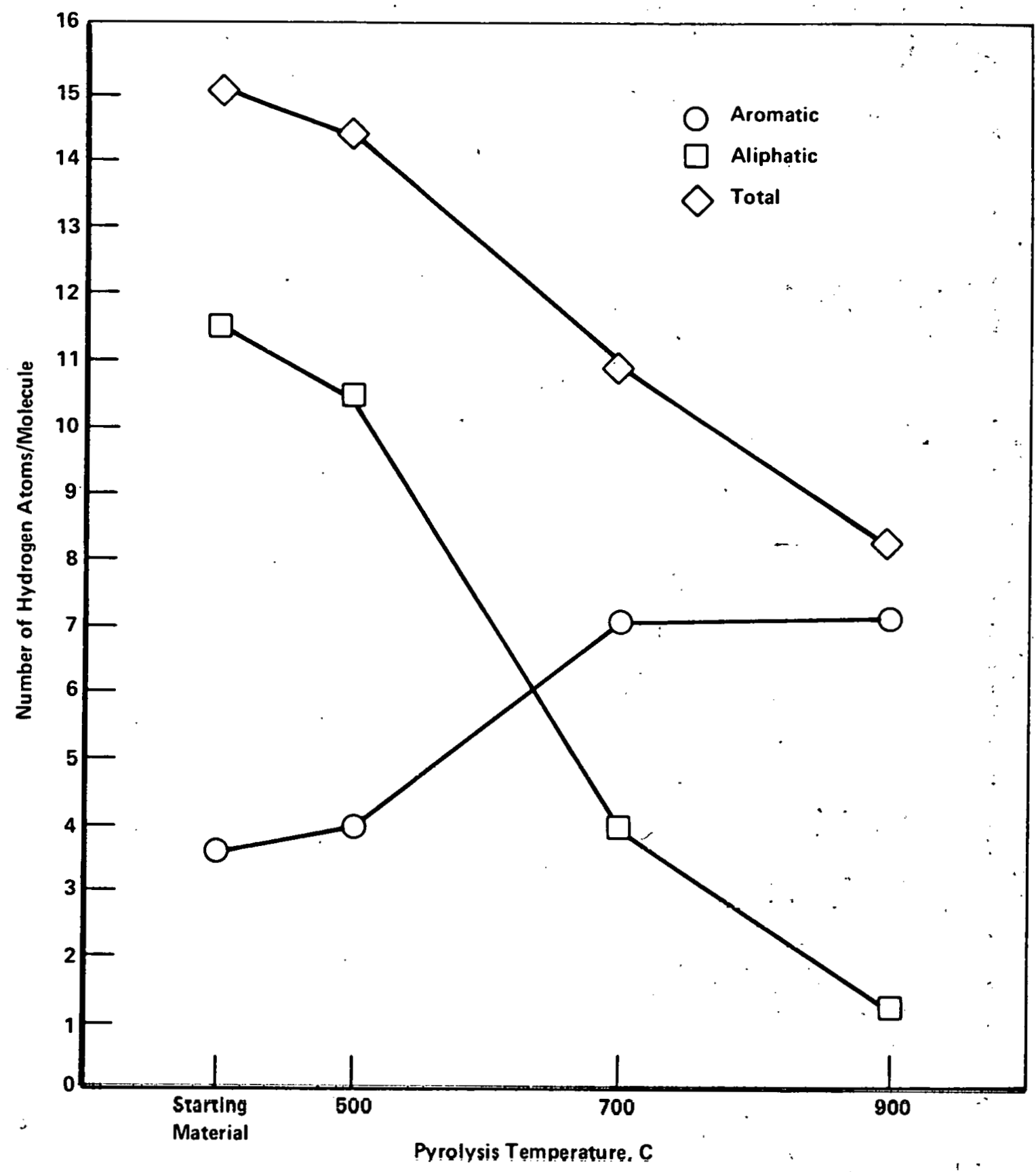

FIGURE 28. HYDROGEN DISTRIBUTION VERSUS PYROLYSIS TEMPERATURE.. .. 


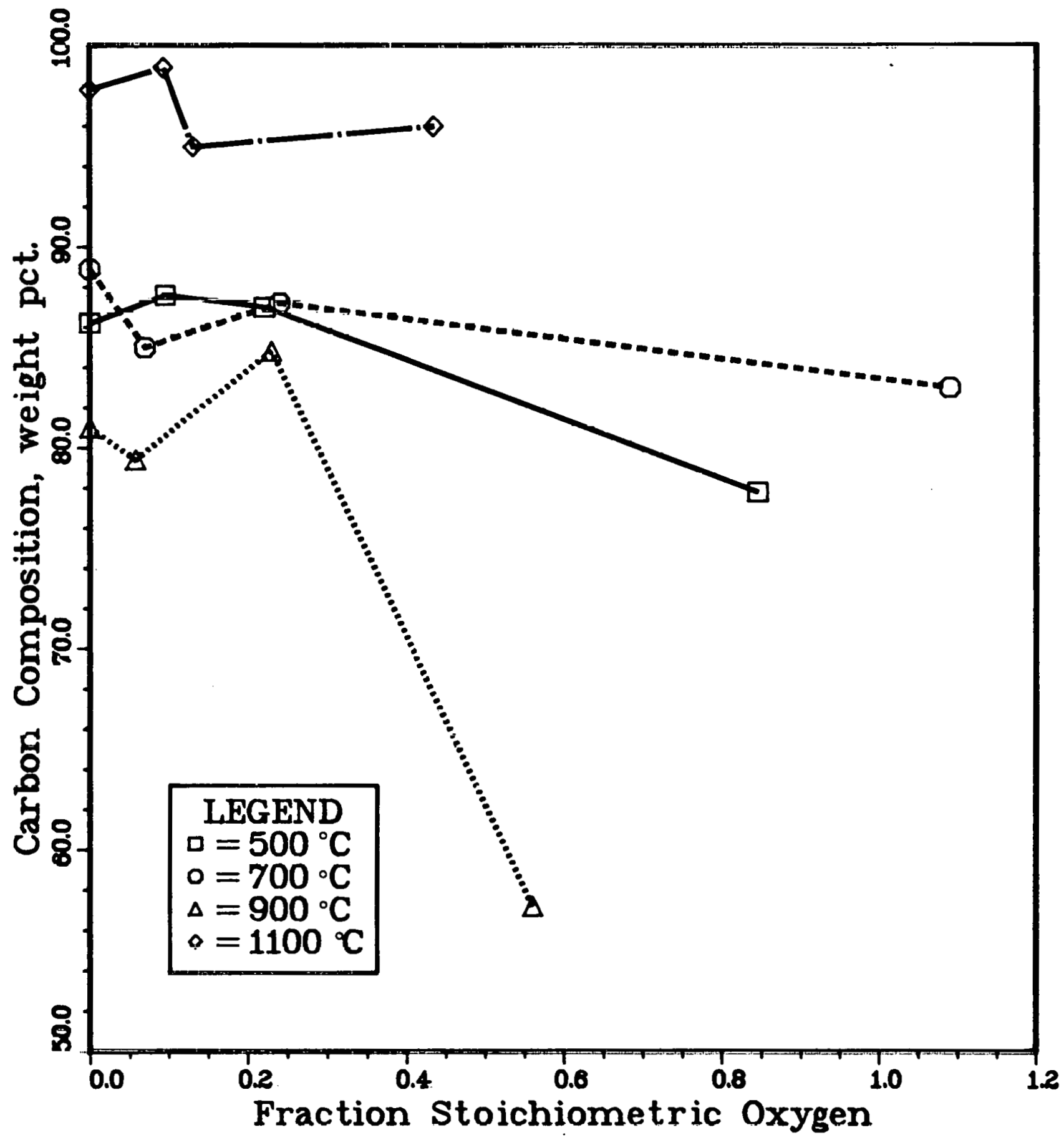

FIGURE 29. CARBON COMPOSITION VERSUS FRACTION OF STOICHIOMETRIC OXYGEN 


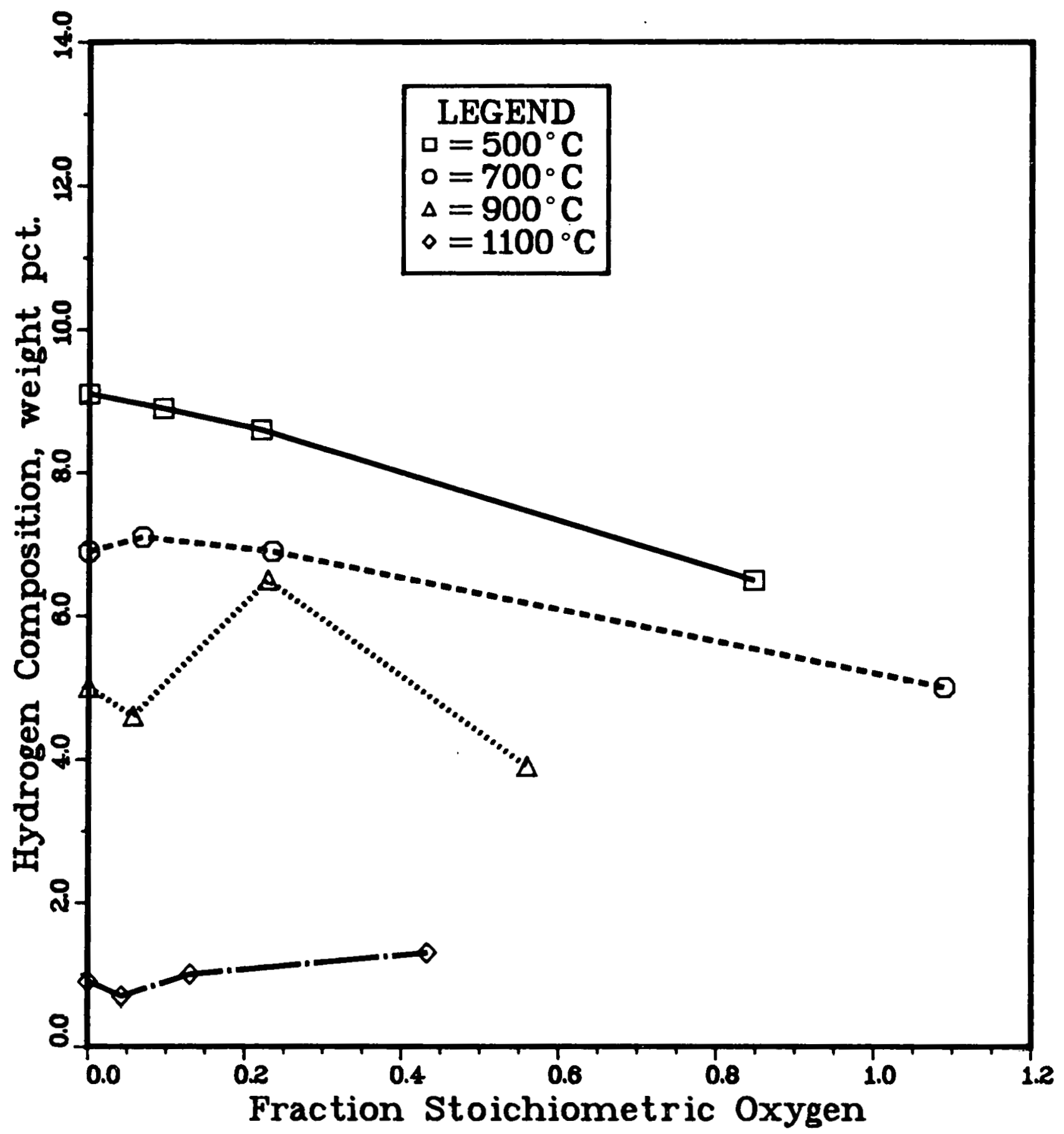

FIGURE 30. HYDROGEN COMPOSITION VERSUS FRACTION OF STOICHIOMETRIC OXYGEN 


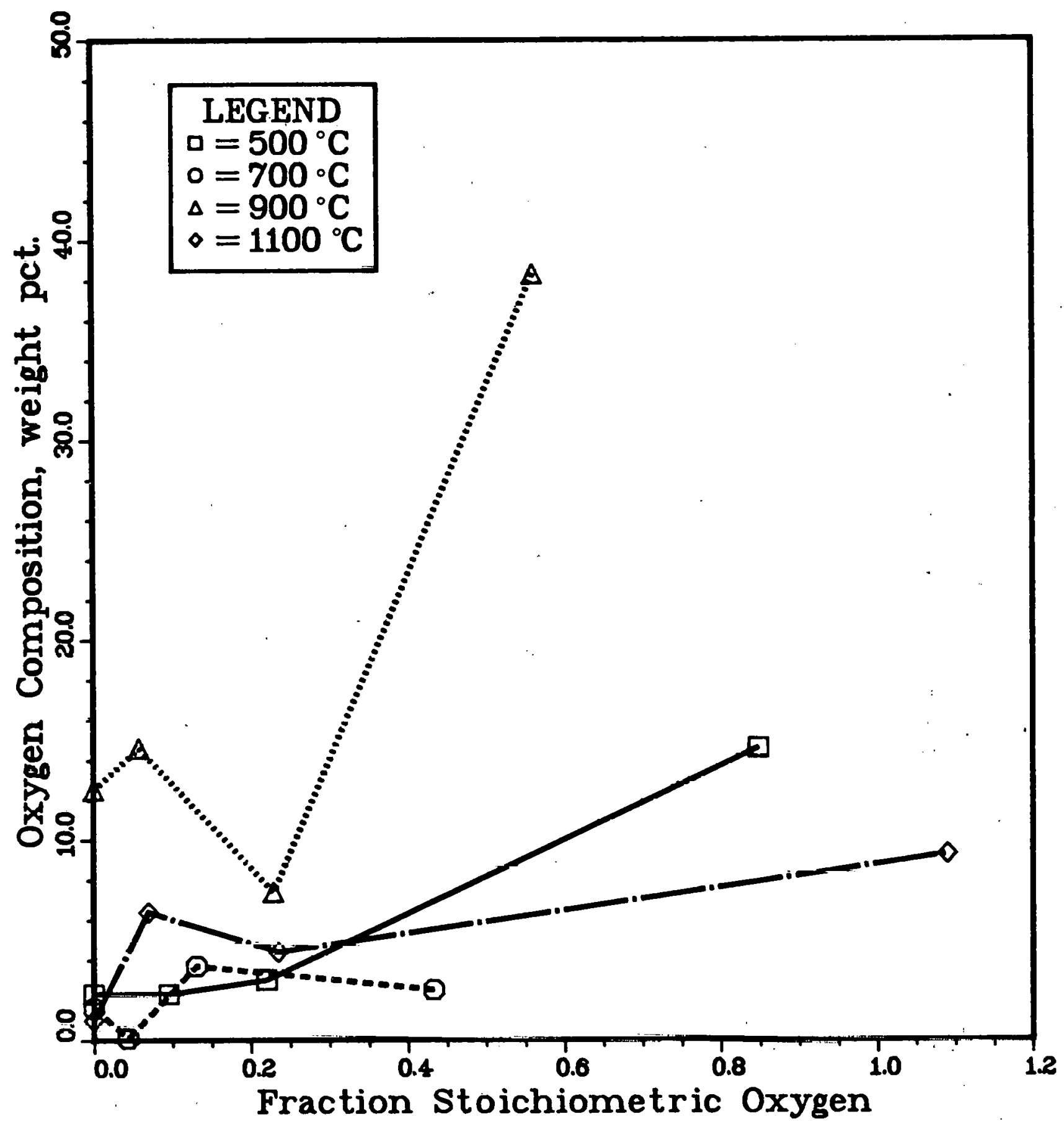

FIGURE 31. HYDROGEN COMPOSITION VERSUS FRACTION OF STOICHIOMETRIC OXYGEN 


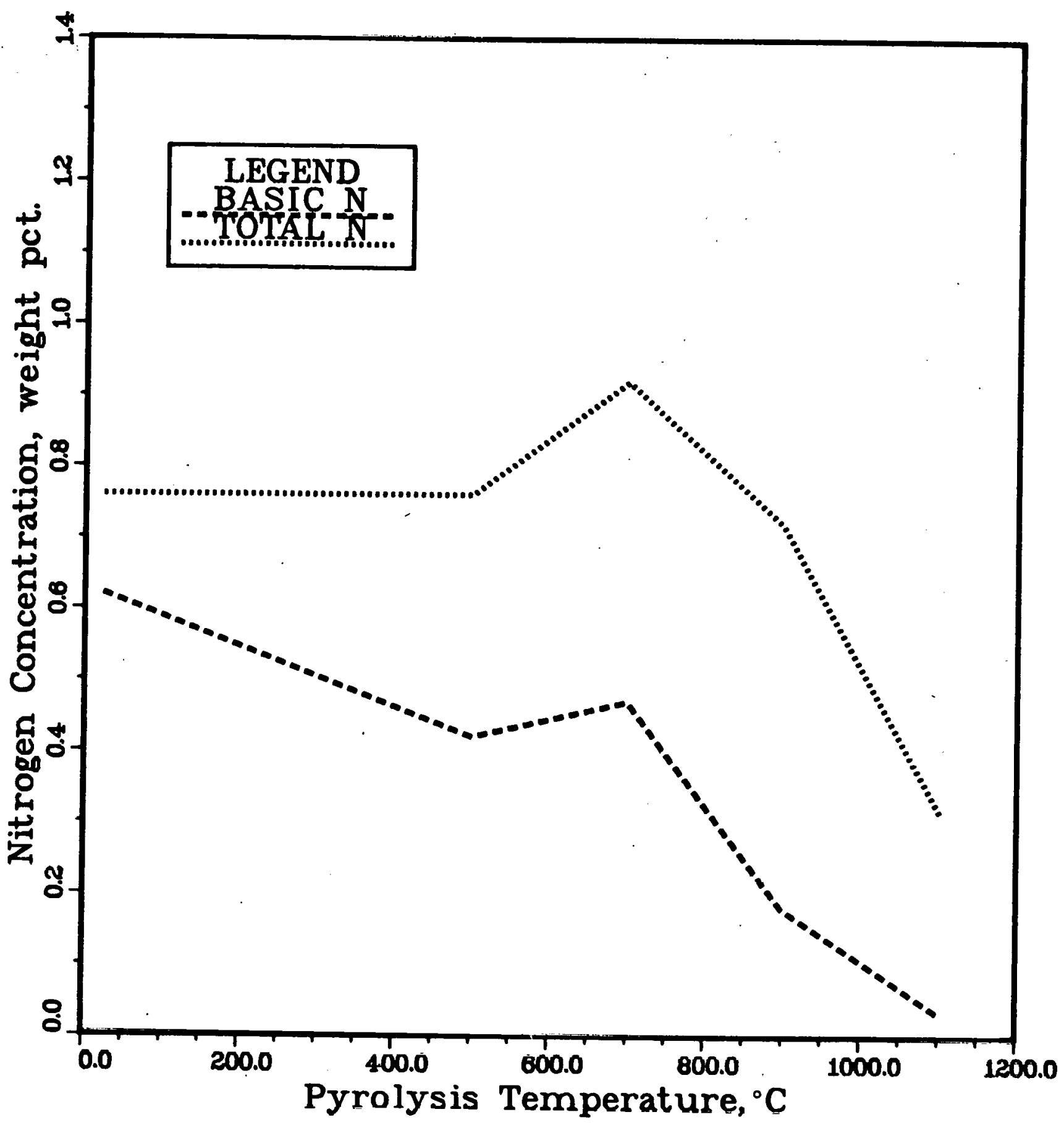

FIGURE 32. NITROGEN DISTRIBUTION VERSUS

PYROLYSIS TEMPERATURE 


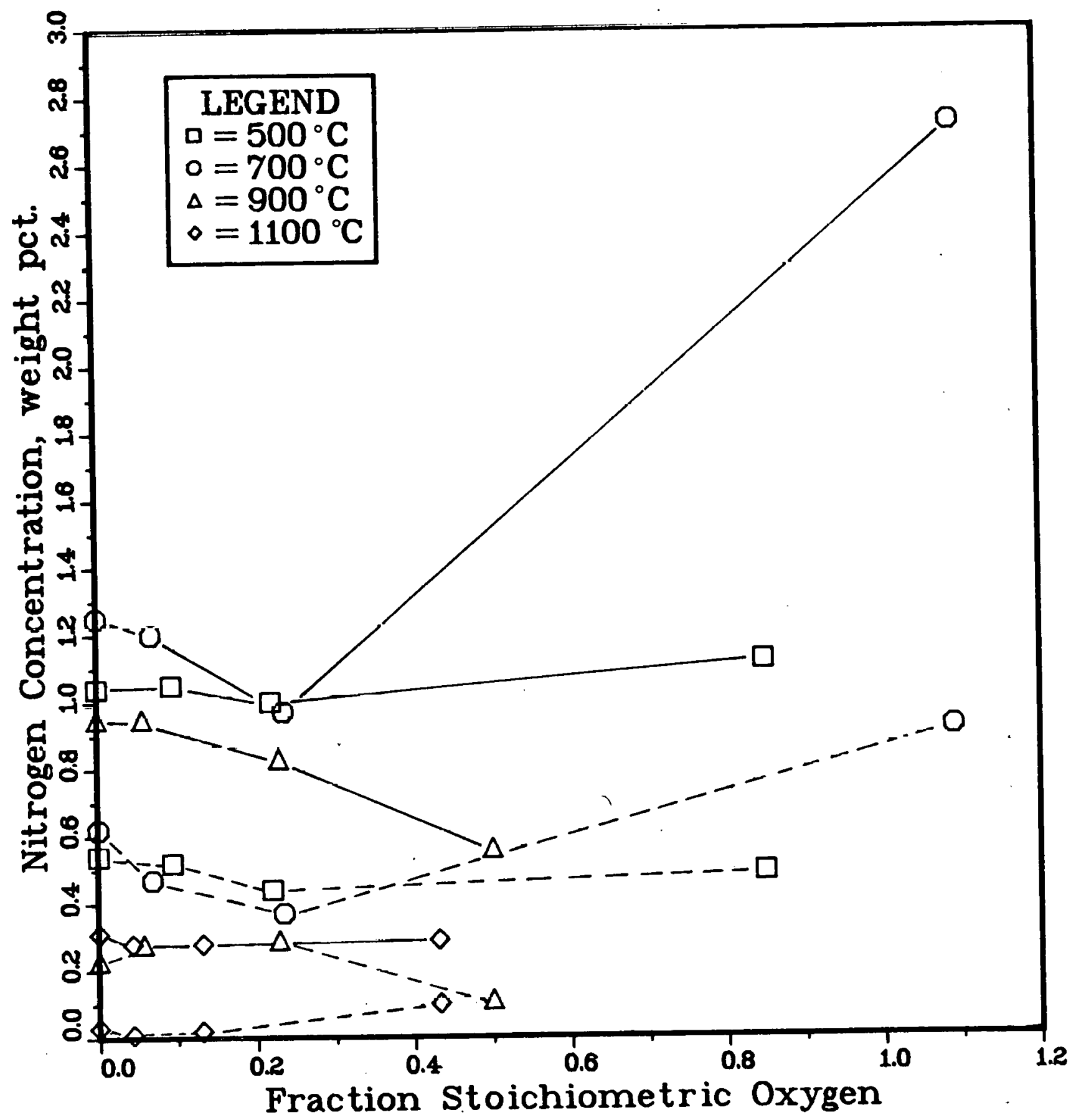

FIGURE 33. NITROGEN DISTRIBUTION VERSUS FRACTION OF STOICHIOMETRIC OXYGEN 
liquids, as well as gases and carbon, are formed. However, substantial amounts of the unsubstituted aromatics are formed. At $900 \mathrm{C}$, more than 50 percent of each liquid product is unsubstituted aromatics. The amounts of one, two, and three ring molecules (i.e., benzene, naphthalene, and phenanthrene) vary with the molecular weight of the starting material. For example, the liquid product of MD-3 at $900 \mathrm{C}$ is more than 50 percent benzene while naphthalene is more than 30 percent of the liquid product from MD-4 at $900 \mathrm{C}$.

Figure 34 shows the concentrations of unsubstituted aromatics in the recovered liquid as a function of pyrolysis temperature. The concentration of each unsubstituted aromatic ring compound increased from 700 to $900 \mathrm{C}$. At $1100 \mathrm{C}$ no liquid products were obtained. Apparently these unsubstituted aromatics are graphitic, are more stable than substituted aromatics, and are carbon precursors and, therefore, probably soot precursors in the combustion of coal-derived synthetic liquid fuels.

Figure 35 shows the amounts of unsubstituted aromatics in the liquid products versus fraction of stoichiometric oxygen present. At the highest levels of stoichiometric oxygen, the amounts of unsubstituted aromatics decreased, apparently due to the formation of molecules with oxygen substituted on the aromatic rings.

\section{Tasks 2 and 3 Conclusions}

Conclusions from Tasks 2 and 3 can be summarized as follows:

- The reactions of the distillation fractions of varying molecular weight under the pyrolysis and oxidative-pyrolysis conditions studied are similar.

- The principal reaction due to temperature alone is aromatization of the hydroaromatics which decreases the number and length of aliphatic side chains on aromatic rings.

- Unsubstituted aromatics are a principal intermediate in the pyrolysis of coal-derived synthetic liquid fuels.

- Nonbasic nitrogen is more stable than basle niliogen. Total nitrogen content of the partially pyrolyzed and oxidized fuel increases up to $700 \mathrm{C}$ and then decreases from 700 to $1100 \mathrm{C}$. 


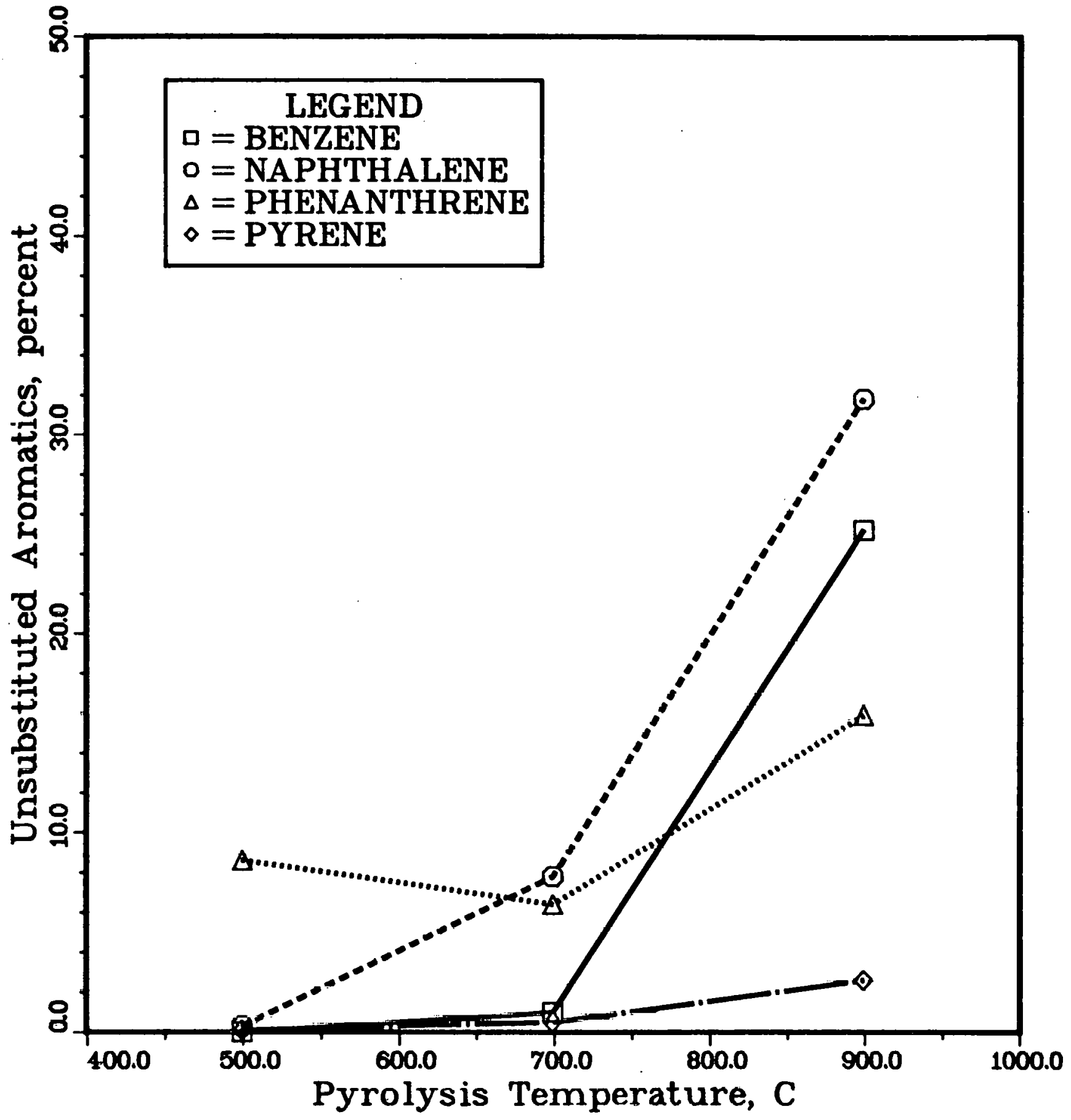

FIGURE 34. PERCENT OF UNSUBSTITUTED AROMATICS VERSUS PYROLYSIS TEMPERATURB 


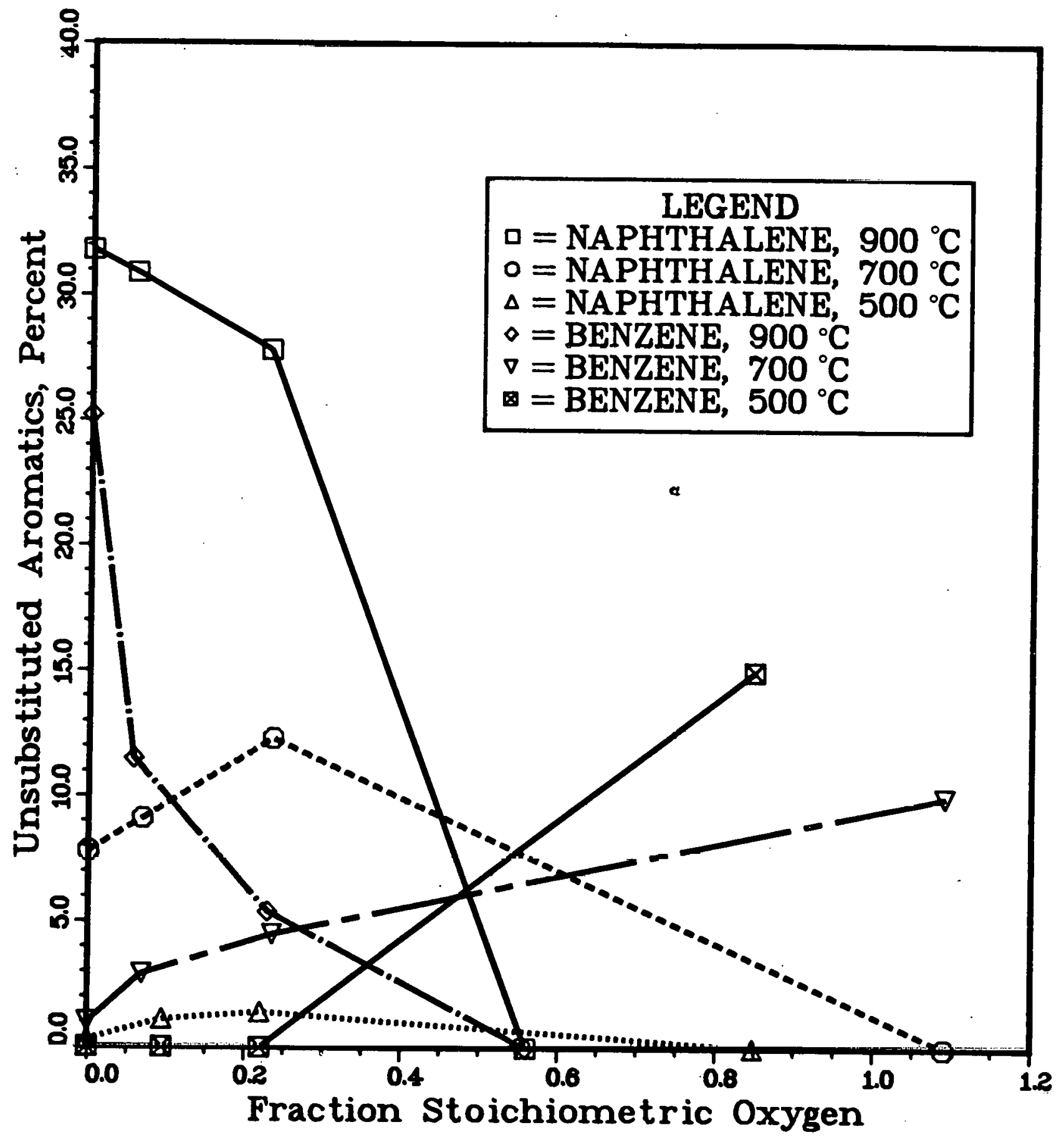

FIGURE 35. CONCENTRATION OF UNSUBSTITUTED AROMATICS IN THE LIQUID PRODUCT VERSUS FRACTION OF STOICHIOMETRIC OXYGEN 
- Carbon and hydrogen contents decline as oxidation increases oxygen content. Aromaticity remains nearly constant. The destruction of unsubstituted aromatics is increased by oxidation, presumably by the formation of oxygen substituted aromatics.

- The nitrogen content and basic/nonbasic distribution are nearly unchanged in the presence of increasing amounts of oxygen.

- The most likely survivors of fuel-rich, first-stage pyrolysis are unsubstituted and oxygen substituted aromatics and nonbasic nitrogen compounds. These are the precursors to soot and $\mathrm{NO}_{\mathbf{x}}$ formation during oxygen-rich, second-stage combustion.

\section{Application of Results to Staged Combustion}

The conditions used in the Tasks 2 and 3 studies were designed to allow the collection of significant amounts of partially pyrolyzed and oxidized fuel for chemical analyses. Nevertheless, they can be related to the fuel-rich stage of staged combustion and the results can be used in the selection of conditions and experiments needed to study $\mathrm{NO}_{x}$ and soot formation under actual staged combustion in Task 4.

The heatup rate used in these studies is some 10-100 times slower than typical combustion heatup rates. The maximum temperature was within $100 \mathrm{C}$ of the maximum temperature expected in fuel-rich combustion (1200 C) and the maximum levels of oxygen used were similar to those expected in fuel-rich combustion $(\phi=1.0-1.4)$. Residence times were much longer than those expected in first-stage combustion ( $1 \mathrm{sec}$ ). The types of reactions which have been observed with increasing temperature and oxygen concentration are summarized in Figure 36.

Based on the results from Tasks 2 and 3, the following are suggested to achieve less soot and $\mathrm{NO}_{\mathrm{x}}$ formation during staged combustion.

- Preheat in the presence of oxygen to suppress the conversion of unstable basic $\mathrm{N}$ to stable nonbasic $\mathrm{N}$, which is more likely to survive to oxidizing conditions where $\mathrm{NO}_{x}$ can be formed.

- Operate at low temperatures where aromatization to unsubstituted aromatics, which are presumed to be soot precursors, is slower.

- Operate at higher oxygen concentrations where the destruction of unsubstituted aromatics by oxidation predominates. 


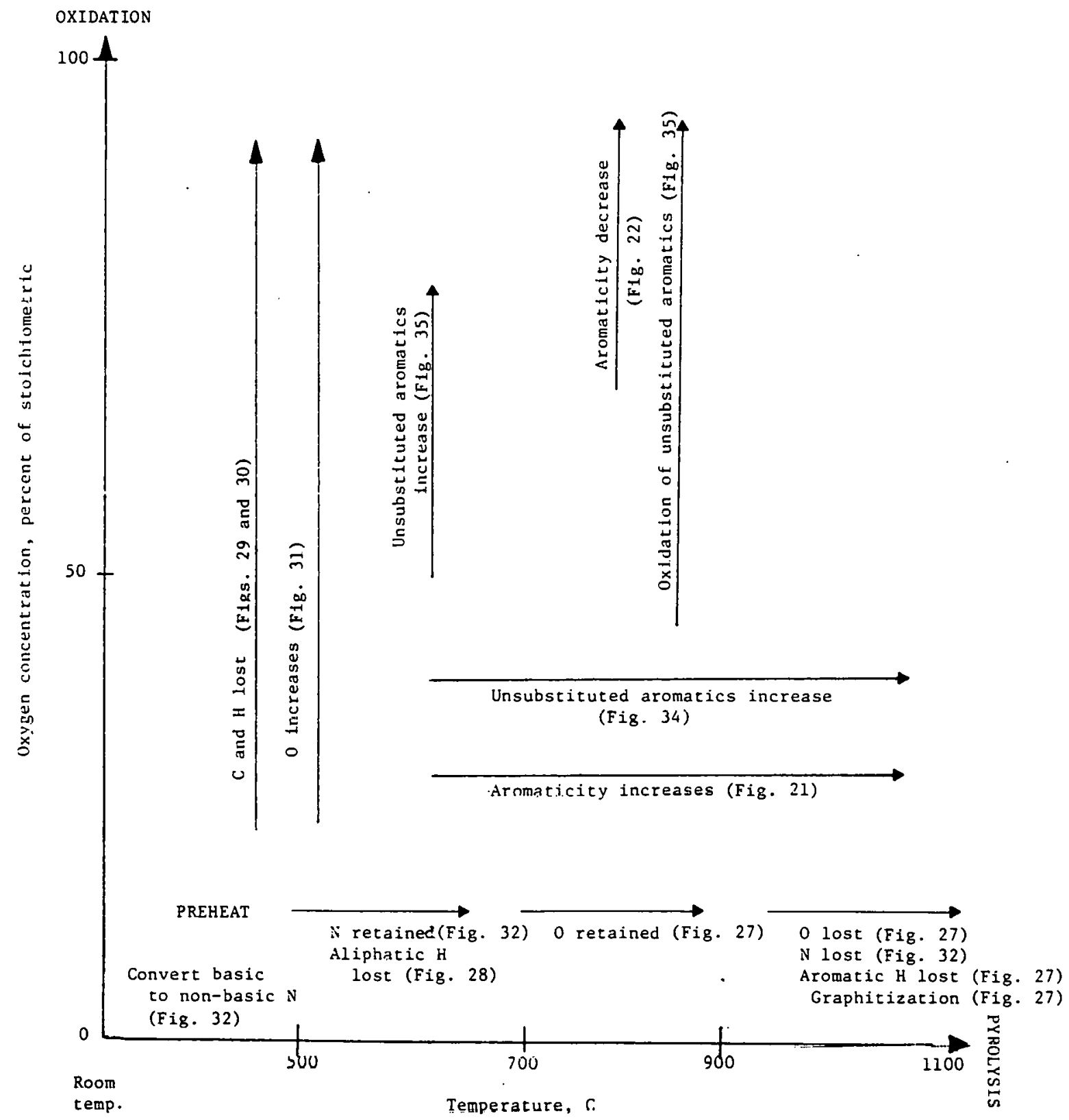

FIGURE 36. CHEMISTRY OF UNBURNED COAL DERIVED LIQUID 
- Add oxygen at low temperatures to react with aliphatic hydrogen before it is lost in subsequent pyrolysis. This loss of hydrogen negates the value of a high $\mathrm{H} / \mathrm{C}$ ratio in the starting fuel. Early addition of oxygen could make the partially pyrolyzed and oxidized fuel more reactive and less likely to soot.

Task 4 - Staged Combustion Studies

Objective

The objective of this task was to exaluine the burning charaoteristics of SRC II as a function of residence time, temperature, and equivalence ratio in a two-stage combustion process, and to establish uptimum combustion conditions for minimizing the production of soot and $\mathrm{NO}_{\mathrm{X}}$.

\section{Staged Combustion Apparatus}

Battelle's small laboratory scale furnace was used for this study. The combustor is a modification of the Babcock and Wilcox Laboratory Ashing Furnace (23) and is designed to fire both solid and liquid fuels. A schematic of the staged combustor is shown in Figure 37.

The combustor consists of an inner combustion chamber separaled by a silicon carbide lining from a surrounding annular burner. The annular burner helps to maintain a constant temperature for the inner furnace. Combustion products from a natural gas flame fired into the bottom of the annular combust.or pass through the gap and exit at the top of the furnace. The annular furnace is designed for a maximum firing rate of $300,000 \mathrm{Btu} / \mathrm{hr}$. It is lined with Cerachrome insulation to minimize heat loss.

The inner combustion chamber has a diameter of $4 \mathrm{in.}$ and a length of 52 in. Coal and fuel oil can be fired at maximum rates of $4 \mathrm{lb} / \mathrm{hr}$ or 0.5 gal/hr $(\sim 50,000 \mathrm{Btu} / \mathrm{hr})$. Residence time for the first stage of the combustor can be from 0.5 to $1.5 \mathrm{sec}$ and from 1 to over $2 \mathrm{sec}$, depending on load, for the overall combustor. The combustor is equipped with a sighting port. Air for the second stage is introduced by means of an inconel tube bent in the 


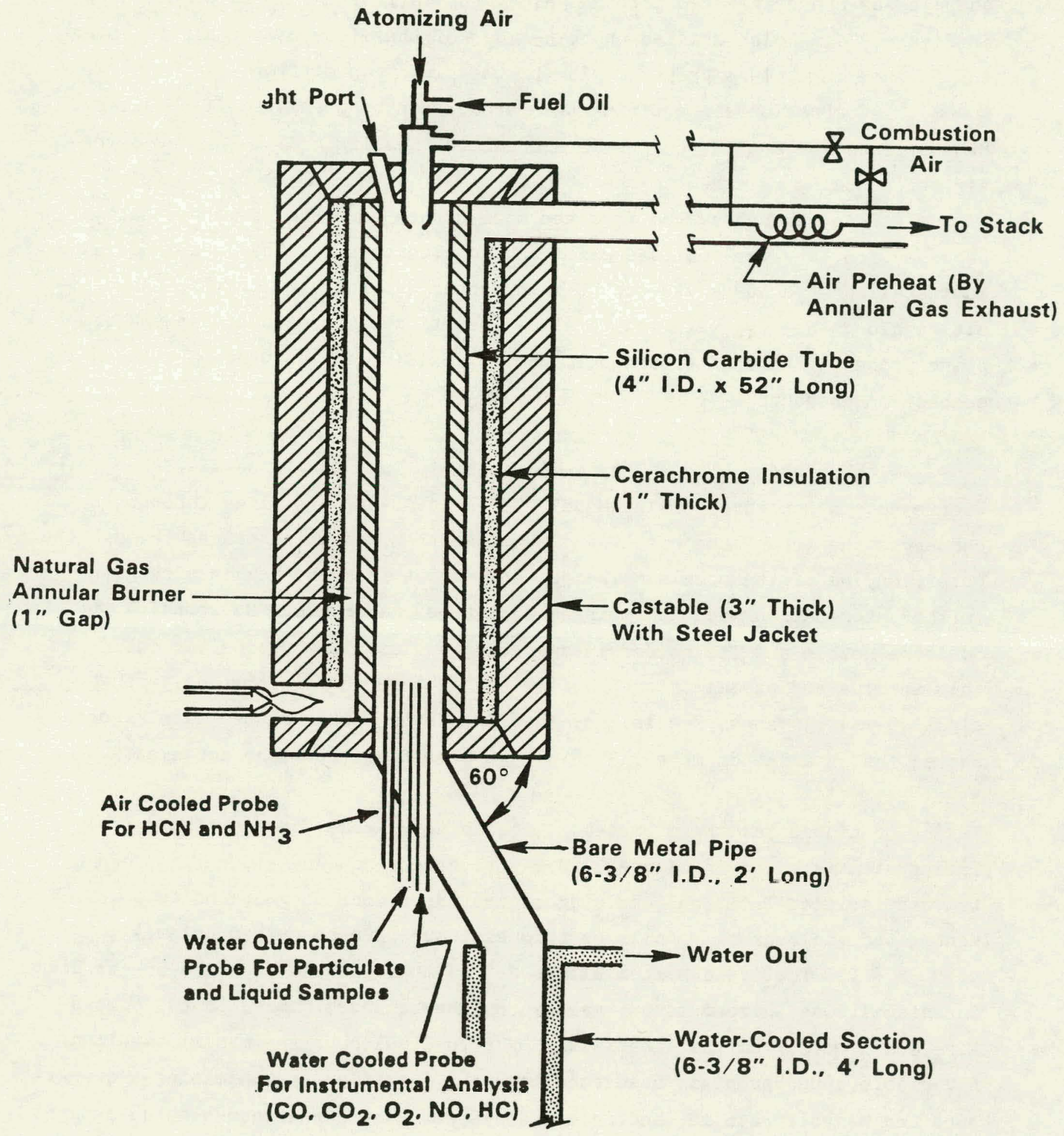

FIGURE 37.SCHEMATIC OF THE TWO-STAGE COMBUSTOR 
shape of an $L$ and inserted into and along the wall of the furnace (not shown in Figure 37). Holes drilled on both sides of the elbow enable air to enter the furnace in a plane perpendicular to the direction of flow.

Combustion air entering the furnace can be preheated if necessary. Exhaust from the annular burner is used as the heating medium for the swirl air before being released to the stack.

The exhaust system from the main burner consists of a bare metal pipe section, a water-cooled section and an afterburner. The bare metal pipe is installed at a 600 angle to the main burner in order to minimize ash deposition along the tube wall and to allow insertion of the staged air and sampling probe(s). The afterburner is used to oxidize any unburned SRC II in the combustion products.

Nozzle Assembly. The nozzle assembly is shown in detail in Figure 38. A Sonicore nozzle, Model 052H-A is used. Air flows through the center to the top of the nozzle and atomizes the fuel which passes through the outer annulus of the nozzle. The jet coming out from the nozzle undergoes further atomization when it impinges on the resonator cup. Surrounding the Sonicore nozzle and its holder is an outer annulus. Combustion air enters this annulus and passes through a flow straightener before exiting through eight $45^{\circ}$ swirl vanes. Preliminary testing of the nozzle system with kerosene showed that a 2 in. diameter, 3 in. long, blue flame could be achieved.

\section{Liquid Fuel Feed System. The piping diagram for the liquid fuel}

feed system is given in Figure 39. Due to safety concerns, the fuel feed system was isolated from the remaining apparatus by confining it inside a well ventilated enclosure. Details of this enclosure are described below.

The fuel feed system allows SRC II to be pumped from the 55-gal drum in which it was shipped to a 5-gal can on the balance, pumped to the combustor, and rinsed from the lines with No. 2 fuel, without any manual handling. A variable speed pump was used to smooth the fuel flow by minimizing the pressure and recycle rate in the fuel feed system. The burner can also be brought to temperature by burning No. 2 fuel oil. The feed line, up to within 6 in. of the burner nozzle, can then be filled with SRC II before burning so that 


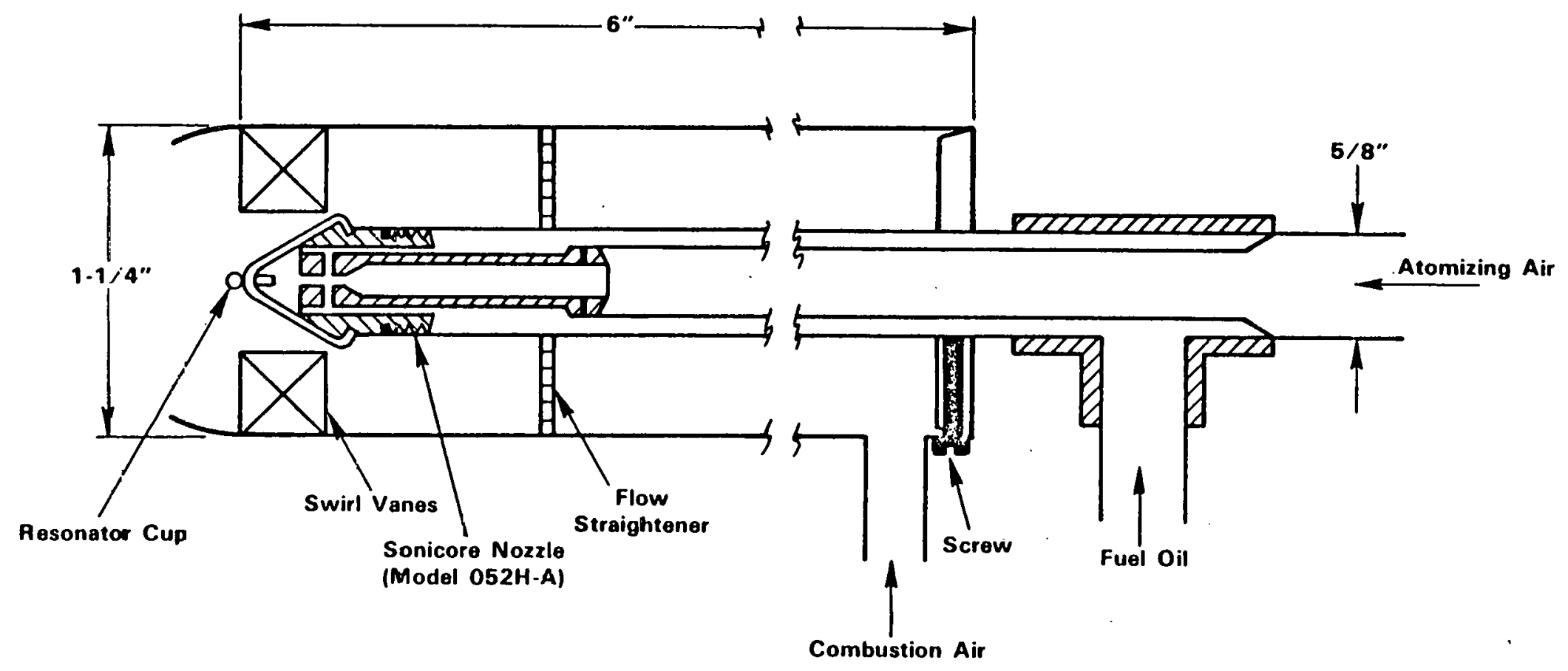

FIGURE 38. NOZZLE ASSEMBLY 


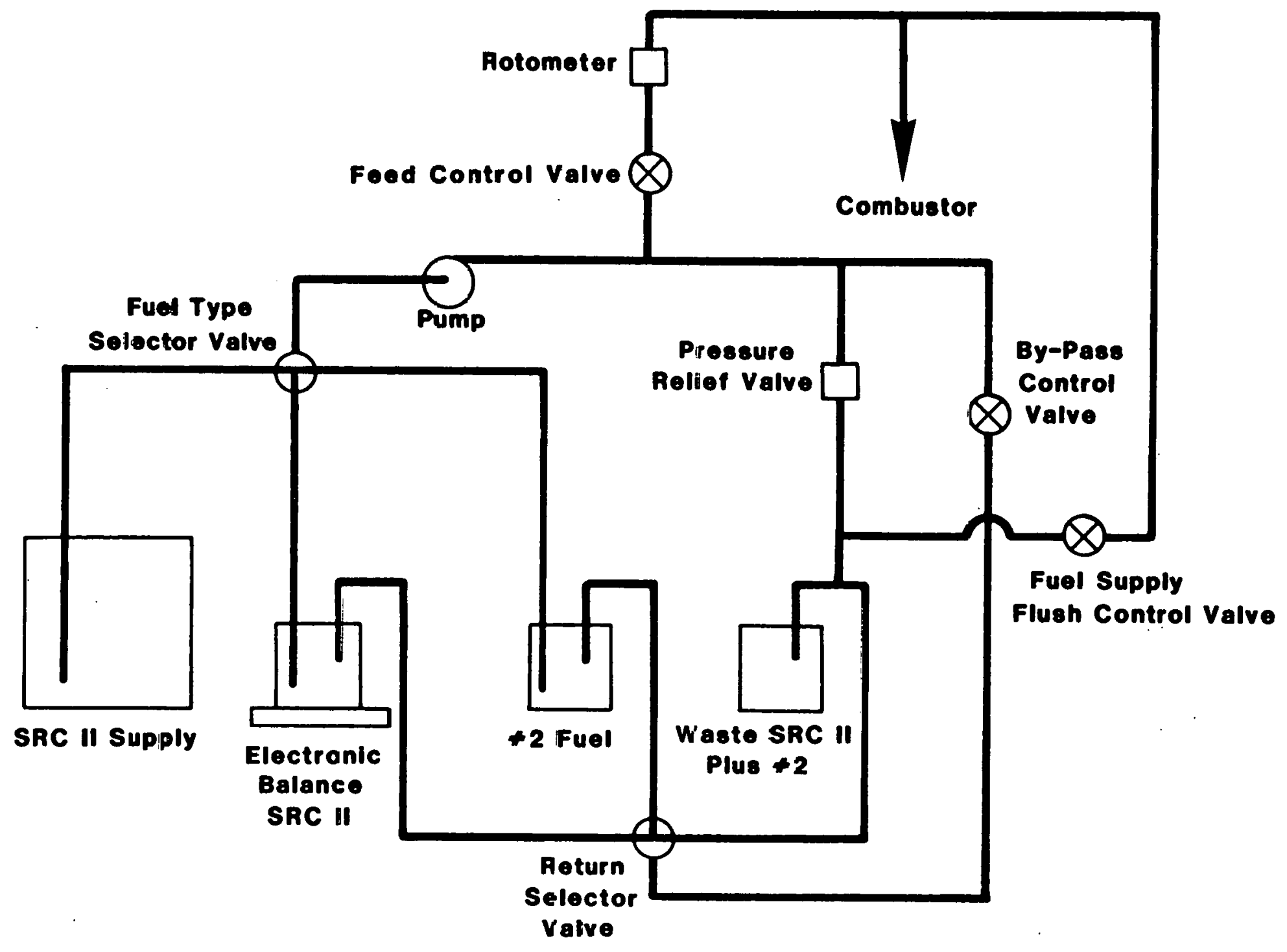

FIGURE 39. FUEL FEED SYSTEM 
fuel changeover can be accomplished quickly. All of the experiments were completed without exposure of operating personnel to fumes or liquid spills.

A rotameter was calibrated for each fuel and used to measure the fuel feed rate. An electronic balance, capable of measuring \pm 5 grams, was used to measure cumulative fuel feed and to obtain average fuel feed rates. Three orifice plates regulated the flows of atomizing air, firststage combustion air and second-stage combustion air. One of the orifice plates was calibrated using a wet test meter. The calibration agreed satisfactorily with the air flow calculated on the basis of the pressure drop across the orifice plate.

Ventilated Enclosure. The two-stage combustor is located in a laboratory which is open to various other working areas. For this reason, a ventilated enclosure was built to store fuel and any contaminated waste, and also to isolate the pumping system from the rest of the combustion apparatus. Contaminated solid waste such as paper towels, gloves and clothing, and liquid waste solvent were disposed of in separate 5-gal sealable metal drums before storing in this enclosure. Any maintenance on the pump assembly was confined within this area. A negative pressure was maintained in this enclosure at all times, and controlling and metering equipment were mounted on one of the walls outside the enclosure.

Probe Design, Sampling and Analysis

Three types of samples were taken using three separate probes. They were (1) sulid and liquid samples, (2) $\mathrm{HCN}$ and $\mathrm{NH}_{3}$, and (3) combustion gases ( $\mathrm{CO}, \mathrm{CO}_{2}$, and $\mathrm{O}_{2}$ ) and product gases ( $\mathrm{NO}$ and unburned gaseous hydrocarbons). The probe design, sampling train and analytical method for each are discussed in detail below.

Solid and Liquid Product Probe and Sampling System. A water-quench probe was used to collect particulate and liquid samples (Figure 40). A stream of water flowed down the interior of a water-cooled probe. The quench water flow rate was controlled by varying the back pressure on the cooling water. The solid samples were collected on a $47 \mathrm{~mm}$ diameter Millipore filter. 


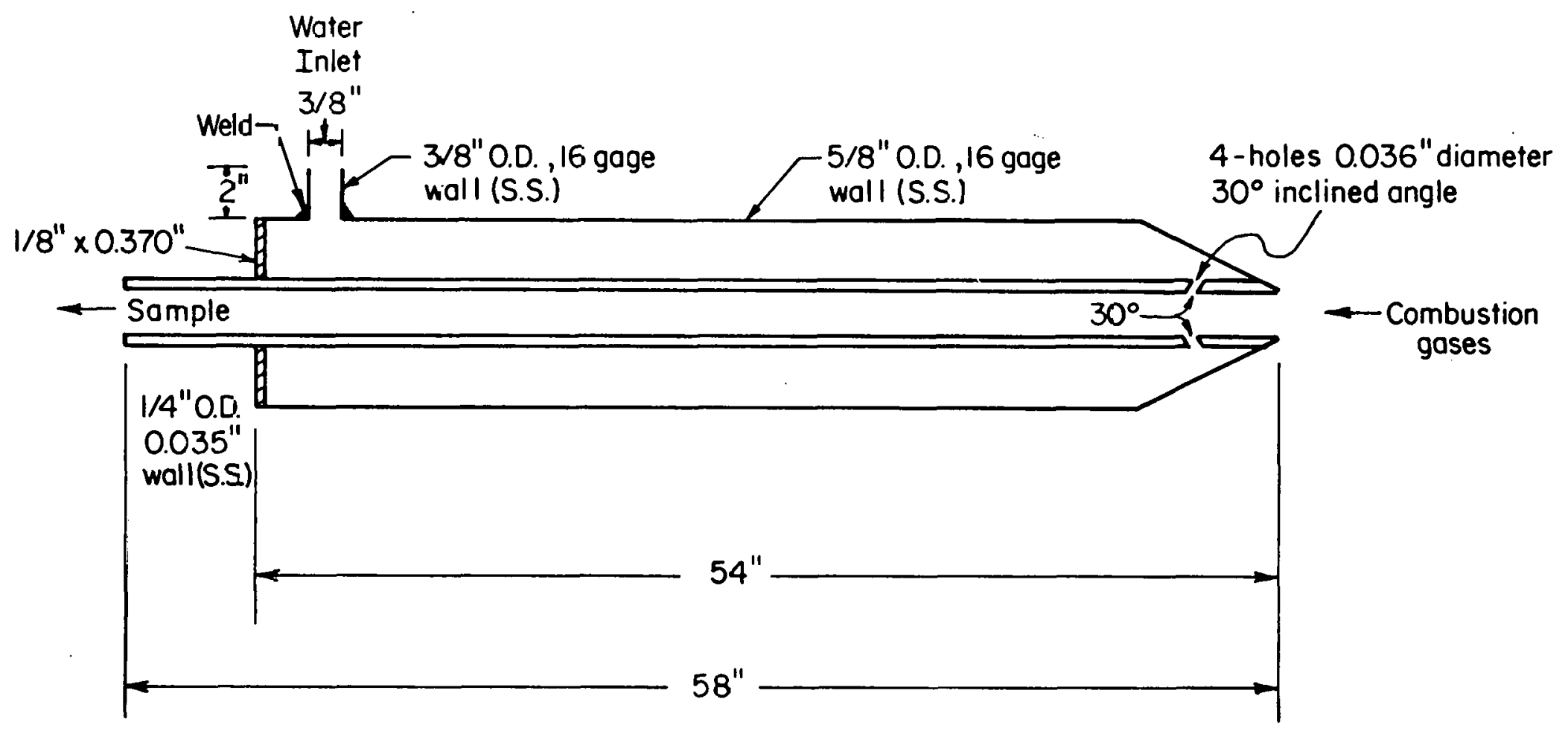

FIGURE 40. HATER QUENCHED PROBE FOR PARTICULATE SAMFLING 
A $5 \mu \mathrm{m}$ pore size was used so that water would pass through readily. The filtered quench water was then collected in a large glass vessel and saved for extraction of organic liquids. The rest of the sampling system consisted of ice/water traps, a Drierite filter, a vacuum pump to control the gas flow rate, a carbon filter and a gas meter to measure the amount of gas which passed through the system (Figure 41).

The particulate samples were extracted with methylene chloride to remove soluble organics, dried and analyzed for carbon, hydrogen and nitrogen using a microcombustion analyzer. The typical weight of solid collected was 10-20 $\mathrm{mg}$ in 30-60 minutes. The quench water was extracted with methylene chloride and the extract was analyzed by gas chromatography to obtain boiling point distribution, nitrogen distribution, and molecular weight. Only a few milligrams of liquid samples were collected.

It has been suggested that the quench water used in the particulate sampling probe can be used to analyze for $\mathrm{HCN}$ and $\mathrm{NH}_{3}$ using specific ion electrode techniques. Comparison of the results of analyses for both $\mathrm{HCN}$ and $\mathrm{NH}_{3}$ from the quench water and the $\mathrm{HCN} / \mathrm{NH}_{3}$ probe sampling system described later indicated that this does not appear to be a good method. The $\mathrm{pH}$ of the quench water was 5.4 (both before and after passing through the system). Under these conditions the quench water was shown to contain much less cyanide per volume of gas passed through the probe and as much or more ammonia than was obtained by the $\mathrm{HCN}-\mathrm{NH}_{3}$ probe and sampling system. Thus, a separate probe and sampling system were used for hydrogen cyanide and ammonia.

Hydrogen Cyanide and Ammonia Probe and Sampling System. The hydrogen cyanide-ammonia $\left(\mathrm{HCN}-\mathrm{NH}_{3}\right)$ probe was alr cooled to krep the gas temperature above the condensation temperature of water ( $>100 \mathrm{C}$ ) to avoid the loss of either cyanide or ammonia by absorption in liquid water before the impingers (Figure 42). The gas passed through a heated glass thimble filter and then was divided into three streams (Figure 43). One stream was vented through a vacuum pump, ice/water condenser and carbon filter. The purpose of this stream was to keep the gas flow through the probe high ennugh to avoid water condensation. The remaining gas flowed to the cyanide and ammonia impingers in parallel and then Drierite traps, vacuum pumps, which controlled the flow 


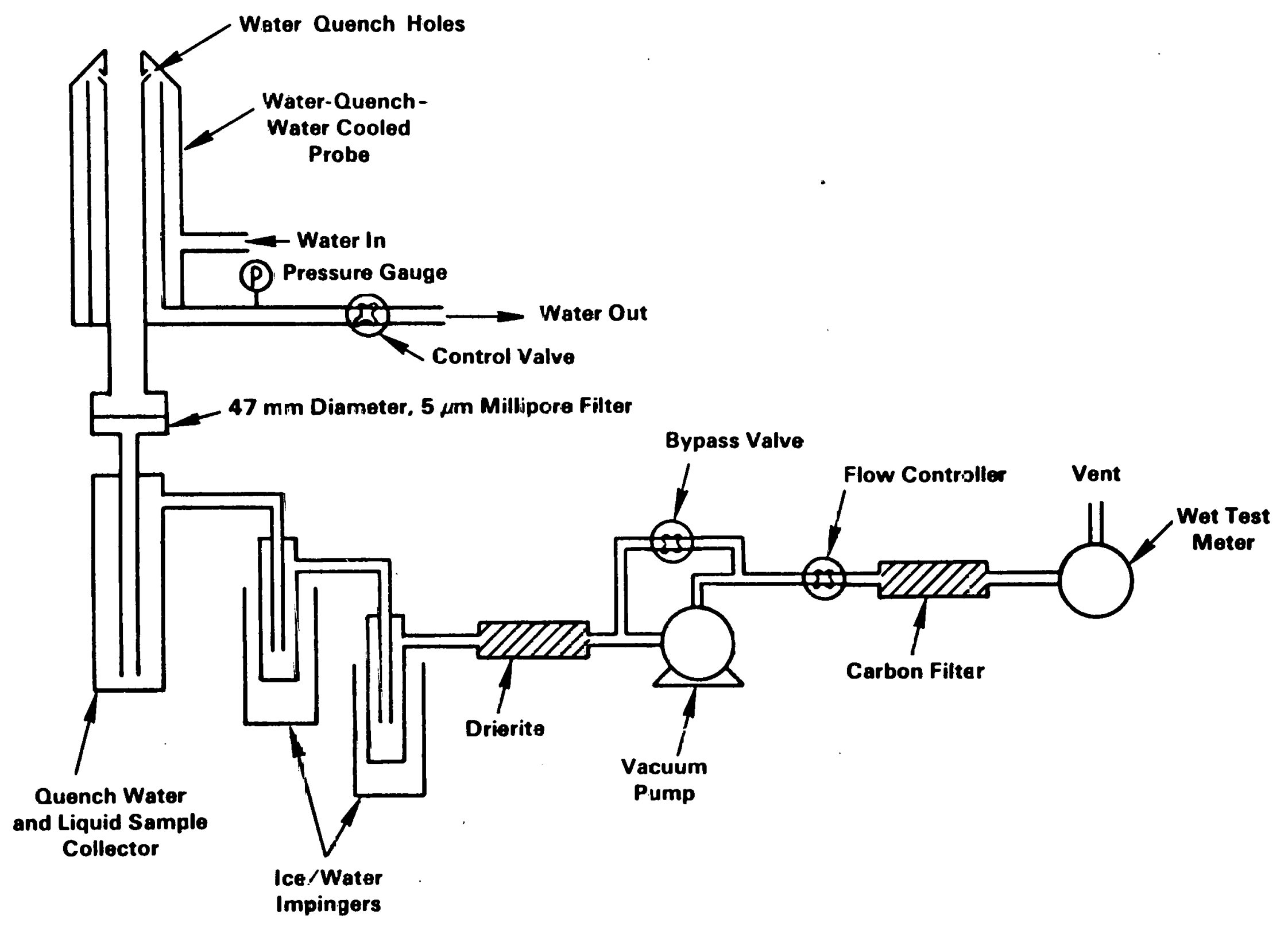




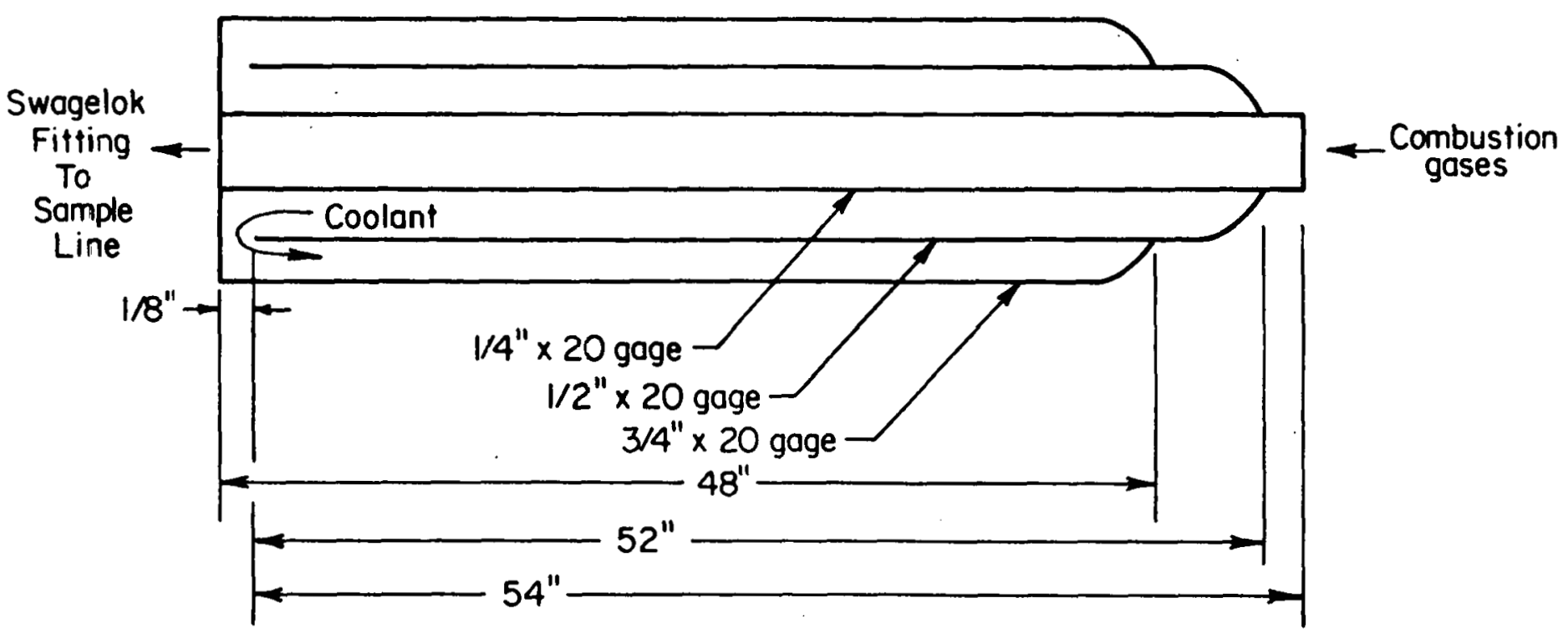

FIGURE 42. COOLED SHEATH PROBE FOR GAS SAMPLING 


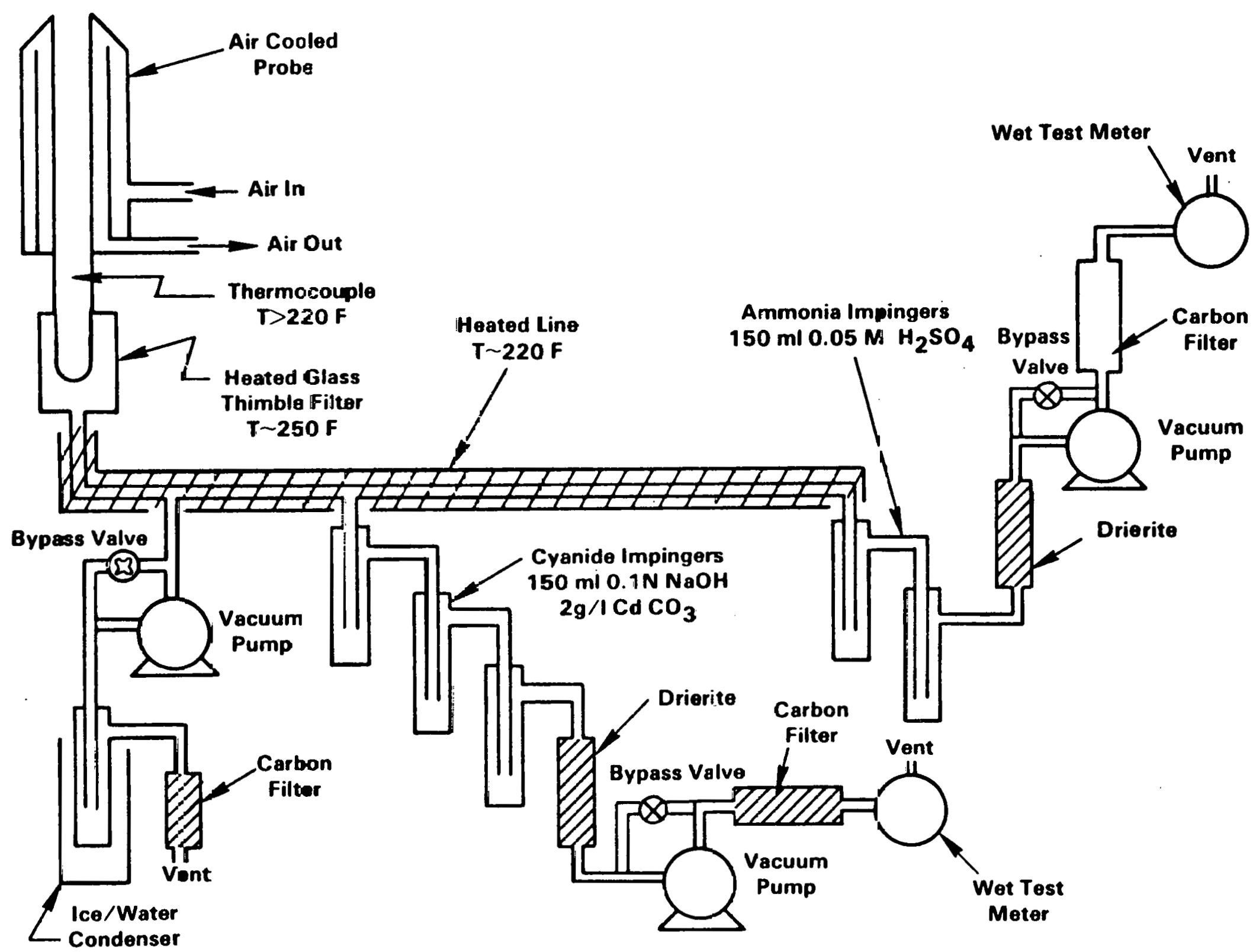


rates, carbon filters and gas meters, which measured the flow rates (Figure 43).

The three cyanide impingers connected in series were each filled with $150 \mathrm{ml}$ of $0.1 \mathrm{~N} \mathrm{NaOH}$ and $2 \mathrm{~g} /$ liter of $\mathrm{CdCO}_{3}$ (to remove $\mathrm{s}$ = which interferes with the measurement of cyanide ion concentration by the specific ion electrode method). Collection efficiency was not satisfactory. The concentration of cyanide collected in the second and third impingers was not very much lower than the concentration collected in the first impinger. Measured cyanide concentrations in the gas varied from 0 to $1000 \mathrm{ppm}$, depending on the combustion stoichiometry, and gas flows averaged $2.3 \mathrm{scfh}$ through the impingers. However, the collection efficiency appeared to be independent of both gas flow rate and cyanide concentration, probably due to the fact that $\mathrm{HCN}$ is a relatively weak acid and the acid-base reaction by which cyanide is collected is incomplete.

The two ammonia impingers connected in series were each filled with $150 \mathrm{ml}$ of $0.05 \mathrm{M} \mathrm{H}_{2} \mathrm{SO}_{4}$. The same gas flow rates were used. The ammonia collection efficiency was much higher. Of the total $\mathrm{NH}_{3}$ collected in the two impingers in series, 96.3 percent was collected in the first impinger. Ammonia concentrations measured in the combustion gas were much lower, ranging from 0-100 ppm.

The specific ion electrode measurements of $\mathrm{CN}$ and $\mathrm{NH}_{3}$ appeared to be satisfactory. Titration of carefully prepared standards showed accuracies within \pm 5 percent for both $\mathrm{NH}_{3}$ and $\mathrm{CN}$, although these were obtained immediately after reconditioning the electrodes, standardizing, etc.

Instrument Gas Probe and Analysis System. A third, water-cooled probe was used for sampling gases for instrumental analyses. The gases passed through a heated glass thimble and ice-water impingers before the flow was regulated for entry to the various analyzers (Figure 44). After analysis the gases were passed through separate carbon filters and vented. Separate instruments, listed in Table 20, were used to analyze for $\mathrm{CO}, \mathrm{CO}_{2}, \mathrm{O}_{2}$, NO, and volatile hydrocarbons. This equipment has been used routinely in previous studies and has been debugged. The results are recorded on a digital data logger along with system temperatures. 


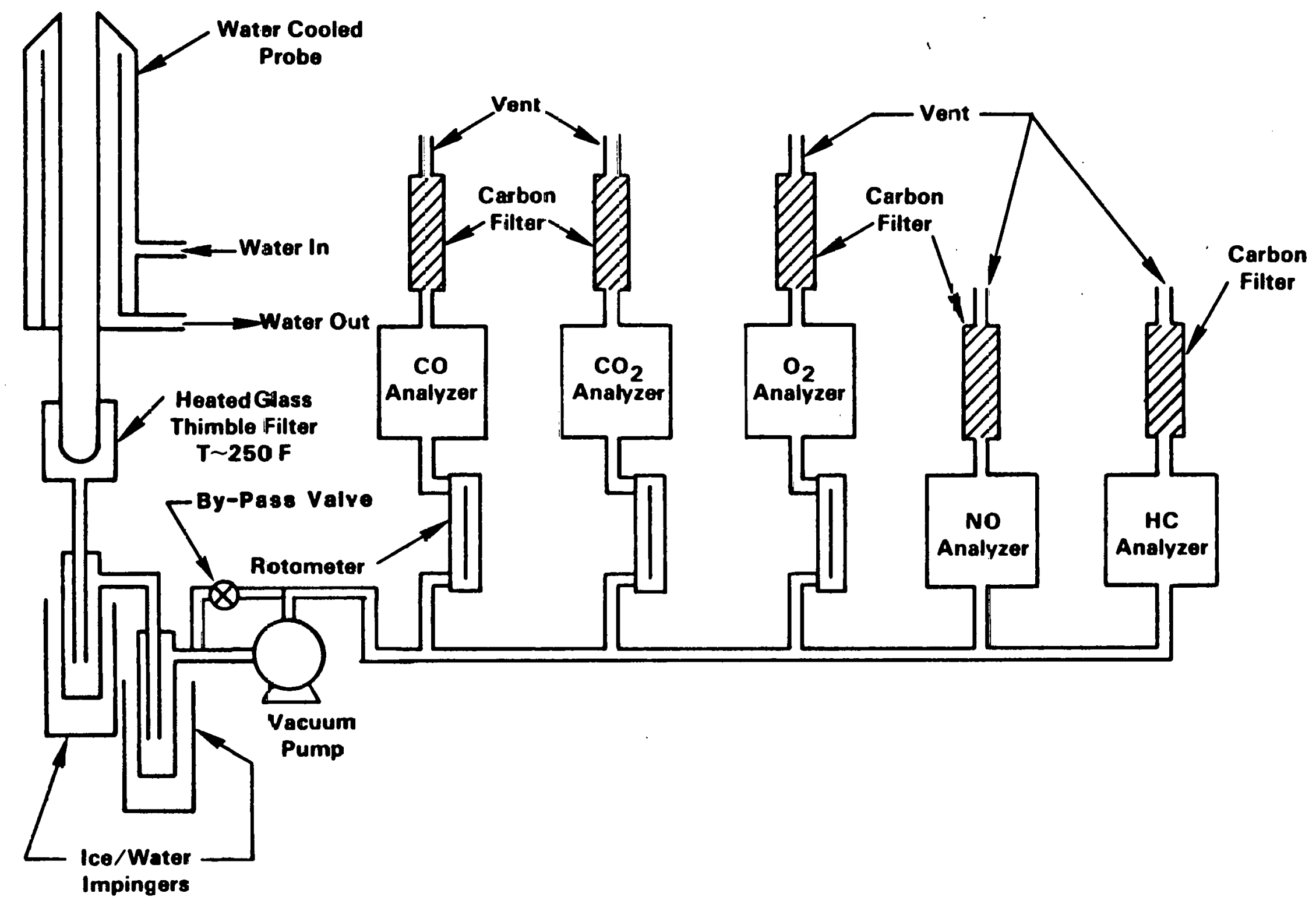

FIGURE 44. INSTRUMENT GAS PROBE AND ANALYSIS SYSTEM 
TABLE 20. CONTINUOUSLY MONITORED GASES

\begin{tabular}{ll}
\hline \hline Species & \multicolumn{1}{c}{ Method } \\
\hline & \\
$\mathrm{O}_{2}$ & Paramagnetic \\
$\mathrm{CO}_{2}$ & NDIR \\
$\mathrm{CO}$ & NDIR \\
$\mathrm{NO}$ & Chemiluminescence \\
$\mathrm{THC}$ & Flame Ionization \\
\hline
\end{tabular}

Process Monitoring. In addition, the following process parameters were continuously monitored:

Combustion chamber exit temperature

Annular exhaust temperature

Steel skin temperature

Burner heat temperature

Fuel weight change.

During the combustion experiments, manometers and pressure gauges were used to monitor the following parameters:
Atomizing air flow
Combustion air flow
Annular burner gas flow
Annular burner air flow
Staged air flow.

\section{Staged Combustion Operating Conditions}

Fuel Characterization. The elemental analyses obtained for the SRC II supplied by PETC and No. 2 fuel oil were used to calculate the air/fuel ratios required for complete combustion. The results are listed in Table 21. SRC II has a slightly lower heat content and requires slightly less air for complete combustion than No. 2 fuel oil.

These air/fuel ratios were used to set the combustion conditions for the stoichiometries desired in the combustion experiments. 
TABLE 21. ELEMENTAL ANALYSES OF SRCII AND \#2 FUEL OIL

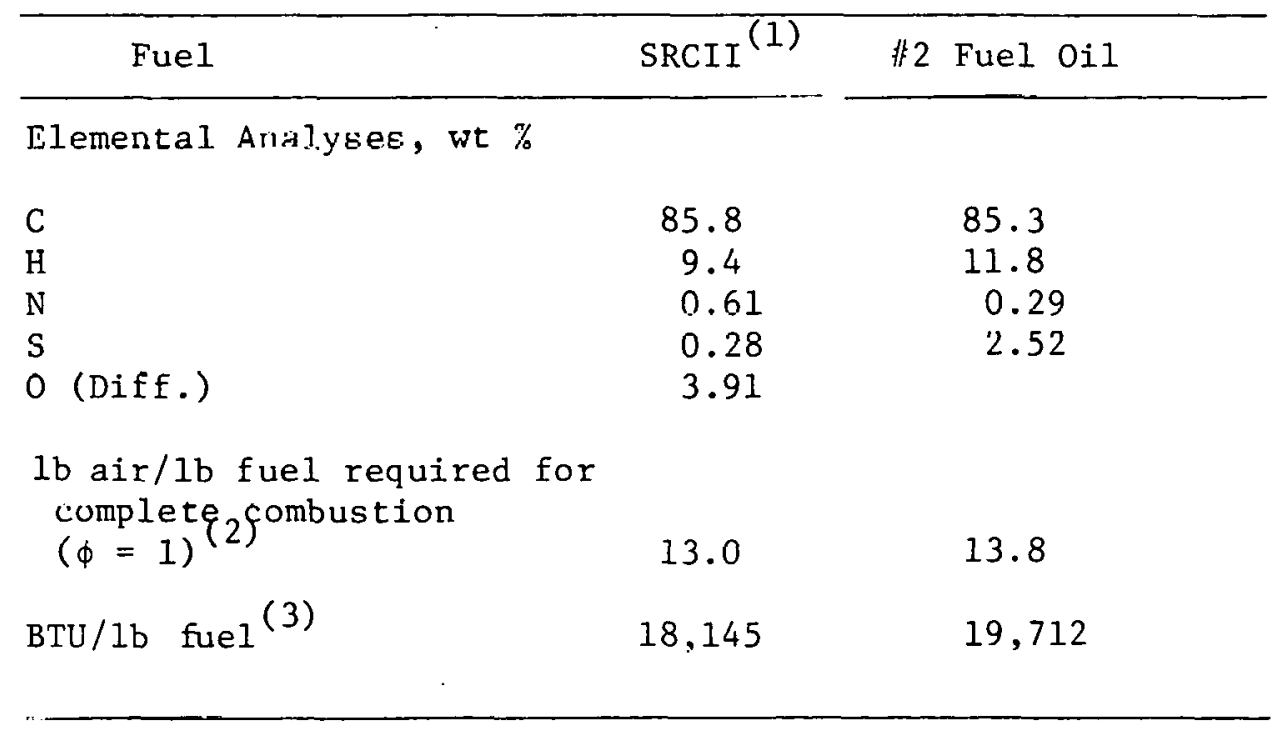

(1) SRCII supplied by PETC.

(2) Calculated using:

1b air/1b fuel $=(2.67 \mathrm{C}+8 \mathrm{H}+1.14 \mathrm{~N}+\mathrm{S}-0) \times$.

where

$$
\begin{aligned}
& \mathrm{C}=\text { wt } \% \text { carbon, } \\
& \mathrm{H}=\text { wt } \% \text { hydrogen, } \\
& \mathrm{N}=\text { wt } \% \text { nitrogen, } \\
& \mathrm{S}=\text { wt } \% \text { sulfur, } \\
& \mathrm{O}=\text { wt } \% \text { oxygen in fuel. }
\end{aligned}
$$

(3) Calculated using: $\mathrm{BTU} / \mathrm{lb}(\mathrm{HHV})=146.5 \mathrm{C}+621(\mathrm{H}-$ $\left.\frac{(\mathrm{N}+\mathrm{O}-1)}{8}\right)+40.0 \mathrm{~s}$. 
Agreement Between Calculated and Measured Stoichiometry. Stoichiometry in the system was determined by noting the fuel and air feed rates in effect when no $\mathrm{CO}$ and $\mathrm{O}_{2}$ were present. The system stoichiometry was calculated and compared to the measured stoichiometry. Much effort was spent trying to obtain agreement between the measured and calculated stoichiometries. As shown in Table 22, the measured stoichiometries were 5 to 10 percent higher than the calculated values. Literature values for both SRC II and No. 2 fuel oil show higher stoichiometries than the calculated values based on the analyses and it is possible that part of the discrepancy is a result of inaccurate analyses.

TABLE 22. AGREEMENT BETWEEN CALCULATED AND MEASURED STOICHIOMETRIES IN THE STAGED COMBUSTOR (Lb Air/Lb Fuel)

\begin{tabular}{lccc}
\hline \hline & & & Measured \\
& Calculated & Measured & Calculated \\
\hline No. 2 Fuel Oil & 13.8 & 14.5 & 1.05 \\
SRC II & 13.0 & 14.2 & 1.09 \\
\hline
\end{tabular}

For the combustion experiments, the atomizing air-to fuel weight ratio was 2 to 1 , the fuel feed rate was $2 \mathrm{lb} / \mathrm{hr}$ and the sampling probes were lowered to approximately 6 in. from the bottom of the combustion zone.

It was noted that placing the sampling probes at the bottom of the combustion zone resulted in an increase in the static combustion zone temperature (the temperature when the annular burner is on, but no fuel is being fed to the combustion zone) from about $800 \mathrm{~F}$ to $1800 \mathrm{~F}$. This is apparently due to decreased heat loss through the cooling water and alr flows in the probes. 
Discussion of Staged Combustion Results

A total of 34 runs were made on the staged combustor. Of the 18 runs made with SRC II supplied by PETC, 8 were good enough to analyze. A summary of the operating conditions and gaseous product concentrations is listed in Table 23 for these runs.

The experimental plan was to study the first, fuel-rich stage of staged combustion by varying the air/fuel ratios so that $\phi=0.6,0.7,0.8$, 0.9 and 1.0. Duplicate runs were attempted at each equivalence ratio. As a result of failure to collect some data at some points, only the rune shown were usable. Stoichiometry was controlled by changling the fuel feed rate rather than the air feed rates in most cases. Run times varied from 1-3 hours. Total fuel nitrogen (TFN) is the sum of the concentrations of $\mathrm{HCN}$, $\mathrm{NH}_{3}$ and $\mathrm{NO}$.

Total Fuel Nitrogen. The results for TFN and the nitrogencontaining gases are plotted in Figure 45. TFN appears to go through a minimum near a stoichiometry of $\phi=0.8$ as a result of a decline in $\mathrm{HCN}$ and $\mathrm{NH}_{3}$ concentrations and an increase in NO concentration with increasing air to fuel ratio. England, et al., have repurled exactly thc oame rosult for the first. stage combustion of a SRC II heavy distillate oil. (24) At the minimum they reported NO levels of $200 \mathrm{ppm}, \mathrm{HCN}$ concentrations of 100-200 ppm and $\mathrm{NH}_{3}$ concentrations of 80-120 ppin compared to levels of $180-250 \mathrm{ppm}, 20-50 \mathrm{ppm}$, and 15-30 ppm, respectively, in this work.

Lanier has also reported nitrogen conversions of 25 percent at $\phi=0.8$ with TFN consisting of 18 percent NO, 4 percent HCN, and 3 percent $\mathrm{NH}_{3}$. (25) The nitrogen conversion obtained in this study at $\phi=0.8$ was 22.8 percent with the TFN consisting of $18 \% \mathrm{NO}, 3 \% \mathrm{HCN}$, and $2 \% \mathrm{NH}_{3}$. These results suggest that the experimental conditions in the Battelle staged combustor are similar to those used by other investigators.

Elemental Analyses of Solid Samples. The water quench probe was used to collect partially reacted fuel and product samples. The solids were collected on the filter described earlier and the liquids were retained in the bulk of the quench water. The quench water and the solids were extracted 
TABI.E 23

SUMMARY OF DPERATING CONDITIONS AND GASEOUS

PRUDUCT CONCENTRATLONS FOR THE SRCIL COMBUSTION EXPERIMIENTS

\begin{tabular}{|c|c|c|c|c|c|c|c|c|c|c|c|c|c|c|c|}
\hline \multirow{3}{*}{$\begin{array}{l}\text { Ranl } \\
\text { Nis. } \\
\frac{28}{28}\end{array}$} & \multirow{3}{*}{$\frac{\begin{array}{c}\text { Stolichlometry } \\
\text { (air/f(uel) }\end{array}}{0.60}$} & \multirow{3}{*}{$\begin{array}{l}\begin{array}{l}\text { Fuel Feed } \\
\text { Rate } \\
\text { lhilir }\end{array} \\
3.33\end{array}$} & \multirow{3}{*}{$\begin{array}{c}\text { Alr reed } \\
\frac{1.77}{1.77 \text { ing }}\end{array}$} & \multirow{3}{*}{$\begin{array}{l}\text { Rece (lis/hr) } \\
\frac{\text { Combustion }}{24.8}\end{array}$} & \multirow{3}{*}{$\begin{array}{l}\text { Average Ten } \\
\frac{\text { Combustor }}{2195}\end{array}$} & \multirow{3}{*}{$\begin{array}{l}\text { rature, } F \\
\text { Annular } \\
\text { Burner } \\
1421\end{array}$} & \multirow{3}{*}{$\frac{\begin{array}{c}\text { Run Time, } \\
\mathrm{min}\end{array}}{70}$} & \multirow{3}{*}{$\begin{array}{c}c 0 \\
(\%) \\
10.9\end{array}$} & \multirow{3}{*}{ Cias } & \multirow{2}{*}{$\begin{array}{l}\text { Concentrat } \\
\mathrm{CO}_{2} \quad \mathrm{O}_{2} \\
(\%)\end{array}$} & \multirow{2}{*}{$\begin{array}{c}\text { ons (vo } \\
\text { HC } \\
(\%) \\
\end{array}$} & \multirow{3}{*}{$\begin{array}{c}\begin{array}{c}\text { ume per } \\
\text { No } \\
(\mathrm{ppm})\end{array} \\
64\end{array}$} & \multirow{3}{*}{ 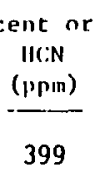 } & \multirow{3}{*}{ 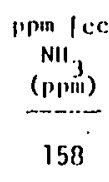 } & \multirow{3}{*}{ 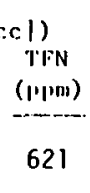 } \\
\hline & & & & & & & & & & & & & & & \\
\hline & & & & & & & & & & $0 . \dot{0}$ & 4152 & & & & \\
\hline $2 i$ & 0.62 & 3.27 & 1.77 & 24.8 & 2117 & 1454 & 61 & 6.0 & 8.1 & 0.1 & 3471 & 72 & 316 & 156 & 514 \\
\hline 25 & 0.70 & 2.84 & 1.77 & 24.8 & 2182 & 1431 & 60 & 9.7 & 9.3 & 0.0 & 2806 & 100 & 194 & 65 & 359 \\
\hline 26 & 0.72 & 2.73 & 1.77 & 24.8 & 2091 & 1423 & 60 & 9.5 & 9.7 & 0.0 & 1220 & 118 & 145 & 93 & 356 \\
\hline 24 & 0.82 & 1.98 & 1.77 & 19.8 & 2045 & 1447 & 60 & 7.3 & 12.1 & 0.0 & 151 & 249 & 7 & 15 & 272 \\
\hline $16^{(1)}$ & 0.87 & $4: 1$ & 2.18 & 44.2 & & 1375 & .50 & 7.6 & 11.8 & 0.0 & 0 & 300 & 20 & 0 & 320 \\
\hline 20 & 0.99 & 3.60 & 1.79 & 44.6 & 2133 & 1391 & 185 & 3.7 & 14.8 & 0.1 & 20 & 595 & 0 & 3 & 598 \\
\hline 21 & $\quad 0.99$ & 1.96 & 1.00 & 25.4 & 2164 & 1477 & 193 & 1.3 & 16.0 & 0.3 & 11 & 877 & 1 & 0 & 878 \\
\hline
\end{tabular}

(1) Sample probes were posttioned midway in the combustor. 


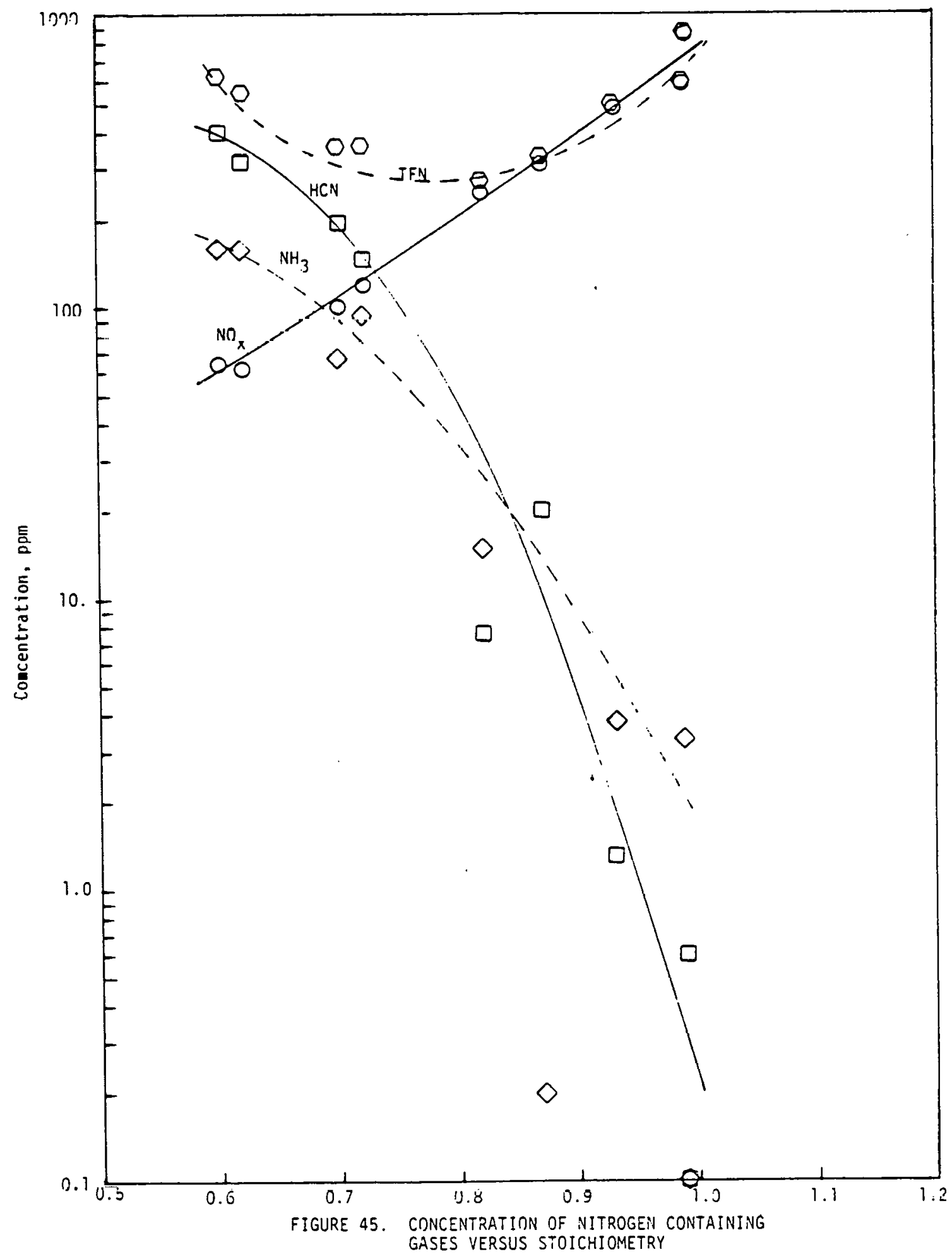


several times each with methylene chloride. These extracts were dried, combined and air evaporated to remove methylene chloride, resulting in 5-10 mg samples of liquids. These were typically thick, brown, tarry substances, probably heavier than the starting SRC II. The solid samples were typically 50-100 mg of black powder.

The solids were sent for $\mathrm{C}, \mathrm{H}$, and $\mathrm{N}$ analyses by microcombustion. The nitrogen analyses are probably not very accurate based on our previous experience described earlier. Oxygen was calculated by difference assuming both sulfur and inorganics were negligible. The results are listed in Table 24.

The oxygen content increases as the air/fuel ratio increases. This was also observed in the Task 2-3 bench-scale oxidative-pyrolysis studies. Hydrogen also increases as air/fuel ratio increases. This suggests that oxygen is added as $-\mathrm{OH}$ groups, again as suggested by Santoro and Glassman. (21) Unfortunately the nitrogen analyses appear to have such large uncertainty that no trend can be developed for fuel nitrogen.

Cl3 NMR measurements were not made on the samples due to insufficient sample size. However, based on the extremely low hydrogen to carbon ratios, which were also seen in the Task 2 and Task 3 results, the solids are expected to be highly aromatic.

Gas Chromatographic Analyses of Liquid Samples. The liquid samples were subjected to gas chromatographic analysis, using a Varian 3700 gas chromatograph equipped with a $50 \mathrm{~m} \times 0.25-\mathrm{mm}$ fused silica capillary column coated with polydimethylsiloxane oV-1, SE-30. Conditions were as follows:

Injector temperature: $300 \mathrm{C}$

Detector temperature: $310 \mathrm{C}$

Column temperature: $35 \mathrm{C}$ for $3 \mathrm{~min}$ raised to $305 \mathrm{C}$ at $10 \mathrm{C} / \mathrm{min}$ and held for $15 \mathrm{~min}$

Helium carrier gas flow rate: $6 \mathrm{cc} / \mathrm{min}$.

The effluent from the column was split into an FID detector to measure the amount of carbon (mass) versus time and a thermionic specific detector to measure the amount of nitrogen versus time. Two Hewlett Packard 3390A Integrators were used to record and integrate the signals from the two detectors. 
TABLE 24. RESULTS OF ELE:AENTAL ANALYSES ON SOLIDS RECOVERED FROM COMBUSTION

\begin{tabular}{|c|c|c|c|c|c|c|c|}
\hline Number & Stoichiometry & Carboa & $\begin{array}{l}\text { Weight Percent of } \\
\text { Hydrogen }\end{array}$ & Nitrogen & $\begin{array}{l}\text { Oxygen } \\
\text { (diff) }\end{array}$ & $\mathrm{H} / \mathrm{C}$ & $0 / C$ \\
\hline 28 & 0.60 & 9.1 .7 & 0.89 & 0.21 & 7.2 & 0.12 & 0.059 \\
\hline 27 & 0.62 & 91.1 & 0.95 & 0.26 & 7.7 & 0.13 & 0.063 \\
\hline 23 & 0.70 & 90.1 & 0.69 & 0.10 & 8.1 & 0.092 & 0.067 \\
\hline 26 & J. 72 & 89.1 & 0.82 & 0.12 & 10.0 & 0.11 & 0.084 \\
\hline 24 & 9.82 & 86.7 & 1.23 & 0.23 & 11.8 & 0.17 & 0.11 \\
\hline 16 & 0.87 & 81.8 & 1.16 & 0.11 & 16.9 & 0.17 & 0.15 \\
\hline 20 & C. .99 & 70.7 & 1.51 & 0.36 & 27.4 & 0.26 & 0.29 \\
\hline 21 & 0.97 & 62.5 & 1.17 & 0.07 & 36.3 & 0.22 & 0.44 \\
\hline
\end{tabular}


Each of the liquid samples was slurried in ether. They were not completely soluble but it is likely that a representative sample could be injected onto the column. (Tetrahydrofuran might have been a better choice as a solvent.)

The response was calibrated with an aromatic standard, an aliphatic standard, and a standard consisting of a mixture of cyanonaphthalene, quinoline, and indole to measure an average nitrogen/carbon response. It was hoped that it would be possible to get some information on the nitrogen content, the boiling point range, and the average molecular weights of the very small (10$20 \mathrm{mg}$ ) liquid samples.

The nitrogen contents showed so much scatter that it was not even possible to obtain a good average value using the GC data. All of the significant nitrogen peaks on the TSD detector appeared to be in molecules with higher molecular weights than pyrene. These peaks are believed to be from the liquid samples but the possibility that they were an anomaly in the gas chromatographic setup cannot be entirely ruled out. This technique needs more development since it has the potential to significantly improve the understanding of the chemistry which the nitrogen in the fuel molecule undergoes before it is converted to one of the gaseous nitrogen products during combustion.

The molecular weights of the liquid samples were divided into materlals boiling below benzene (less than 1 aromatic ring), between benzene and naphthalene ( 1 aromatic ring), between naphthalene and anthracene/phenanthrene ( 2 aromatic rings), between anthracene/phenanthrene and pyrene ( 3 aromatic rings), and above pyrene ( 4 or more aromatic rings). The results are summarized in Table 25.

There were no compounds present with boiling points below naphthalene. This may have been due to the way the samples were collected and prepared. There were increasing amounts of material of higher boiling point with the majority of the materlal buing wuch heavier than pyrene.

Most of the liquid samples were obtained from extraction of the solid samples rather than from extraction of the water, as estimated by the color of the extracts. The fact that the samples are extremely heavy is not surprising. No trend in molecular weight/boiling point could be established as a function of stoichiometry because of the scatter in the data. 
TABLE 25. AVERAGE BOILING POINTS/MOLECULAR

WEIGHTS OF LIQUID COMBUSTION SAMPLES

\begin{tabular}{cc}
\hline No. of Aromatic Rings & Percent of Sample \\
\hline$<1$ & 0 \\
$1-2$ & 0 \\
$2-3$ & 8 \\
$3-4$ & 11 \\
$>4$ & 81 \\
\hline
\end{tabular}

NMR data could not be obtained on lie samples because of insufficient funds.

Task 4 Conclusions

This work has shown, as has the work of others, that a minimum in total fuel nitrogen emissions ( $\mathrm{HCN}+\mathrm{NH}_{3}+\mathrm{NO}$ ) occurs at an air/fuel ratio of 0.8 of the amount of air required to completely burn SRC II to $\mathrm{CO}_{2}$ and $\mathrm{H}_{2} \mathrm{O}$. The total TFN emissions resulting from complete combustion of the SRC II under both stages of staged combustion have not been measured.

Analyses of solid and liquid samples obtained from the combustion zone have indicated that., for the most part, very heavy matcrials survive to second-stage combustion. There is a continuum of liquids and solids. The solids contain an average of only 0.18 weight percent nitrogen. As air/fuel ratio increases and combustion approaches completion the oxygen/oarbon ratio and the hydrogen/carbon ratio both increase, indicating that oxygen is added as $\mathrm{OH}$, as others have suggested.

No information was obtained on the nitrogen types which survive in the solids and liquids but, based on the results of Tasks 2 and 3 , they are probably predominantly nonbasic, possibly cyano compounds.

The aromatic structure was not observed directly but most of the molecules contained four or more aromatic rings, substituted with an average of one oxygen for every 10 carbons ( 2 aromatic rings) at $\phi=0.8$ and almost 4 oxygens per 10 carbons at $\phi=1.0$. 


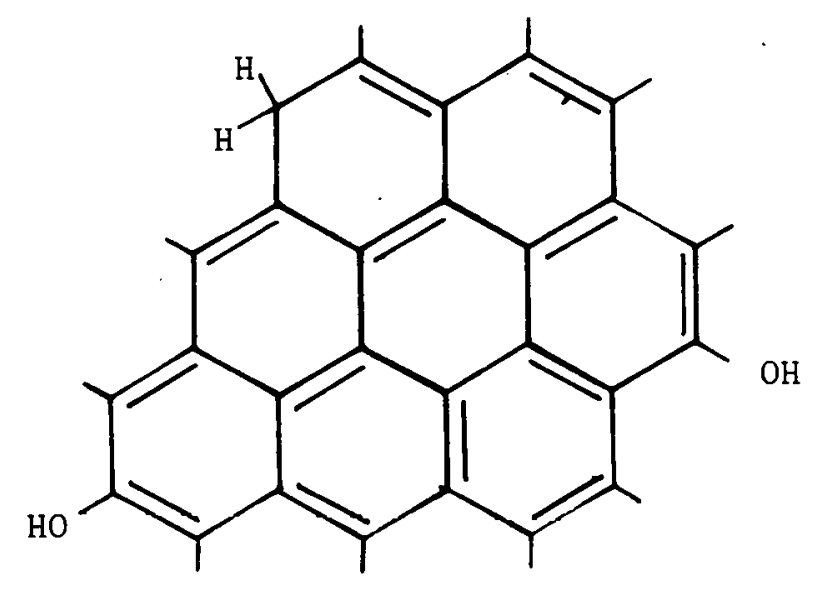


ACKNOWLEDGMENTS

The assistance of the following people contributed to the successful completion of this program and is gratefully acknowledged. Don Hupp, Terry Sullivan, Bruce Rising and Paul Webb performed much of the experimental studies carried out during this program.

Discussions of SRC II safety and handling procedures with Dr. Jon Haebig of Gulf and Dr. Egon DeZubay and P. Richard Mulik of Westinghouse were helpful in implementing similar systems at Battelle.

Dr. David Schmalzer of the Pittsburg \& Midway Coal Mining Company provided the samples of SRC II naphtha, middle diștillate and heavy distillate used in this program. Dr. Douglas M. Jewell of the Pittsburg \& Midway Coal Mining Company provided analytical data on narrow boiling range SRC II distillation cuts for comparison. 


\section{REFERENCES}

1. Longwell, J. P., "Synthetic Fuels and Combustion", Prog. Energy Comb. Sci., $\underline{3}, 127$ (1977)

2. Black, C. H., Chiu, H. H., Fischer, J., and Clinch, J. M., "Review and Analysis of Spray Combustion as Related to Alternative Fuels", Argonne National Laboratory Report, ANL-79-77, September (1979).

3. Moore, R. T., McCuthceon, P., and Young, D. A., "Basic Nitrogen Determined by Titration with Perchloric Acid", Anal. Chem., 23 (11), 16391641 (1951).

4. Petrakis, L., Ruberto, R. G., Young, D. C., and Gates, B. C., Unpublished results.

5. Richter, F. P., Caesar, P. D., Meisel, S. L., and Offenhauer, D. D., "Distribution of Nitrogen in Petroleum According to Basicity", Ind. Eng. Chem., 44 (11), 2601-2605 (1952).

6. Brown, J. K. and Ladner, W. R., "A Study of the Hydrogen Distribution in Coal-Like Materials by High Resolution Nuclear Magnetic Resonance Spectroscopy II -- A Comparison with Infrared Measurement and the Conversion to Carbon Structure", Fuel, 39, 87 (1960).

7. Whitehurst, D. D., Mitchell, T. O., Farcasiu, M., and Dickert, J. J., Jr., "The Nature and Origin of Asphaltenes in Processed Coals, Volume I", EPRI AF-1298 from Mobil Research and Development Corporation, December (1979).

8. Schwager, I., Farmanian, P. A., and Yen, T. F., "Structural Characterization of Solvent Fractions from Five Major Coal Liquids by Proton Nuclear Magnetic Resonance", Analytical Chemistry of Liquid Fuel Sources, ACS Advances in Chemistry Series 170, Chapter 5 (1978).

9. Retcofsky, H. L., 3chweighardt, F. K., and Hough, M., "Determination of Aromaticities of Coal Derivatives by Nuclear Magnetic Resonance Spectrometry and the Brown-Ladner Equation", Analytical Chemistry, 49 (4), 585-588 (1977).

10. Martin, R. L., Anal. Chem., 38, 1209 (1966).

11. Lake, G. R., McCutchan, P., Van Meter, R., and Neel, J. C., "Effects of Digestion Temperature on Kjeldahl Analyses", Anal. Chem., 23, (11), $1634-38$ (1951).

12. Drushel, H. V., Prep. Div. Pet. Chem., Am. Chem. Soc., 21 (1), 146 (1976).

13. Drushel, H. V., Anal. Chem:, 49 (7), 932 (1977). 
14. Parks, R. E., "Analysis for Chemically Bound Nitrogen Using PyroChemiluminescence", Paper presented at the 27 th Pittsburgh Conference on Analytical Chemistry and Applied Spectroscopy, Cleveland, Ohio (March 2, 1976).

15. Crutchfield, C. A., "Total Nitrogen in Fuel Oils", Truesdail Laboratories, Inc.

16. Moore, R. T., McCutchan, P., and Young, D. A., Anal. Chem., 23 (11), 1639 (1951).

27. Gray, et al., GuLf, Analyses of Aromatics in SRC II Distillation Fractions.

18. Solomon, P.R., and Colket, M.B., "Coal Devolatilization", Seventeenth Symposium (International) Combustion, The Combustion Institute, 1978, p. 131.

19. Suuberg, E. M., Peters, W. A., and Howard, J. B., "Coal Devolatilization", Seventeenth Symposium (International) on Combustion, The Combustion Institute, 1978, pp. 117.

20. Beer, J. M., Sarofim, A. F., Timothy, L. D., Harson, S. P., Gupta, A., and Levy, J. M., "Two Phase Processes Involved in the Control of Nitrogen Oxide Formation in Fossil Fuel Flames", Proceedings of the Joint Symposium on Stationary Combustion $\mathrm{NO}_{x}$ Control, Volume IV, p. 43 (1980).

21. Blazowski, W. S., "Dependence of Soot Production on Fuel Structure in Backmixed Combustion", Combustion Science and Technology, 21, 87 (1980).

22. Santoro, R. J., and Glassman, I., "Review of Oxidation of Aromatic Compounds", Combustion Science and Technology, 19, 161-164 (1979).

23. Downs, W., and Kubasco, A. J., "Characterization and Combustion of SRC II Fuel Oil", The Babcox and Wilcox Co., Final Report No. EPRI FP-1028, Projects 1235-3-4 and 1412-1 prepared for Electric Power Research Institute, June, 1979.

24. England, G. C., Heap, M. P., Pershing, D. W., Nihart, R. K., and Martin, G. B., "Mechanisms of $\mathrm{NO}_{\mathrm{x}}$ Formation and Control: Alternative and Petroleum-Derived Liquid Fuels", Eighteenth Symposium (International) on Combustion, pp. 163-174, The Combustion Institute (1981).

25. Lanier, W. S., private communication (May 13, 1982). 